\title{
Paleo-environmental reconstruction of a Late Quaternary organic-rich section preserved near Ohakune, central North Island,
}

New Zealand

HANNAH JUCHNOWICZ

\author{
Victoria \\ Te Whare Wänanga

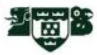

\begin{abstract}
A THESIS
submitted in partial fulfilment of the requirements for the degree
\end{abstract}

MASTER OF SCIENCE

Department of Earth Science

Victoria University of Wellington

New Zealand 


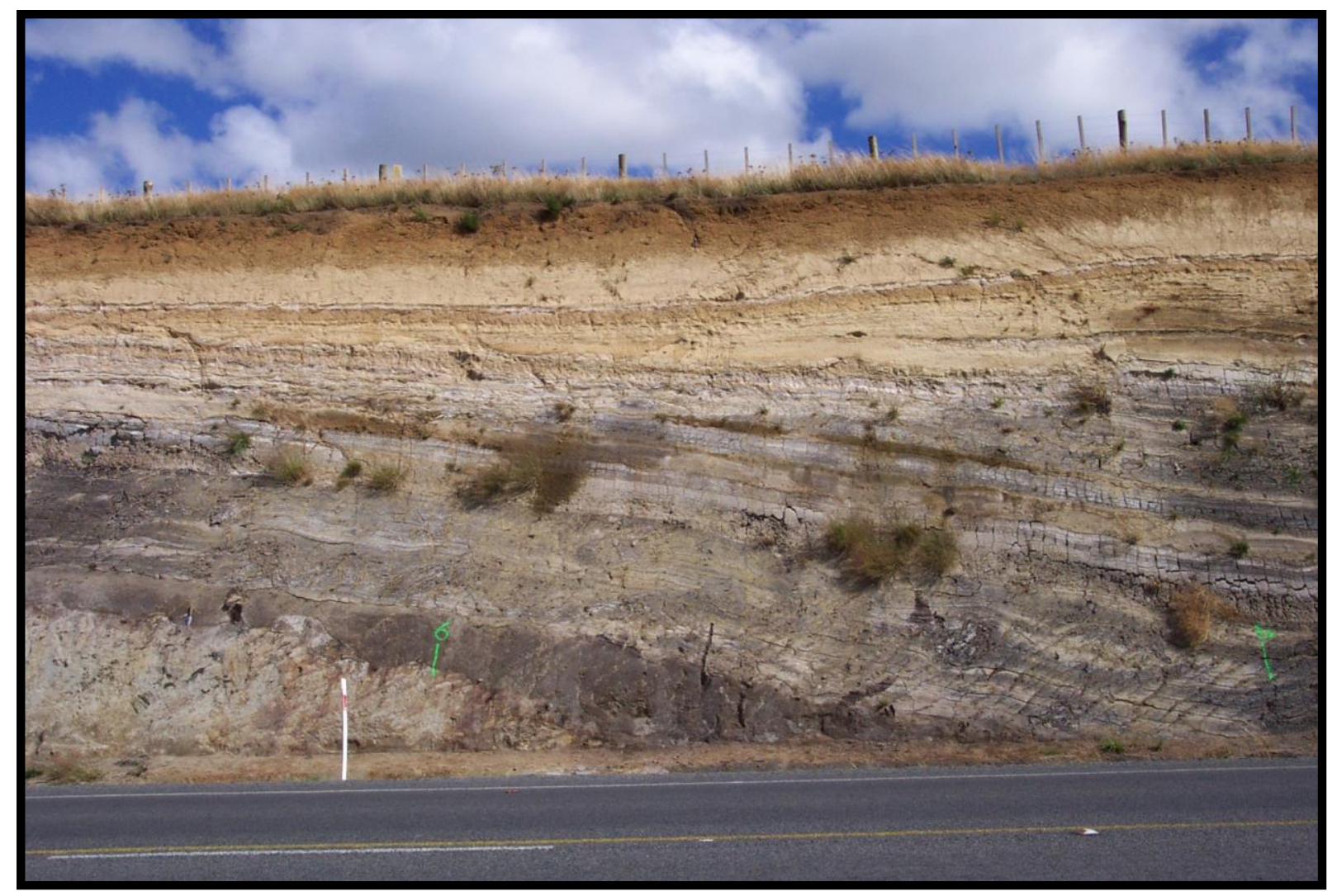

Frontispiece - The Karioi section as a fresh cut surface in 2003. Photo: Dr Brent Alloway. 


\section{Abstract}

A $6 \mathrm{~m}$ thick section of organic-rich sediment, exposed at Karioi, near Ohakune, central North Island (672m above sea level), presents an opportunity to form a detailed palynological record of Late Quaternary vegetation and climate change. The organic-rich sequence at Karioi lies beneath a $3.29 \mathrm{~m}$ thick cover-bed sequence that contains towards its base the c. 25.4 ka cal BP Kawakawa/Oruanui Tephra, a key chronostratigraphic marker for the Last Glacial Maximum (LGM) throughout New Zealand. A previous palynological investigation of the underlying organic sediments suggested they extended back from the LGM (Marine isotope stage 2 ) to the previous interglacial (MIS 5). Such apparently continuous terrestrial records spanning this age range and located at this altitude are rare.

A key feature of the Karioi organic sequence is the occurrence of numerous millimetre- to decimetre- thick tephra, derived from a variety of North Island eruptive sources. The possibility that volcanic processes have influenced vegetation change makes climate inferences at this important site potentially problematic. In this new study of the Karioi section, centimetre-scale palynological and diatom sampling conducted above and below three selected tephra (here named 'Big Lower Lapilli', 'Unknown' tephra, and 'Little' tephra) at Karioi, were used to assess the influence of these volcanic events on the vegetation and local hydrology. Loss-on-ignition and magnetic susceptibility were used, alongside pollen and diatom analysis, to infer changes in local hydrology and depositional processes in relation to environmental stability. Together, these analyses helped determine the volcanic impacts on vegetation assemblages gained from the pollen record at the site and allowed these to be disassociated from larger scale climate influences of interest.

The results of this study indicate a discernible volcanic impact on vegetation and hydrology following just one of the three volcanic events targeted in the record. High-resolution $(0.5 \mathrm{~cm})$ pollen analysis above and below the largest of the three tephra layers, the $22 \mathrm{~cm}$ thick 'Big Lower Lapilli' showed a notable change in vegetation assemblage immediately following tephra deposition. The most significant of these changes was the marked increase in herbs. This was an unexpected result thought to be due to the proximity of the site to sub-alpine and alpine herbaceous communities, which in turn were closer to the source of volcanism than other vegetation communities depicted in 
the pollen record. The changes to the pollen spectra are estimated to have taken 300 years to return to pre-eruption assemblages.

Magnetic susceptibility and loss-on-ignition results further add to this research by indicating the comparative stability of the depositional environment around the time of deposition of the 'Big Lower Lapilli'. Statistical analysis further identified a change in vegetation communities associated with tephra deposition, coinciding with an increase in diatom species abundance, which signified an increase in water volume and depth at the site. This was most clearly seen by the marked increase in Aulacoseira ambigua, which is almost exclusively found in water bodies of at least 2 metres depth.

These results have major implications for pollen-based climate reconstructions from sequences with interbedded tephra layers. First, such investigations should include fine resolution analyses around prominent tephra layers to test for possible volcanic disturbance that may be a confounding factor in any paleoclimatic reconstructions applied. In this study, for example, vegetation assemblages may have taken up to 300 years to return to pre-eruption levels, but this recovery phase was well within the c. 1000 year inter-sample period of the original coarse $(10 \mathrm{~cm})$ resolution record. Without the fine resolution study conducted here, the decline of shrubs and increase in grasses, with no obvious changes to trees following deposition of the 'Big Lower Lapilli' could have been inferred as a shortterm cooling interval. Beyond this restricted zone of volcanic disturbance, greater confidence in the paleoclimatic interpretation of the Karioi pollen record has been achieved as a result of this finer resolution 'test' for volcanic disturbance. Second, the volcanic disturbance indicated following the 'big lower lapilli' has shed light on pollen taphonomic sources and pathways at this site and in turn, on spatial patterns of vegetation communities. In this case, the increase in tree pollen relative to non-arboreal pollen is interpreted as originating from more distant forest stands that have been comparatively less affected by the deposition of tephra than locally growing vegetation. 


\section{Acknowledgments}

I would like to give a huge thank you to my amazing supervisors Rewi Newnham and Brent Alloway, and honorary supervisor Andrew Rees (Victoria University of Wellington). Without your help, support, and knowledge over this past year this project would not have been possible.

I would also like to thank Matt McGlone (Landcare Research, Lincoln) for allowing me access to your raw pollen data for the Karioi site, without which this project would have no background.

A massive thank you to my wonderful family who kept me going throughout this research, supplying me with cooked lunches when I wouldn't leave the computer, and transport when I decided an unannounced trip was in order to gather a piece of research I had left behind.

And to my awesome boyfriend, thank you for always keeping me smiling, even when I thought all was lost. You kept me motivated until the end. 


\section{Table of Contents}

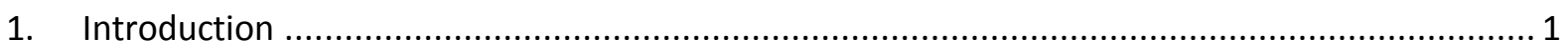

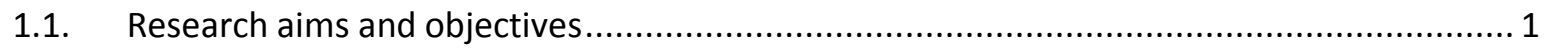

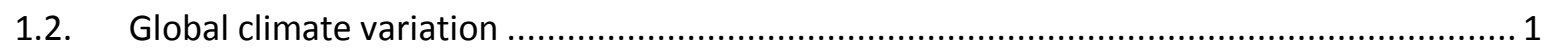

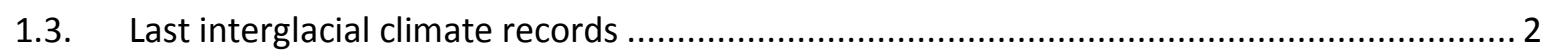

1.4. Last Interglacial pollen records from New Zealand and their significance........................... 3

1.5. Significance of volcanic impacts on last interglacial climate records as shown in pollen

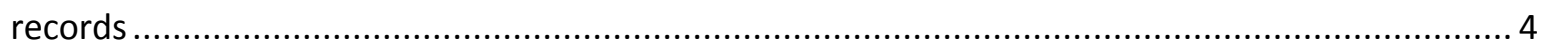

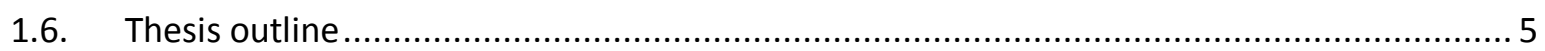

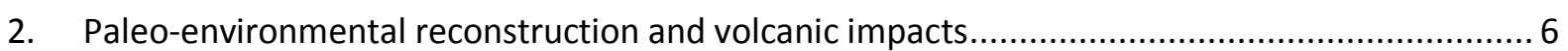

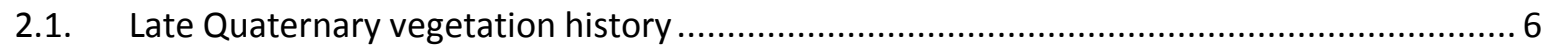

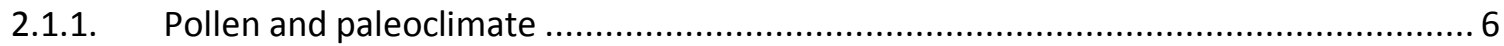

2.2. Late Quaternary volcanism in New Zealand and its effects on the surrounding environment 9

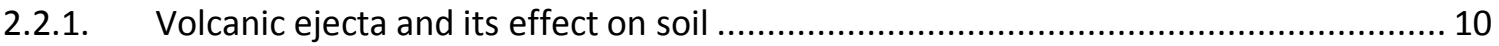

2.2.2. Volcanic ejecta and its effects on vegetation ....................................................... 13

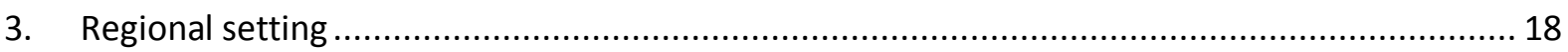

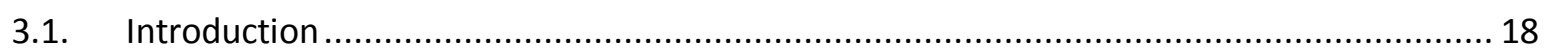

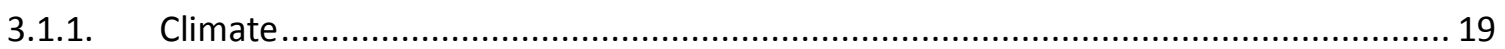

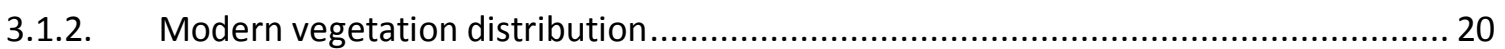

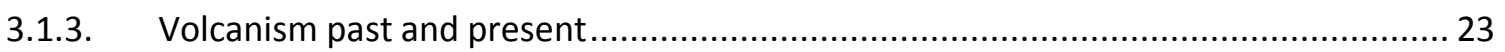

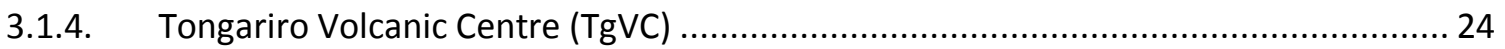

3.1.5. Egmont Volcanic Centre (Mt. Taranaki) ..................................................................... 24

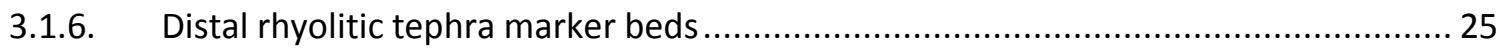

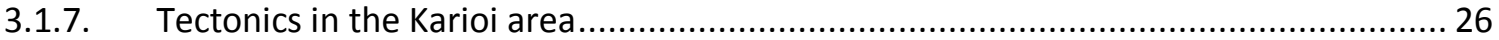

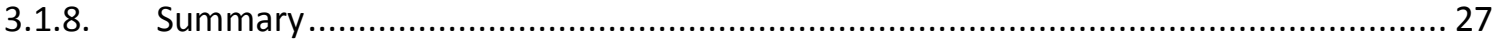

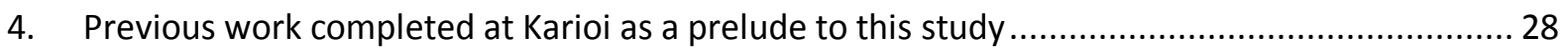

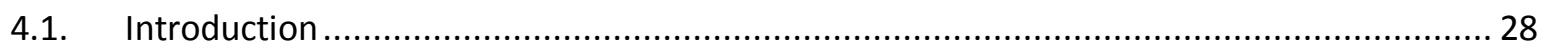




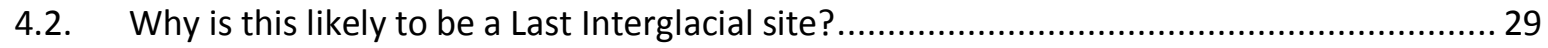

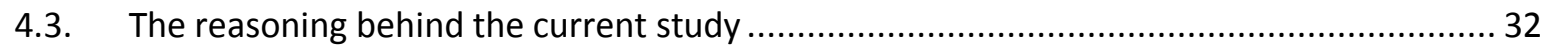

4.4. Geochemical analysis of selected tephra from within the Karioi section .......................... 33

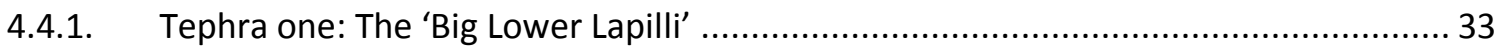

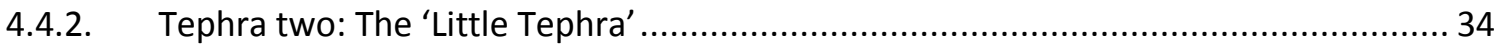

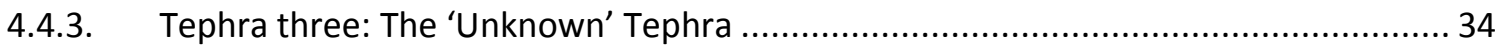

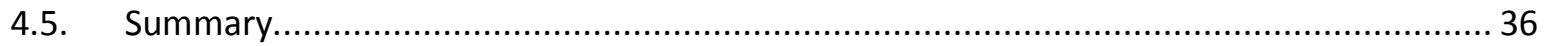

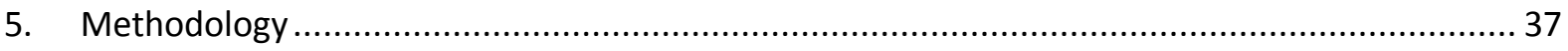

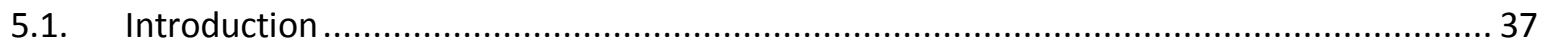

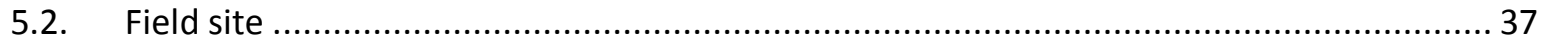

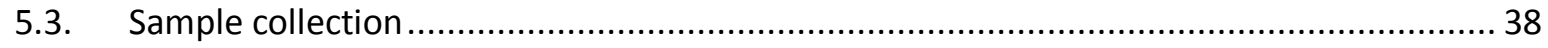

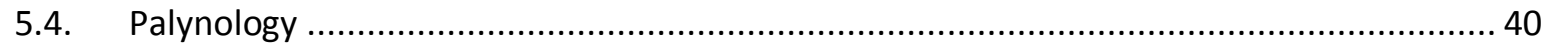

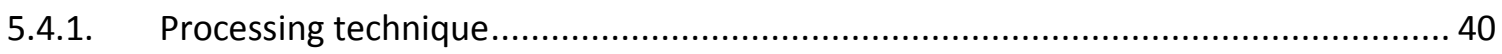

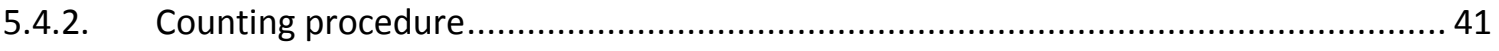

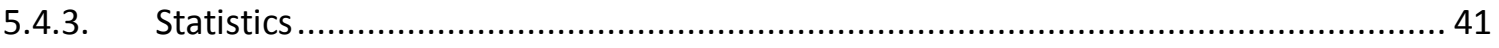

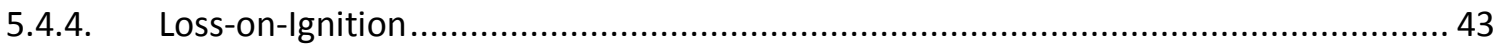

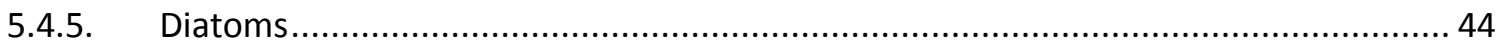

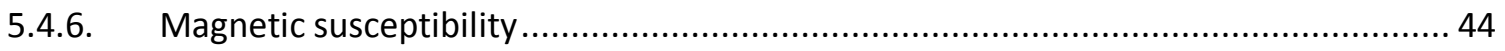

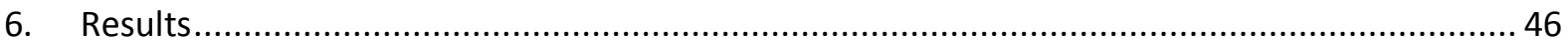

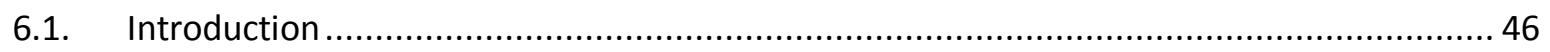

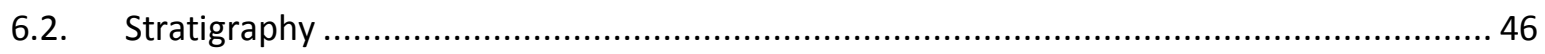

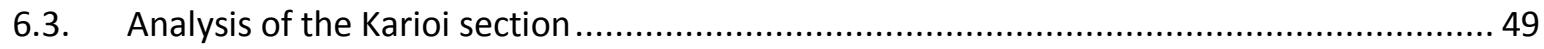

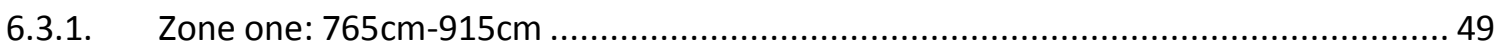

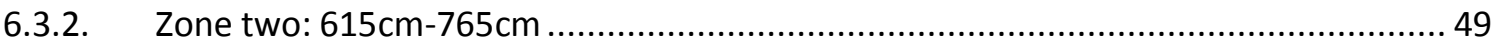

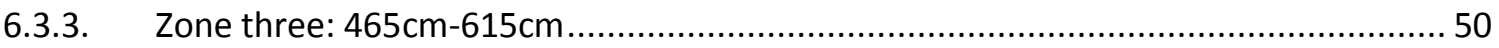

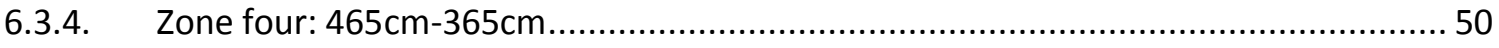

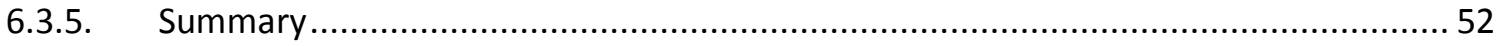

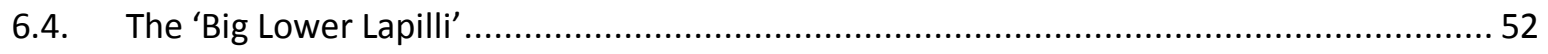

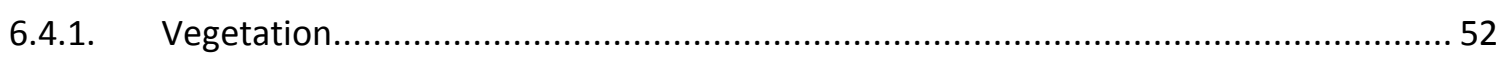

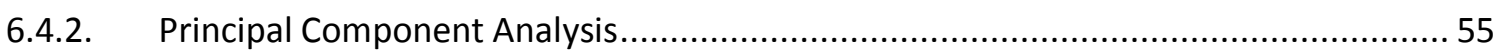

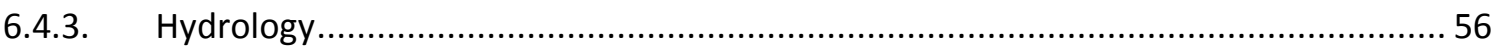




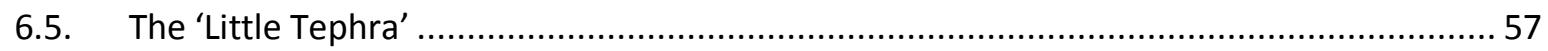

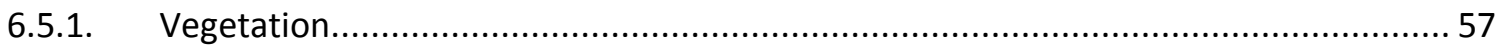

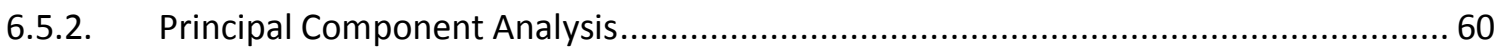

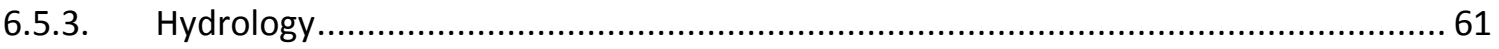

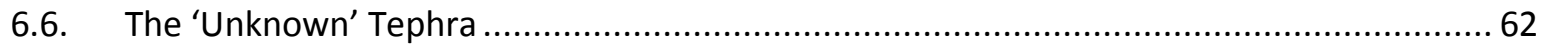

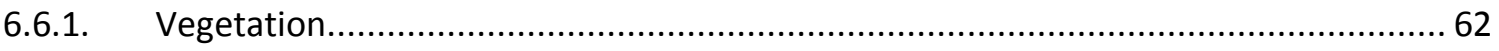

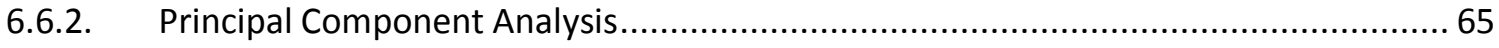

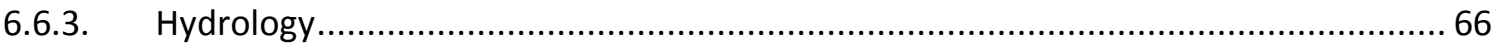

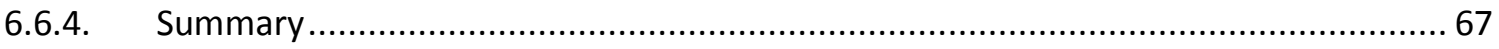

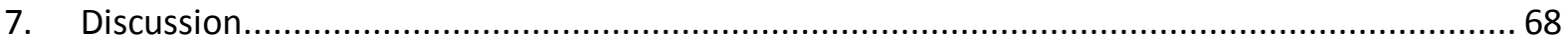

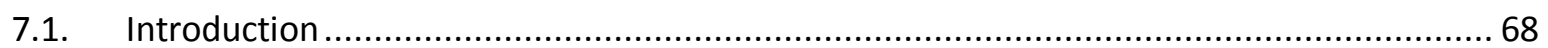

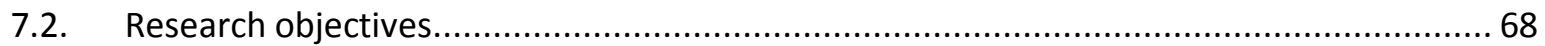

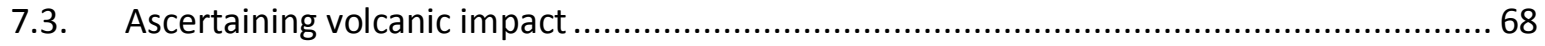

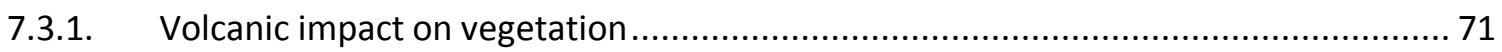

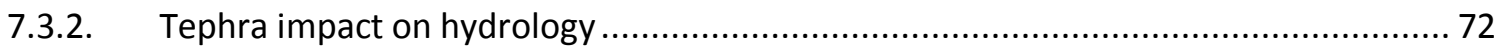

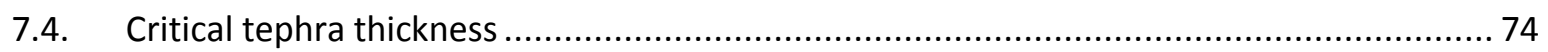

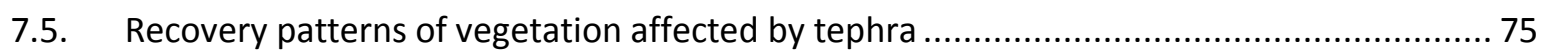

7.6. Implications for the vegetation and environment at Karioi in the light of this study on

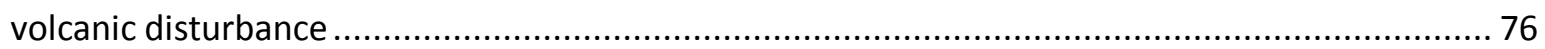

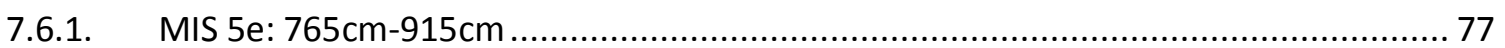

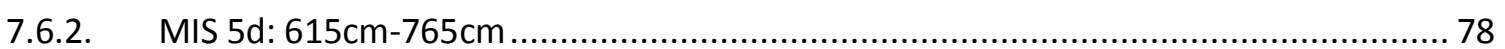

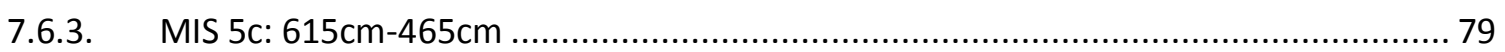

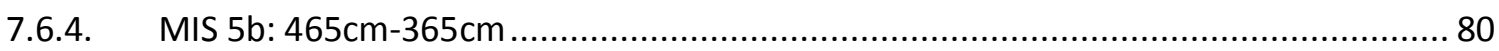

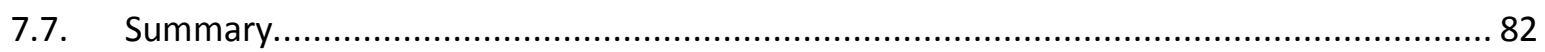

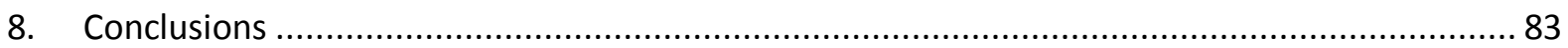

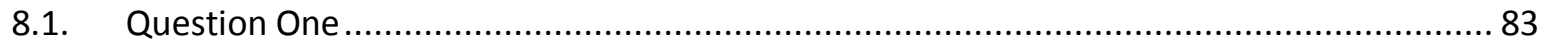

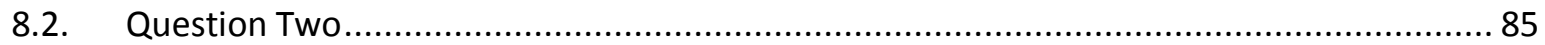

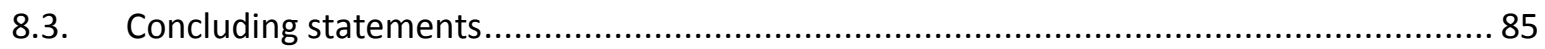

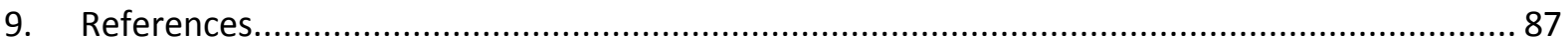

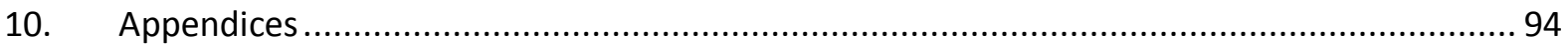

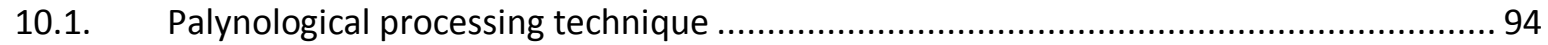




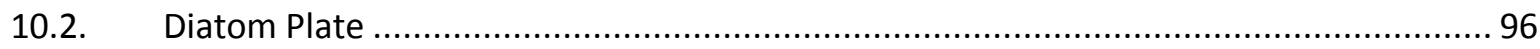

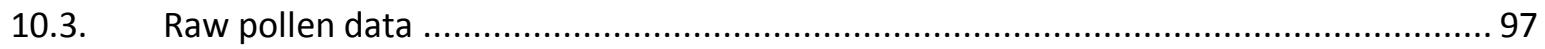

10.4. Loss-on-Ignition, Magnetic Susceptibility, and DCA raw data for the Karioi section..... 107

10.5. Eiganvalues - supplementary to the statistical analysis ............................................. 110 


\section{List of Figures}

Figure 1. Map of the Ohakune area, with the Karioi site marked by the black circle. Image: Google Maps. Inset map of the North Island, black circle making the approximate location of Karioi. Image: Google.

Figure 2. The Karioi Section as a fresh cut surface ca. 2000. To the right of the section, the sediment can be seen to unlap against Tertiary-aged sediment, as a result of the movement on the Karioi Fault. Image courtesy of Dr Brent Alloway.

Figure 3. Left: Graphed data of the average monthly temperature for the Karioi area for 2012 and 2013. Right graphed data for the average monthly rainfall in the Karioi area for 2012 and 2013. Data recorded at the Ohakune weather station, $7 \mathrm{~km}$ north-west of the Karioi site. Data accessed from NIWA January 2014.

Figure 4. Map marking the location of the Karioi site in relation to the volcanic centres of the North Island, New Zealand. Image: www.civildefence.govt.nz.

Figure 5. Distribution of the Kawakawa/Oruanui Tephra. Contours represent $\mathrm{cm}$ depth of deposited tephra (Campbell, 1986).

Figure 6. Map showing the extent of the Karioi Fault (yellow). The black dot marks the location of the Karioi section. Image sourced from GNS.

Figure 7. From the top, four pollen curves representing taxa as a $\%$ of the dry pollen sum, and the percentage of Trees, shrubs and herbs represented as a \% plot. Raw counts from Dr Matt McGlone (unpublished).

Figure 8. Two back-scattered electron images of different glass shards obtained from the 'Big Lower Lapilli' by Dr Brent Alloway. The images display the thin-walls and abundant microlites that made this sample impossible to geochemically analyse.

Figure 9. Two back-scattered electron images of glass shards obtained with the 'Little Tephra'. They display the abundant microlites and thin walls that made this tephra impossible to geochemically analyse.

Figure 10. Le Maitre plots showing the geochemistry of the 'Unknown' Tephra in relation to other tephra found in the vicinity of Karioi. $R=$ rhyolite, $D=$ dacite, $A=$ andesite, $T=$ trachyte, Ta=trachyteandesite. The arrow points to the three Taranaki eruptives which geochemically match the 'Unknown' tephra. Circles combine similar data points. Data and graphs courtesy of Dr Brent Alloway. 
Figure 11. Eastward view of the Karioi section. Note the Tertiary-aged mudstone outcrop unconformably overlain by the woody organic rich sequence. The organic sequence is unconformably overlain by fluviatile sediments and volcanic loess containing the Kawakawa/Oruanui Tephra (indicated by the yellow arrow). Photo: Dr Brent Alloway. 38

Figure 12. Image showing the dimensions of the "cookie cutter" used during sample extraction. .... 40 Figure 13. A stratigraphic column of the Karioi section produced in the course of this work. Tick marks on the left-hand side of the image mark the locations of sampling completed by Dr Matt McGlone. Tick marks located on the right-hand side of the image mark the locations of sampling completed in this work. Initial image supplied by Dr Brent Alloway; the image was then reworked and descriptions were added by the author of this work.

Figure 14. From the top: Stratigraphic DCA curve for the entire pollen data of the entire Karioi section calculated for data supplied by Dr McGlone. Magnetic susceptibility curve calculated in this study. Loss on Ignition curve calculated in this study. Percentages plot for vegetation type calculated from pollen data supplied by Dr McGlone. Simple stratigraphic log outlining the position of organic sediment and tephra in relation to the above graphs. Dashed lines and numbers mark the boundaries used in the above description of the section.

Figure 15. Pollen diagram displaying the individual pollen curves obtained in this discrete analysis with a DCA curve. The tan box represents the location of the tephra layer.

Figure 16. PCA site score plot for the 'Big Lower Lapilli' with selected species scores inset. Numbers represent depth from the top of the section.

Figure 17. Graph displaying the diatom species abundances in samples on either side of the 'Big Lower Lapilli'.

Figure 18. Pollen diagram displaying the individual pollen curves obtained in this discrete analysis against a DCA curve. The tan box represents the position of the tephra.

Figure 19. PCA site score plot with inserted selected species scores. Numbers represent depths in the section.

Figure 20. Graph depicting the overall species abundance in samples from either side of the 'Little Tephra'

Figure 21. Pollen diagram displaying the individual pollen curves obtained in this discrete analysis against the DCA curve for the 'Unknown' tephra. The tan box represents the exact location of the tephra.

Figure 22. PCA site score plot for the 'Unknown' tephra with selected species scores plotted. Numbers represent depth of the sample. 
Figure 23. Graph displaying the diatom species abundance from samples surrounding the 'Únknown' tephra.

Figure 24. From the top: Benthic $\delta 180$ curve (Lisiecki and Raymo, 2005). DCA1 curve from data supplied by Dr McGlone. Loss-on-Ignition curve. Magnetic susceptibility curve. Dacrydium cupressinum pollen relative abundance curve from data supplied by Dr McGlone. Fuscospora pollen relative abundance curve from data supplied by Dr McGlone. Percentage plot for total vegetation type from data supplied by Dr McGlone. Simple stratigraphic log outlining the main organic content and tephra location at the section. Red line= 'Little Tephra', Blue forward slash line= 'Big Lower Lapilli', Green line= 'Únknown' tephra. Dashed lines denote MIS boundaries. Bottom $\mathrm{x}=\mathrm{axis}=$ depth $(\mathrm{cm})$, Top $x$-axis=Age $(\mathrm{ka})$

Figure 25. Table summarising the location, age, characteristics, and environment surrounding each discrete sub-section sampled in this work. 


\section{Introduction}

\subsection{Research aims and objectives}

The main objective of this study is to determine the pattern of vegetation change, inferred from the palynology of the Karioi section, with regards to volcanic impact. An understanding of how volcanic events may have impacted the pollen-vegetation record will enable these signals to be excluded from climate records obtained from volcanically active areas, and enable a clearer picture of the role of climate in driving vegetation change. This is of great significance in relation to the global warming trend we are currently experiencing, as a record of how New Zealand vegetation responded to a warmer climate can help us prepare for future changes to our environment. With the possibility of a paleoclimate record obtained from the Karioi site, we hope to effectively identify any volcanic disturbance that may also be present in the record.

Research objectives:

- To investigate possible volcanic disturbances recorded within the Karioi section and ascertain their extent.

- To consider the possible implications of these volcanic disturbances for paleoclimate reconstructions obtained from this site.

These research objectives have been phrased as two questions to be answered during the course of this work:

1) Has deposition of volcanic ash caused any impact on vegetation that can be observed in the Karioi pollen record, and to what extent?

2) If so, what are the implications of any volcanic disturbances for reconstructing paleoclimate from the Karioi pollen record?

\subsection{Global climate variation}

It is widely accepted that changes in Earth's climate, during the Quaternary, are due to the variations in Earth's orbital patterns. In the 1930's, Milutin Milanković proposed that glaciation occurs when insolation (a measure of solar radiation energy received on a given surface area and recorded during 
a given time) intensity is weak at high northern latitudes during summer. This happens when both the Earth's spin axis is less tilted with respect to the orbital plane, and aphelion (the point in the Earth's orbit where it is farthest from the Sun) coincides with summer in the Northern Hemisphere. Under these conditions there is less insolation during the summer, causing snow and ice to persist through the year and gradually accumulate into ice sheets (Raymo et al., 2008). Milanković theorised that as the Earth spins around its axis and orbits around the Sun, several quasi-periodic variations occur due to gravitational interactions. Although the curves have a large number of sinusoidal components, three cycles are dominant. Taken in unison, variations in these three cycles create alterations in the seasonality of solar radiation reaching the Earth's surface, which influence Earth's climate variation on glacial-interglacial timescales. These are: 1) Eccentricity, the shape Earth's orbit takes, varying on time scales from c. $100 \mathrm{ka}$ to c. $400 \mathrm{ka}$; 2) Precession, the variation in the 'wobble' of Earth's axis, alternating every c. 20ka; and 3) Obliquity, the variation in the tilt of Earth's axis from the vertical which cycles every c. $41 \mathrm{ka}$. These cycles are the powerful influencing factors that drive insolation intensity, giving rise to glacial-interglacial transitions which affect vegetation assemblages globally. Paleo-vegetation records are therefore important for interpreting these changes.

These glacial-interglacial transitions can be recognised from oxygen isotope data gained from deep sea cores. The balance of oxygen 16 to oxygen 18 isotopes in foraminifera shells gained from these cores change with the presence of ice sheets, as oxygen 16 is preferentially evapourated from the oceans and trapped in ice. The ratio of oxygen 16 to oxygen 18 can, therefore, infer the amount of ice present on Earth's surface, and thus planetary climate changes. These measurements have been separated into different Marine Isotope Stages (MIS) throughout the Quaternary, where odd numbers refer to interglacials and even numbers refer to glacials. These stage names will be used in the course of this work.

\subsection{Last interglacial climate records}

The last interglacial refers to a time when the climate was very similar to, or warmer than, that of present day (Kukla et al., 2002). MIS 5, informally referred to as the last interglacial (sensu latero), includes a sequence of stadials and interstadials which represent a five-fold subdivision (MIS 5a, b, c, d, and e) (Vandergoes et al., 2005; Newnham and Alloway, 2004; Ryan et al., 2012).

The interval spanning the last interglacial to last glacial stage (MIS 5 - MIS 2) is important as it marks the most recent example of a transition out of warm in to cold climate. This transition is 
characterised by a pro-longed period of orbitally forced climate oscillations, spanning c. 50ka, commonly referred to as a five-fold subdivision. It began with the onset of full interglacial conditions in MIS $5 e$ and was followed by four intervals of pronounced oscillations (MIS $5 d-5 a$ ) that indicated a global climate returning to glacial conditions (Newnham et al., 2004). This transition has occurred many times, linked with periodic shifts in Earth's orbit (Kukla et al., 2002). Milanković orbital cycles are well connected to interglacial and glacial cycles; however, debate remains as to the cause and mechanisms that control the switch from an interglacial to a glacial.

The most detailed proxy record of interglacial climate is found in the Vostok ice core where the record suggests that temperatures reached present day levels c. 132ka and continued to rise for another two millennia (Kukla et al., 2002). This period is widely accepted as corresponding to MIS 5e, of particular interest in this study, which is more formally referred to as the Last Interglacial (sensu stricto), dated to begin c. $127 \mathrm{ka}$ and end c. $116 \mathrm{ka}$ with the onset of the early glacial unit MIS $5 \mathrm{~d}$ (Kukla et al., 2002).

As orbital configuration today is very similar to that of the last Interglacial (Kukla et al., 2002), it is important to develop records of paleoclimate through proxy information such as pollen, for the Last Interglacial period. This will allow us insights into these configurations, as well as our current climate state and stability and will give a better understanding of our future climate. The Karioi site has the potential to produce a continuous terrestrial record that spans from MIS $5 e$ to the present.

\subsection{Last Interglacial pollen records from New Zealand and their significance}

Mid-latitude Southern Hemisphere regions lack continuous, well-constrained terrestrial records, crucial in understanding global climate patterns, especially during the last interglacial. Previous New Zealand pollen records that cover MIS 5 tend to be found on the coast or at low elevation, where optimum preservation environments are most common. Sites at higher altitudes experience harsher conditions, including but not limited to, scouring by the wind, and harsh frosts, which are not ideal for preservation of sediment. Coastal records are however, often discontinuous due to erosion by the sea, fluvial processes, or volcanic impacts (e.g Airedale Reef, Newnham and Alloway, 2004). Most pollen records do, however, contain the vegetation fluctuations that signify the five-fold subdivision outlined above as a common feature. Compiled pollen data from several sites across the Hokitika-Westpost area, South Island, noted that at a regional level, MIS 5e is characterised by 
podocarp forests that resemble present day vegetational assemblages, followed by a change to more extensive Fuscospora forest during MIS 5d. Fuscospora remains dominant throughout MIS 5d to 5 a, but a temporary return of Dacrydium cupressinum is noted in MIS $5 c$ marking a return of slighter warmer temperatures (Moar and Suggate, 1996). These changes are also noted in the Airedale Reef record (Newnham and Alloway, 2004) and the pollen record from marine core TAN0513-14 of the west coast of New Zealand's South Island (Ryan et al., 2012).

\subsection{Significance of volcanic impacts on last interglacial climate records as shown in pollen records}

New Zealand's paleoclimate records show marked environmental change in response to climate oscillations, but due to New Zealand's location on an obliquely convergent plate boundary, these changes could also be driven by active volcanism. Detailed pollen analysis of the central North Island has been reported by McGlone and Topping (1983) who produced pollen profiles from beneath the Kawakawa/Oruanui tephra located in the Rotoaira Basin, Tongariro. These pollen profiles extended back to an estimated $80 \mathrm{ka}$ BP and included two interstadials within an extended glacial phase. As there was an abundance of volcanic material in the sections used, McGlone and Topping (1983) theorised that volcanic impacts would have influenced the vegetation cover in this region and potentially altered the paleoclimate record to varying degrees. We therefore need to identify how volcanic disturbance may complicate the climate interpretation.

There are three general ways that volcanic disturbance may complicate or limit the interpretation of paleoclimate:

- Volcanic activity or eruption results in damage to local-regional vegetation causing pollen assemblages to change in ways that might otherwise be interpreted as climate change;

- Volcanic activity or eruption results in changes to the local environment of deposition resulting in partial or total hiatus in sediment accumulation (and therefore a discontinuous record);

- Volcanic activity or eruption results in erosion of existing sediments resulting in fragmentation of the record.

Analysis of the effect the tephra has on vegetation assemblages was undertaken by high-resolution sampling, and analysing the pollen spectra pre- and post-tephra deposition to establish whether 
there is a change in vegetation directly related to the volcanic event. Diatom identification was used to determine how depositional environments may have changed as a result of tephra deposition. This data can then be used to highlight any volcanic interference that may be present in climate records gained from pollen analysis.

\subsection{Thesis outline}

Terrestrial sites which preserve continuous pollen records for the last interglacial at higher elevations in New Zealand are scarce, and the sites which are available are often located close to volcanic activity. It is hoped that a volcanic disturbance record can be gained from pollen and diatom analysis, along with the use of standard methods such as Loss-on-ignition (LOI), and Magnetic Susceptibility (MS), for the Karioi section. This work will complement the preliminary work completed by Dr Matt McGlone (Landcare Research) which provides a potentially continuous vegetation assemblage record spanning the last Interglacial.

This thesis is presented in eight chapters. Chapter one outlines the broad context of this thesis and introduces the main problems that were targeted. Chapter two covers the use of pollen as a paleoclimate proxy and the effects tephra can have on soil and vegetation. Chapter three outlines the regional and local setting of the undertaken work. Chapter four covers previous work completed at the site. Chapter five describes the analytical methods used in this study. Chapter six covers the results, which are discussed and synthesised in Chapter seven. Conclusions are presented in Chapter eight. 


\section{Paleo-environmental reconstruction and volcanic impacts}

This chapter is split into two parts. Section 2.1 reviews literature concerning the use of pollen grains as a paleoclimate proxy. It covers representation with the subsections production, dispersal and preservation of pollen grains, as well as, identification, and ecological affinity. Section 2.2 focuses on the specific effects volcanic impacts, in particular tephra deposition, can have on soil and vegetation. These points are deemed the key influencing factors when assessing any volcanic impact within a pollen-inferred climate record. The overall aim of this chapter is to give a detailed literature review covering the aspects under consideration within this thesis.

\subsection{Late Quaternary vegetation history}

\subsubsection{Pollen and paleoclimate}

Pollen grains are well suited for paleoclimate analysis as they have extremely resilient, tough outer walls (exines). The exine of most pollen grains is made of sporopollenin, which is resilient to degradation and preserves well in anaerobic sedimentary environments (Birks et al., 2006). Due to their anaerobic depositional conditions, organic-rich sequences such as the Karioi section are particularly effective for the preservation of pollen grains.

Pollen are small cellular bodies which range from 10-100 $\mu \mathrm{m}$ in size. They consist of a male gametophyte enclosed within the exine (Campbell et al., 2008) and are produced as part of the reproductive cycle of seed-bearing plants. They form in either the male strobili of gymnosperm plants or the anthers of angiopsperm plants and are primarily wind or insect dispersed. It is very important to note in relation to paleoclimate studies that pollen morphology is characteristic of the parent plant that produced them (Traverse, 2008).

Spores and their morphpology can also be characteristic of the parent plant. They are single- or fewcelled bodies that are produced as part of the lifecycle of non-seed-bearing plants. These plants undergo an "alteration of generations" where they alternate between a spore-producing asexual 
reproductive generation and a gamete-producing sexual reproductive generation (Campbell et al., 2008).

Pollen data has been used in a wide variety of Quaternary applications, including chronostratigraphic correlation, paleoecology, paleoclimatology and archaeology (Macdonald, 1988). Quaternary pollen data also provides a valuable quantitative record to which climatic models, such as general circulation models, can be validated. This data strengthens predictions of how vegetation is likely to respond to future climatic conditions and in broad terms may also provide an indication of future agricultural potential in different regions (Huntley, 1990).

\subsubsection{Representation}

Representation describes the relationship between the abundance of the parent plant and the amount of pollen recorded at a particular location. Interpretation of pollen assemblages in terms of the vegetation communities they represent is biased by factors such as differences in pollen production, dispersal and preservation (Marcos et al., 2011), as well as pollen data often being presented in proportions of a total pollen sum as opposed to discrete numbers (Davis, 1963). Some taxa produce far greater quantities of pollen, while others produce pollen which is much more widely dispersed (Birks and Birks, 2005). For example, as the pollen of insect- and animal-pollinated plants is transported directly from the source to the receptor, they produce fewer pollen grains than wind-pollinated plants. They occur, therefore, in smaller amounts and are often under-represented or sometimes not represented at all in pollen records (Moar, 1970). On the other hand, some taxa may be over-represented in pollen records. A good example of this is certain Fuscospora taxa. Fuscospora type pollen is the most widely wind dispersed pollen type in New Zealand (McGlone et al., 1983). As a result of this high productivity, Fuscospora taxa are often over-represented at sample sites. These high levels in the pollen rain do not necessarily mean that Fuscospora forest is dominant, or even common, close to the sampled site as the pollen may have travelled a fair distance (McGlone, 1985), and this will affect the percentage representation of any pollen type in the record (McGlone et al., 1983). Preferential preservation of some pollen types may also increase their relative abundance, thereby affecting representation in the record (Faegri and Iverson, 1989), especially in relation to the preferential deterioration of fragile grains under oxidized conditions (Delusina, 2007). 


\subsection{Primary production and dispersal}

The number of pollen grains produced by different plant taxa is largely dependent on the plant's dispersal strategy (Faegri and Iverson, 1989). Plants can be either wind-pollinated, insect-pollinated, or animal-pollinated (Batten and Dutta, 1996). Insect-pollinated and animal-pollinated plants produce fewer pollen grains than wind-pollinated plants because they are transported directly from the source to the target and coverage over a wide area is not needed. Wind-pollinated plants produce greater amounts of pollen because their reproductive strategy needs dispersal of large numbers of grains over a wide area to maximize the chance of finding its intended destination (Faegri and Iverson, 1989), and therefore they are more common in sediments.

\subsection{Preservation}

Well preserved pollen grains are often found in depositional environments with a low $\mathrm{pH}$ and a negative oxidation-reduction potential (Traverse, 2008), although preservation can also be excellent in alkaline lakes and marine sediments under low oxygen conditions (Egan et al., 2001). Suitable conditions for preservation are typically observed in lakes, peat bogs, and enclosed basin environments. In an acidic bog environment, the oxygen available for bacterial degradation of organic components decreases progressively with depth (Tschudy et al., 1969). Lake sediments and peat bogs are particularly valuable for preserving pollen grains as they accumulate over time, creating a continuous record.

\subsubsection{Identification}

A major part of using pollen records in paleoclimate analysis is relating the palynomorphs found in the samples to known taxa (Faegri and Iverson, 1989). A number of New Zealand plants are represented by similar or even identical palynomorphs which can be an issue where these plants occupy different ecological niches and are therefore associated with different climates. A good example of this is the genus Coprosma. Members of this genus can live anywhere from coastal to sub-alpine environments and yet there is very little in the way of distinguishing features at species level in their palynomorphs. Other palynomorphs, such as Dacrydium cupressinum, are very easily distinguished to species level.

In this study, palynomoprhs were identified where possible to the highest taxonomic precision possible under light microscopy. This resulted in some grains being identified down to species, some 
to genus, and some only to family level. Identification was achieved with the reference texts Moar (1993), and Cranwell (1953).

\subsubsection{Ecological affinity}

The use of pollen grains as a climate indicator has so far been mainly qualitative in nature. This is largely due to the difficulty of relating relative abundances of pollen grains to relative abundances of the originating parent plants, as discussed above, as well as the lack of knowledge surrounding the ecological niches of the parent plants and what climatic controls influence them. Past pollen work has thus been confined to terms such as "wetter and drier" when describing the climates associated with pollen analysis. Knowledge of the specific climates in which each taxa grow best is therefore essential for an accurate reconstruction of past climate using pollen grains. Though some advances regarding quantitative methods have been made as was shown by Wilmshurst et al. (2007) where the transfer function approach was used.

\subsubsection{Summary}

There are several important key points outlined in the above section. Most importantly, pollen grains are readily preserved in sediment and are easily related to parent taxa. The preferred niche of each parent taxa can then be researched and this information can be used to infer the climate at the time of sediment deposition.

\subsection{Late Quaternary volcanism in New Zealand and its effects on the surrounding environment}

The Late Quaternary has been a period of active volcanism in New Zealand. Numerous volcanic events across the North Island originated from several large volcanic centres which dominate the landscape. Large amounts of volcanic material in the form of tephra fall, pyroclastic flow deposits, and lava flows over-lie the mostly Tertiary-aged sediments beneath. Many of these events would have had a major effect on the surrounding environment, plant growth and soil development. The sections below will specifically outline the effect of tephra fall had on soil and vegetation. 


\subsubsection{Volcanic ejecta and its effect on soil}

Volcanic ejecta include a wide range of volcanic deposits, but for the purpose of this study I will focus on tephra. Tephra consists of fragments of pulverized rock, minerals and volcanic glass. It is formed during explosive eruptions in which dissolved gases in magma expand and violently escape into the atmosphere. This force shatters the magma and propels it into the atmosphere where it solidifies into tephra.

Tephra fall occurs from the rising eruption column and from the plume as it drifts downwind. As the eruption column rises, it extends laterally as surrounding air is entrained and wind patterns vary. The higher the column rises, the less dense it becomes, causing the larger and heavier particles to fall out closer to the source. The concentration of the tephra therefore decreases with distance from the source vent, resulting in tephra deposits becoming thinner on the ground. The area affected by tephra fall can be very large, for instance $827,000 \mathrm{~km}^{2}$ of land was covered in tephra fall during the 1883 Krakatau eruption (Blong, 1984).

The impact ash can have on soils depends on the thickness of the ash layer as well as its chemical composition, which in turn is dependent on the composition of the magma from which it originated.

\subsubsection{Soil moisture content}

The use of volcanic tephra as soil cover is well recorded in arid areas where the surface ash layer is used to retard evaporation of water from the soil and keep the soil wet for longer during rainless periods. The tephra layer acts as surface mulch, both reflecting incident shortwave solar radiation (which reduces the energy available for evaporation) and barring liquid water flow and evaporation from the soil to the atmosphere. It appears likely that the ash layer, where left undisturbed, will for a time increase the supply of water for plants (Cook et al., 1981).

In areas such as the Canary Islands, which receive minimal rain fall but suffer great evaporation stress, the use of volcanic rock cover allows the farming of vines, onions and other such crops (Diaz et al., 2005). Research completed by van Staaten (2002) also showed that trees in Saudi Arabia growing in soil covered by scoria needed $90 \%$ less water to be supplied then they would if the soil was uncovered; the tephra impedes the evaporation of moisture from the soil beneath it. Pérez (2000) constructed a 22 day experiment in which he compared saturated bare soil to saturated 
tephra-covered soil from Haleakala, Hawai'i. His results showed that bare soil lost $50 \%$ of its water within 9-14 hours, while soils with a tephra covering took 112-191 hours to lose the same amount.

There is also a greater reflectance of solar radiation by ash-covered surfaces which results in lower peak soil temperatures and less water evaporation (Pérez, 2009). Reflectance of such surfaces has been estimated as 40 to $60 \%$ while tephra-free soils in the ash fall areas reflect only about 15 to $20 \%$ of incoming radiation. This was noted following the Mount St. Helens eruptions, where peak daytime soil temperatures measured in late May beneath 2 to $3 \mathrm{~cm}$ of undisturbed tephra were $6^{\circ}$ to $10^{\circ} \mathrm{C}$ lower than those of adjacent sites with ash incorporated (Cook et al., 1981).

The deposition of tephra can also raise the water table by blocking drainage. Intact forest canopies also catch rainwater, preventing it from reaching the ground surface. Damaged forest canopies, as described below, cannot intercept as much water (McGlone et al., 1988)

\subsubsection{Acid pollution}

For average soils with thin organic layers, acid precipitation caused by the addition of tephra increases the leaching of cations such as calcium, magnesium, potassium and sodium from the soil. This loss of cations causes an overabundance of protons, resulting in a lowering of the soil pH. Leached cations can be replaced by biogeochemical weathering of the underlying bedrock, as well as the ion-exchange properties of vegetation, and precipitation. For organic layers (peat) which are more than $0.5 \mathrm{~m}$ thick, however, the bedrock is too deep. The surface layers of peats therefore rely directly upon the ion-exchange properties of vegetation, and precipitation for a supply of cations (Skiba et al., 1989).

Following the October 1995 eruptions of Ruapehu, field and glasshouse investigations undertaken by Cronin et al. (1997) showed that the addition of tephra to the soils in the northern Rangitikei district significantly raised soil sulphate levels. The tephra cover caused prolonged depressions in soil pH due to hydrogen ion generation during the oxidation of elemental sulphur deposited with the tephra. Despite tephra thickness of only $2.5 \mathrm{~mm}$, these effects were still significant 8 months after the eruption occurred (Cronin et al., 1997).

Similar lowering of $\mathrm{pH}$ was also noted following the Mt St Helens eruption in 1980. The tephra produced during this eruption was high in basic cations and sulphates. These readily dissolved and leached from the tephra resulting in the displacement of hydrogen ions from the acidic functional 
groups of humic substances, causing a depression in the $\mathrm{pH}$ levels of the covered soil (Dahlgren and Ugolini, 1989).

Increased acid deposition in the form of tephra will therefore enhance leaching of the minerals essential for plant nutrition, especially as the acidity of a tephra increases as it dries (Ugolini and Zasoski, 1979; Will, 1966). Further acidification can inhibit soil processes such as plant decomposition, restricting the further addition of new minerals to the soil. This process is heavily dependent on the type of soil and whether there is easily weathered basement rock available to contribute the minerals that are being depleted. Therefore a highly fertile soil with easily weathered basement rock will only become depleted after substantial acid pollution.

\subsubsection{Tephra accumulation}

Tephra does not percolate into the soil profile; it is moved primarily by erosion processes. Therefore ash tends to accumulate on the soil surface. Where ash accumulates to a thickness of $0.6 \mathrm{~m}$ or more, the process of soil formation begins anew (Gibbs, 1968), whereas thinner deposits are eventually incorporate into the soil. This accumulation affects the water retention and circulation properties of soil. Tephra has a lower permeability than soil, due in part to its lack of continuous pores for both capillary and saturated flow. The range and distribution of particle sizes of tephra and the angular shape of the particles are such that the fine grains readily fill in the spaces around the coarser fragments, reducing the porosity and flow paths within the tephra and creating dead end spaces that do not conduct water. The pore arrangement of the ash also reduces its permeability to air and water vapour compared to most soils (Cook et al., 1981).

Despite this, most ash layers are excellent media for soil formation. The loosely packed, fine particles give plant roots and mirco-organisms insulation against extremes of moisture and temperature, and their rock particles provide easily accessible minerals which, along with the nitrogen supplied from rain-water, allow vegetation to thrive. This growth covers the ground in a never-ending supply of organics to decompose, allowing the first stage of soil formation (Gibbs, 1968). 


\subsubsection{Volcanic ejecta and its effects on vegetation}

New Zealand forests can tolerate high impacts from volcanic ejecta while environments and climatic conditions are stable. Most of New Zealand's native trees are evergreen with strong leaves that have a leathery texture. This enables the trees to withstand diurnal and seasonal temperature changes and promotes resilience from storm damage and frost. However volcanic activity has damaged or destroyed at least 20,000 ha of indigenous vegetation in the North Island of New Zealand in the last 450 years alone (Clarkson, 1990). Pollen records outlined by Giles et al. (1999) indicate that changes in vegetation on Matakana Island, Bay of Plenty, occurred immediately after the deposition of the Kaharoa Tephra (c. 665 years BP). Repongaere Swamp, Gisborne, New Zealand, received $17 \mathrm{~cm}$ of Taupo Tephra, after which the pollen record shows a decline of tall forest taxa (Wilmshurst et al., 1996). Toxic fumes, acid rain, and ash accumulation are the main causes of distal plant death. Immediately adjacent to the source, blasting, burning and burial are very significant effects (Kent et al., 2001). The eruption of Krakatau in 1883 resulted in much of the vegetation on the island being destroyed. However, within a few years it had regenerated, with vegetation spreading from undamaged areas on the island (Backer, 1929).

\subsubsection{Tephra fall}

The act of tephra falling to the ground breaks small branches, as well as defoliating and damaging the crowns of trees. Many forest trees and large shrubs were stripped of their leaves and small branches during the $1886 \mathrm{Mt}$ Tarawera eruption, near Rotorua (Turner, 1928). Charring also occurs in cases where large pumice lapilli have not cooled before deposition (Blong, 1984). Thermally oxidised pumice blocks from Plinian eruptions have shown that the impact of temperatures of such lapilli may be high enough to ignite vegetation $30 \mathrm{~km}$ from the source vent (Blong, 1984).

\subsubsection{Acid pollution}

During an eruption, chemical substances initially released as volcanic gasses are spread in three different ways: 1) as acid aerosols, 2) as salt particles, and 3) as compounds absorbed into tephra particles (Blong, 1984). Different types of plants react to chemicals in different ways. Some taxa can build up a tolerance to prolonged exposure to harsh acidic environments. Le Guern and Garrec (1988) reported that when Austrian black pine was first planted on the slopes of Sicily's Mount Etna at the turn of the century, only $20 \%$ of the trees grew to maturity due to the high fluorine emissions from the volcano. However, the new generation of trees were unaffected despite having extremely high fluorine concentrations in their leaves. Newnham et al. (1995) reported that, in pollen diagrams 
produced from Papamoa, New Zealand, there was a sharp decline in the abundance of Metrosideros pollen immediately above the $4 \mathrm{~cm}$ Taupo Tephra, while other taxa recorded do not appear to have been affected. This result was attributed to this taxon being more susceptible to the toxic effects of tephra. During this century, numbers of Metrosideros excelsa have also been reduced by more than half on White Island, an active volcano off the north-eastern coast of the North Island of New Zealand. Due to the lack of charcoal, which would point to a population reduction that was the result of fire damage, it is reported by Clarkson and Clarkson (1994) that this decline may be due to acid pollution.

Another example is the $7 \mathrm{~cm}$ Taupo Tephra that fell near Tunapahore. The pollen record here shows that podocarp abundance, along with other large forest taxa, dropped to less than $8 \%$ of the pollen sum. The tephra thickness was too thin to have caused the sharp decline and an increase in charcoal at this time points to forest fire and toxicity from the ash being the cause (Wilmshurst et al., 1996).

\subsubsection{Tephra accumulation}

Tephra accumulation on leaves and branches has varying effects on vegetation and damage from unpolluted tephra usually depends on the thickness of the layer (Newnham et al., 1999). Any exposed vegetation will suffer from adherence of tephra to the leaves. Magill et al. (2013) reported observations from the 2011 eruption of Shinmoedake, Japan, where tephra adherence led to deficiency in photosynthesis, thereby killing the plants. In particular, it was noted that fine-grained, highly-angular tephra particles most strongly adhered to the vegetation.

Reports by Burnham (1994) stated that following the eruption of Mount Saint Helens in 1980, cocoa trees up to $12 \mathrm{~km}$ from the crater withstood the initial blasting of the eruption, but were later damaged by tephra accumulation on the leaves, which was compounded by rainfall. The chances of vegetation survival following tephra accumulation appears to be greatly reduced if rainfall follows its deposition (Kent et al., 2001), as the addition of water increases the weight of the tephra by 50$100 \%$. In the case of Mount Saint Helens, leaves of non-cocoa taxa appeared to be snapped off by the weight of the tephra loading.

Frenzen and Franklin (1985) used conifers to test how tephra accumulation on the ground affects the establishment of plants. Two different tephra thicknesses were studied following the deposition of tephra from the Mount St Helens eruption. It was found that the establishment of Pinus contorta, 
Pinus monticule and two other conifer taxa was very poor on the tephra deposit compared to if establishment was on the underlying soil.

The burden of tephra on smaller plant taxa generally proves fatal. In cases where the tephra accumulated to more than $10 \mathrm{~kg} / \mathrm{m}^{2}$, smaller plants were smothered and there was some limb breakage (Magill et al., 2013). In order to survive burial, smaller plants usually need to rapidly grow through the varying depths of the tephra to reach the new surface. If the tephra remains moist, as would happen during snow melt, growth of small plants that have been smothered can be quite rapid, as fast as $1 \mathrm{~cm}$ per month. With this speed of growth, the plant could be expected to reach the surface before the tephra dries out, resulting in desiccation (Collins, 1969). Antos and Zobel (1985) found that, following the 1980 eruption of Mount St. Helens, buried herbaceous taxa representing all morphological categories could penetrate $0-12 \mathrm{~cm}$ of tephra, while at sites buried by $15 \mathrm{~cm}$ or more, few individuals survived.

In occurrences where tephra has been deposited on cultivated fields, the crops are usually crushed by the weight of the tephra. A survey of one such field showed that even 50 years after eruption of the Paricutin Volcano, overall plant cover was patchy, and vegetation covered less than $10 \%$ of the total area of the deposit (Gomez-Romero et al., 2006). Most vegetation was found to be living on tephra deposits of less than $39 \mathrm{~cm}$ deep, which suggests that the thicker deposits act as a barrier for plant establishment. Greenhouse experiments undertaken by Gomez-Romero et al. (2006) support this with tephra greater than $10 \mathrm{~cm}$ detrimentally affecting the growth of Eupatorium glabratum. Their conclusion was that deeper tephra layers prevent the vegetation roots from reaching the soil below. The duration of growth prevention by the tephra depends on the specific morphology of the affected plants. For example, in New Zealand, trees such as Weinmannia and Beilschmiedia tawa have the ability to re-sprout from epicormic buds and can even flower within a year of the disruption (Clarkson, 1990).

\subsubsection{4. $\mathrm{pH}$ change in the substrate}

As discussed above, the deposition of tephra onto a soil can change its nutrient concentration levels. While this can have adverse effects, in some cases, the nutrients added can replenish nutrient poor soils (Collins, 1969). This can lead to a decline in taxa that are tolerant of infertile soils. Therefore even if the affected vegetation can recover from the impact of the tephra, long term changes in soil mineral properties will eventually affect vegetation communities growing in the affected soil (Giles, 1999). 


\subsubsection{Vegetation recovery}

The amount of time it takes for vegetation to recover from volcanic impacts depends both on the type of vegetation and on the extent of the impact. Following the eruption of Mt Tarawera in 1886, it took 70 years for bare surfaces to progress to grass-herb-lichen assemblages (Burke, 1974), and a further 15 years for Coriaria scrub to develop (Clarkson and Clarkson, 1983), in which Weinmannia racemosa and Griselinia littoralis seedlings sprouted. This time frame was shortened for bare areas closer to pockets of surviving forest (Clarkson, 1990). Where forest was only partly damaged, Weinmannia racemosa and Beilschmiedia tawa re-sprouted from epicormic buds within a year of the disturbance (Clarkson, 1990). This adaptation allowed Weinmannia racemosa to gain forest dominance within 50 years of the Burrell eruption of Mt Taranaki c. 1655 AD (Druce, 1964). The Newall Formation (c. 1500 AD) and the Burrell Formation destroyed vast tracts of forest and damaged the canopies of surviving forest on the north-western, eastern, and south-eastern slopes of Mt Taranaki. Secondary succession on exposed land began with the establishment of Coriaria, followed by dense stands of Weinmannia within 50 years of the disruption. This dense growth of Weinmannia hindered the re-establishment of other vegetation, and it has only been in the 100 years since c. 1888, as Weinmannia trees have come to the end of their natural life, that forest has opened up allowing for forest to return to its pre-eruption state (McGlone et al., 1988).

The speed of re-vegetation back to pre-eruption assemblages, following the 1850 BP Taupo eruption, varied between 120- 225 (radiocarbon) years (Wilmshurst et al., 1996). This was found not to be related to tephra thickness or distance from the vent, so was likely due to climate factors. Initial colonising plants included Pteridium esclentum, Poaceae, Asteraceae, and Gonocarpus. These were later followed by a decline in Pteridium, an increase in Poaceae, and the establishment of Halocarpus as the dominant shrub, along with Coprosma, Pseudopanax, and Leptospermum. A decline in Halocarpus occurred before Phyllocladus regained its pre-eruption dominance (Wilmshurst et al., 1996).

\subsubsection{Summary}

This section has concentrated on the effect tephra deposition can have on both the soil and vegetation. Research summarised revealed that moisture interference, acid pollution, and tephra accumulation have varying impacts, depending on the thickness (relies on the distance of the site from the active vent) and the chemical make-up (depends on the chemical make-up of the magma it originated from) of the deposited tephra. The rate of which vegetation returned to pre-eruption 
states depends on several factors, including the density of initial colonising vegetation. It is widely recorded that vegetation destroyed by volcanic impact can re-sprout within a year, but it may take several hundreds of years for climax forest to return to original pre-eruption assemblages. These are important considerations when researching the potential volcanic impacts influencing a paloeclimate record, inferred from pollen analysis. 


\section{Regional setting}

\subsection{Introduction}

The study site situated on State Highway 49, 7 $\mathrm{km}$ south-east of Ohakune at an altitude of c. $672 \mathrm{~m}$ above sea level (a.s.I) (fig. 1). The site can be found at the GPS co-ordinates $39^{\circ} 26^{\prime} 52.4^{\prime \prime} \mathrm{S}$ $175^{\circ} 28^{\prime} 41.6^{\prime \prime} \mathrm{E}$. The section occurs adjacent the south-west boundary of Tongariro National Park which encompasses the Tongariro Volcanic Centre (TgVC). Of the three principal volcanoes (Tongariro, Ngaurahoe and Ruapheu) that constitute the TgVC, Mt. Ruapehu is the closest volcano to the section with its summit occurring approximately $20 \mathrm{~km}$ to the north-east. The proximity of this site to Ruapehu Volcano has resulted in a unique set of factors that have contributed to the depositional architecture of the section. These factors are outlined in this chapter below.

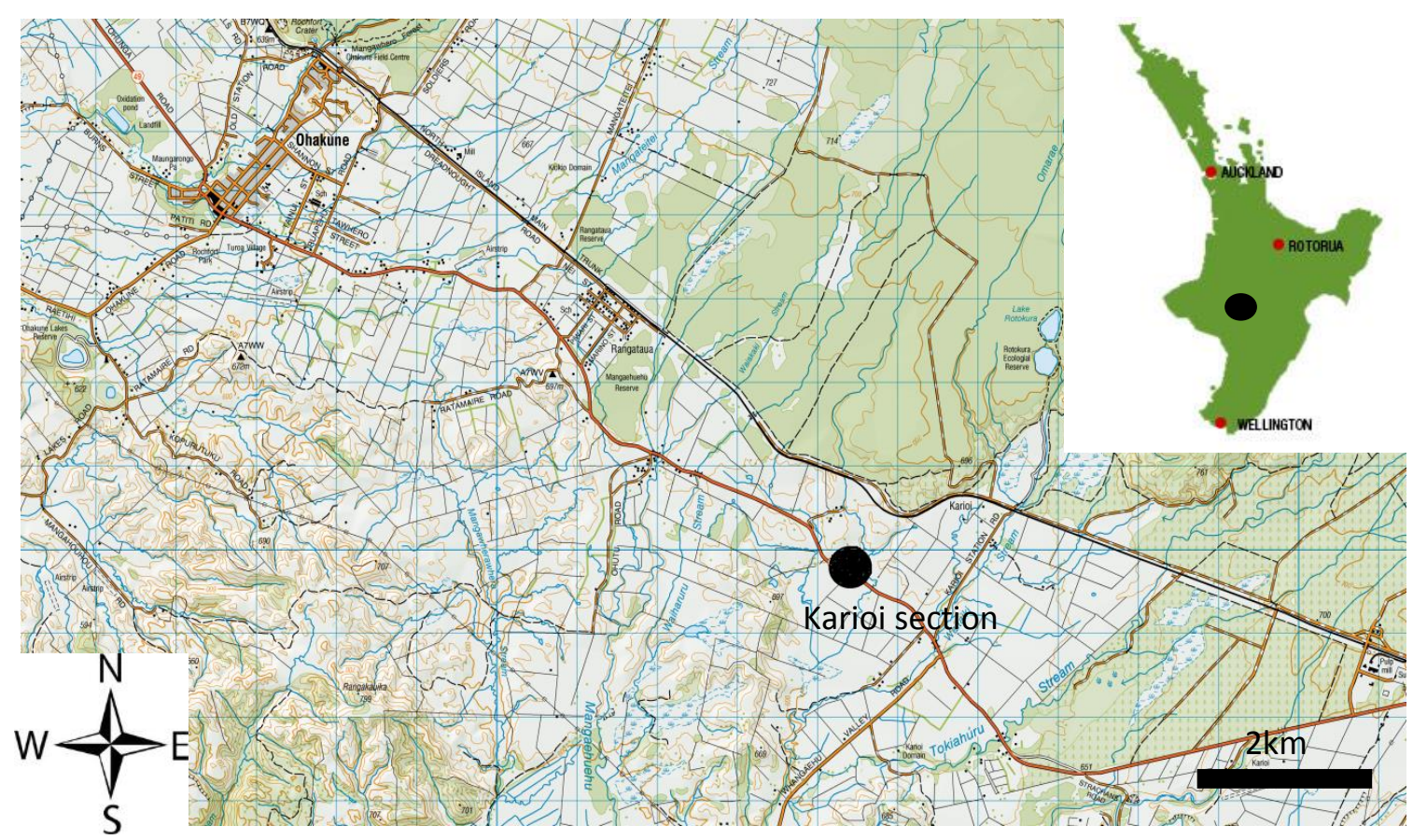

Figure 1. Map of the Ohakune area, with the Karioi site marked by the black circle. Image: Google Maps. Inset map of the North Island, black circle making the approximate location of Karioi. Image: Google. 


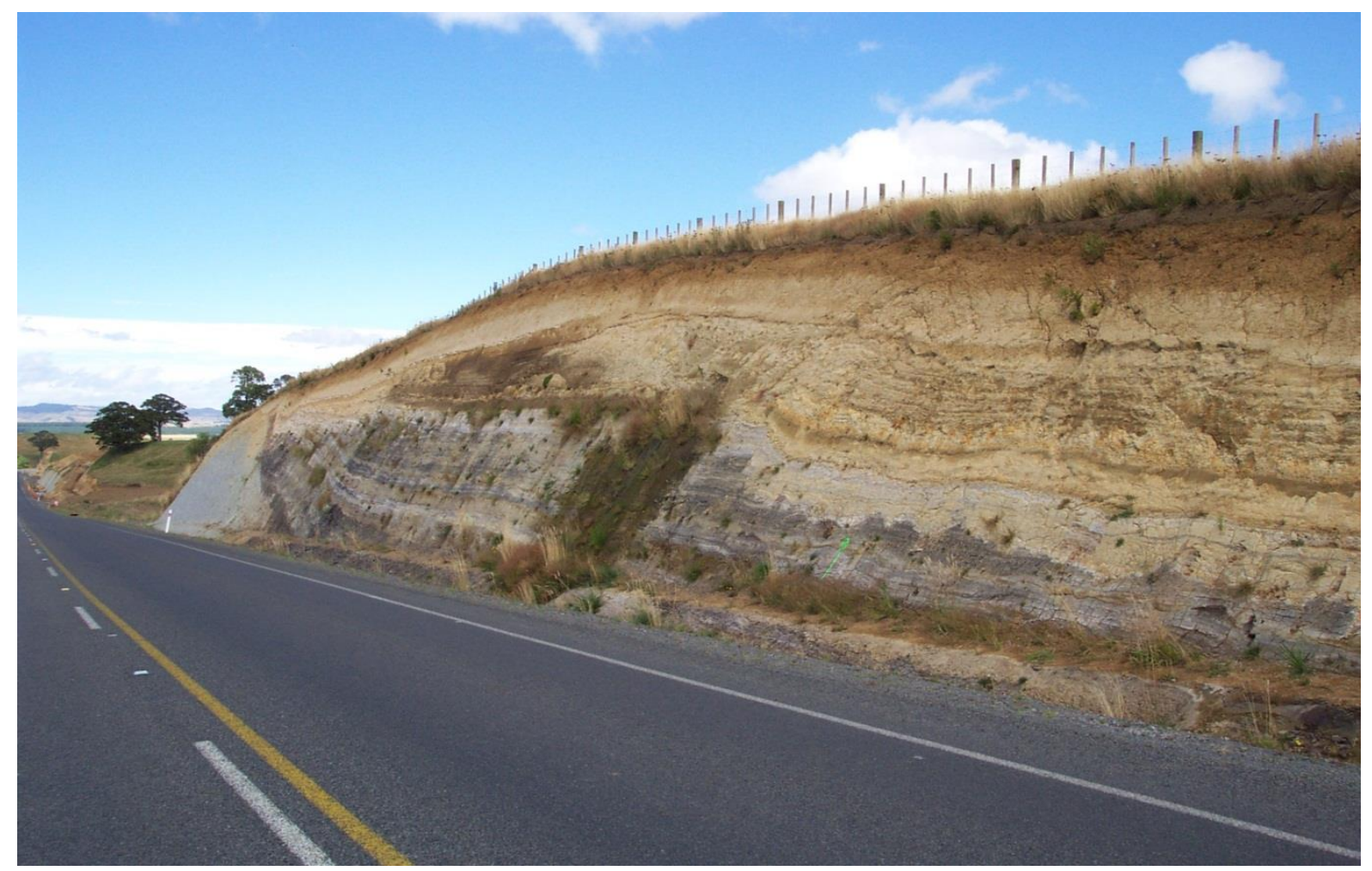

Figure 2. The Karioi Section as a fresh cut surface ca. 2000. To the right of the section, the sediment can be seen to unlap against Tertiary-aged sediment, as a result of the movement on the Karioi Fault. Image courtesy of Dr Brent Alloway.

\subsubsection{Climate}

While the central North Island is sheltered from the dominantly westerly winds by high country to the south and east, the Tongariro Volcanic Centre itself lies directly in the path of the main cyclonic depressions that pass over the North Island. As a consequence, the annual rainfall around the peaks can be more than $3810 \mathrm{~mm}$ (Gregg, 1960). The wettest period is between April and November. Annual rainfall in the area is about $1800-2500 \mathrm{~mm}$ (McGlone and Topping, 1983). Water shortages occur in summer, though drought is rare (McGlone and Topping, 1977). July is the coldest month with typical winter daytime maximum air temperatures ranging from $10^{\circ} \mathrm{C}$ to $14^{\circ} \mathrm{C}$. January and February are the hottest months, with warm, dry and settled weather predominating and daytime maximum air temperatures ranging from $21^{\circ} \mathrm{C}$ to $26^{\circ} \mathrm{C}$, rarely exceeding $30^{\circ} \mathrm{C}$ (NIWA, 2013). The average annual temperature at $600 \mathrm{~m}$.a.s.I, the altitude of Karioi, is $\sim 10^{\circ} \mathrm{C}$ (de Lisle, 1962; McGlone and Topping, 1983). Frosts in the area are extremely common and the Karioi area is covered with snow for an average of 11 days per the year (Gregg, 1960). Sunshine hours average 2000 to 2100 in most places (NIWA, 2013). Average monthly rainfall and temperatures recorded for 2012 and 2013 at the Ohakune weather station are displayed in figure 3. 


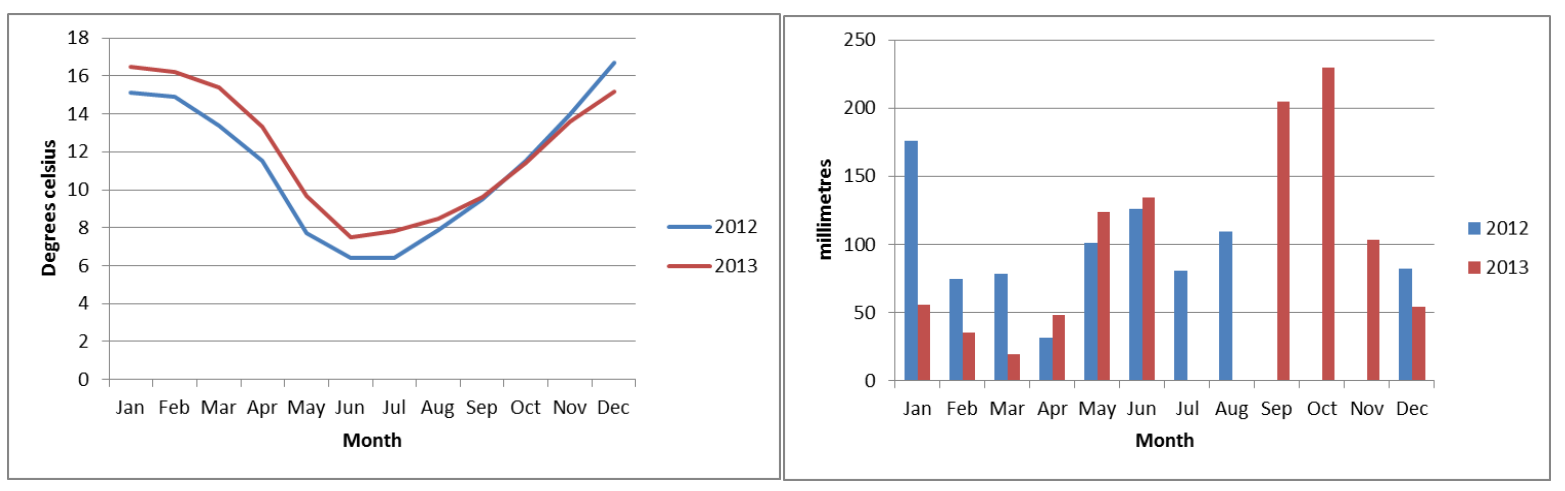

Figure 3. Left: Graphed data of the average monthly temperature for the Karioi area for 2012 and 2013. Right graphed data for the average monthly rainfall in the Karioi area for 2012 and 2013. Data recorded at the Ohakune weather station, $7 \mathrm{~km}$ north-west of the Karioi site. Data accessed from NIWA January 2014.

\subsubsection{Modern vegetation distribution}

The modern vegetation of the central North Island of New Zealand is comprehensively outlined by McGlone et al. (1977). With the exception of swamps and alpine areas, the region was extensively forested up until the arrival of Polynesians who began to clear forest for cultivation. A lot of this forest has been cleared more recently to make way for cultivated grasslands and exotic forestry plantations. Today, surviving native forest is limited to small areas (McGlone et al., 1977).

Podocarp-hardwood forest is the main forest type with Prumnopitys taxifolia and Dacrydium cupressinum being the most common large trees (McGlone et al., 1983). These occur up to an altitude limit of $950 \mathrm{~m}$.a.s.l., which is taken as the boundary between montane and sub-alpine forest (McGlone et al., 1977). Podocarps in general tend to stand as individual emergents amongst a dense canopy of hardwood forest, of which Weinmannia racemosa, Nestegis, and Eleaocarpus dentatus are the most common. Beilschmiedia tawa is abundant in lowland areas that have little pumice cover (McGlone et al., 1983). The sub-canopy usually consists of a combination of Aristotelia, Brachyglottis, Carpodetus, Coprosma, Fuchia, Griselinia, Hedycarya, Melicytus, Myrsine, Olearia, Pennantia, Pittosporum, Pseudopanax, Pseudowintera, and Quintinia (McGlone et al., 1977). Lianas, epiphytes and tree ferns are common. In wetter areas, Dacrycarpus dacrydioides forms dense swamp forest, while on soils with impeded drainage Libocedrus bidwillii forms pure stands (Wardle, 1991). On very boggy or semi-swamp soils Manoao colensoi, Halocarpus bidwillii, and Phyllocladus alpinus can form open scrub or low forest (McGlone et al., 1977). 
The vegetation on Mount Ruapehu consists of mainly beech-podocarp forest. Fuscospora forest dominates the montane and subalpine areas of Mt Ruapehu and often forms pure stands (Wilmshurst et al., 1996), though Libocedrus and Fuscospora solandri share dominance in the lower reaches of the sub alpine zone (McGlone et al., 1983). The timberline reaches as high as $1510 \mathrm{~m}$ above sea level in places and is mostly formed by pure stands of Fuscospora cliffortioides (Wardle, 1984) which forms a continuous belt on the southern and western sides of the mountain from 1128 -1219m.a.s.l. (Cockayne, 1908). Lophozonia menziesii forms near pure stands between $975 \mathrm{~m}$ and $1128 \mathrm{~m}$ on the southern and western slopes, but will mix with Fuscospora fusca as low as 610m.a.s.l.

Cockayne (1908) gives a very detailed account of the vegetation outside of the forest in the Tongariro National Park, which he splits into grass steppe, shrub steppe, sub-alpine shrub, bogs, river gullies, and running water. His descriptions are summarised below:

\begin{tabular}{|l|l|}
\hline Grass steppe: & $\begin{array}{l}\text { Dominant between } 920 \text { and 1220m. This altitude } \\
\text { is dominated by the taxa Danthonia raoulii, } \\
\text { Celmisia longifolia var. gracilenta, Dracophyllum } \\
\text { subulatum, Coprosma depressa, Celmisia } \\
\text { spectabilis, Euphrasia cuneata var. tricolour, } \\
\text { Celmisia glandulosa, Pentachondra pumila, } \\
\text { Gaultheria antipodia, Styphelia frazeri, } \\
\text { Lycopodium fastigiatum, and Poa. }\end{array}$ \\
\hline Shrub steppe: & $\begin{array}{l}\text { Prominent between 1100 and 1400m and is } \\
\text { characterised by an abundance of Pentachondra } \\
\text { pumila, Dacrydium laxifolium, and Dacrydium } \\
\text { bidwilli, the genera Dracophyllum, Epacris, Poa, } \\
\text { Podocarpus, Coprosma, and Gleichenia, and the } \\
\text { families Myrsinaceae, and Compositae. }\end{array}$ \\
\hline Sub-alpine shrub: & $\begin{array}{l}\text { Found on the western and southern slopes of } \\
\text { Mount Ruapehu between steppe and the upper } \\
\text { forest. It is a continuous belt of shrubs which } \\
\text { consists of Phyllocladus, Dacrydium biforme, } \\
\text { Dacrydium bidwilli, Coprosma, Nothopanax, } \\
\text { Griselinia littoralis, Astelia, Veronica, Gleichenia, }\end{array}$ \\
\hline
\end{tabular}




\begin{tabular}{|c|c|}
\hline & $\begin{array}{l}\text { Podocarpus bidwilli (prostrate), Gahnia, and } \\
\text { Libocedrus bidwilli (small). }\end{array}$ \\
\hline River gullies: & $\begin{array}{l}\text { At an elevation of 920m river gullies are full of } \\
\text { Leptospermum, Pittosporum colensoi, Veronica } \\
\text { salicifolia, Arundo conspicua, Olearia nitida, } \\
\text { Griselinia littoralis, Nothopanax, Pseudopanax } \\
\text { crassifolium, and Phorium. }\end{array}$ \\
\hline Shallow running water: & $\begin{array}{l}\text { Mainly Montia fontana, Ranunculus, Juncus } \\
\text { novae-zelandiae, and Epilobium. Schoenus } \\
\text { pauciflorus, Gunnera dentate, Ranunculus } \\
\text { rivularis, and Epilobium are found in small deep } \\
\text { streams, while shallow, muddier areas are full of } \\
\text { Juncus antarcticus, Myriophyllum, and Drosera. }\end{array}$ \\
\hline Bogs: & $\begin{array}{l}\text { Carpha alpine, Liparophyllum gunnii, Urticularia } \\
\text { monanthus, Drosera, Scirpus, Celmisia, and } \\
\text { Centrolepis were common within the bog } \\
\text { boundaries. While Potomogeton natans was } \\
\text { found were water lies, and Gleichenia, Juncus, } \\
\text { Gaspedia, Ourisia, Celmisia, Gentiana, Forstera, } \\
\text { Coproma, Carex, and Aciphylla were found in the } \\
\text { surrounding area. }\end{array}$ \\
\hline
\end{tabular}

The Karioi site itself is currently cleared farm land, so a description of what forest would naturally be growing there needs to be gained from other forested sites close by. Wardle (1984) outlines the forest assemblages for the lower reaches of the south-western flank of Mt. Ruapehu, which includes the Karioi area. Dacrydium cupressinum dominates, with some Prumnopitys taxifolia and Prumnopitys ferruginea, and the associated hardwoods Elaeocarpus dentatus, Elaeocarpus hookerianus and Weinmannia racemosa. Fuscospora solandri and Fuscospora cliffortioides, however, remain in high numbers where drainage is poor. 


\subsubsection{Volcanism past and present}

New Zealand's volcanic activity is due to its location across an obliquely converging plate boundary between the Pacific and Australian Plates.

Taupo Volcanic Zone, located in central North Island, New Zealand, is the southern expression of the Tonga-Kermadec subduction system (Price et al., 2005). It is a region of rapid extension and high heat flow. It experienced intense Quaternary volcanism that was accompanied by rapid extension of the continental crust (Houghton et al., 1995). At $300 \mathrm{~km}$ long and $60 \mathrm{~km}$ wide, it has been active since 2Ma according to K-Ar dating (Wilson et al., 1995). Volcanism within this zone is dominated by rhyolitic volcanism originating from Okataina, Rotorua, Taupo, Maroa, Mangakino, Whakamaru, Reporoa and Tuhua volcanic centres, with andesitic volcanism originating from Tongariro Volcanic Centre (Soons and Selby, 1992). Locations of these volcanic centres are outlined in figure 4.

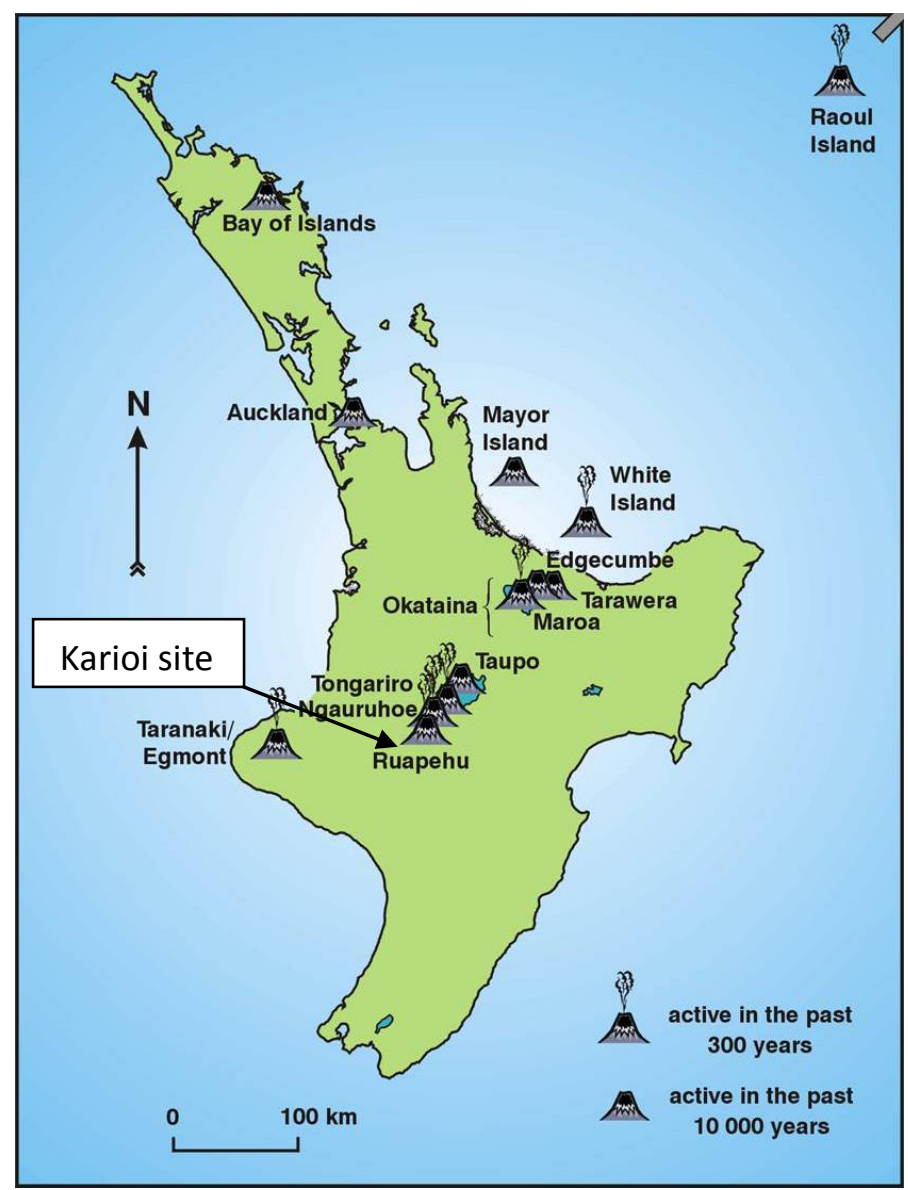

Figure 4. Map marking the location of the Karioi site in relation to the volcanic centres of the North Island, New Zealand. Image: www.civildefence.govt.nz. 


\subsubsection{Tongariro Volcanic Centre (TgVC)}

The Tongariro Volcanic Centre lies at the southern end of the Taupo Volcanic Zone and comprises four main andesitic volcanic massifs: Kakaramea, Pihanga, Tongariro, and Ruapehu. Each of these volcanoes comprises a number of cones with their own volcanic history. Volcanism in this area dates from the early Quaternary. The underlying sediments are comprised of Tertiary-aged mudstones, sandstones and limestones (McGlone et al., 1977).

Mount Ruapehu, a complex andesitic stratovolcano, is at the southern terminus of the Tongariro Volcanic Centre and has been active for the last 300-340ka (Tanaka et al., 1997). It dominates the area with a maximum height of 2797 m.a.s.l. and is surrounded by an equally large volume of Late Quaternary volcaniclastic deposits, forming a ring plain around the mountain. The currently active volcano cone has a bulk volume of $110 \mathrm{~km}^{3}$, and the surrounding ring plain represents multiple deposits at a bulk volume of at least $100 \mathrm{~km}^{3}$ (Hackett and Houghton, 1989). The composition of Mt. Ruapehu lavas varies from basalt to dacite, but basatic andesites and andesites prevail (Gamble et al., 2003).

This volcano is best known for producing lahars and associated deposits. Since historical observations began in 1861, over 50 lahars have been recorded in the Whangaehu River Valley which is the principle outlet for the Crater Lake (Cronin et al., 1997a). Much of the material entering the ring plain has been transported by lahars, either generated directly by eruptions, or triggered by high intensity rain storms (Hackett and Houghton, 1989). The Karioi site is located on the southwestern boundary of the Tongariro Volcanic Centre.

\subsubsection{Egmont Volcanic Centre (Mt. Taranaki)}

Egmont Volcanic Centre is located at the western tip of the North Island. The area is dominated by the $2518 \mathrm{~m}$ Taranaki stratovolcano, a near perfect cone of the Fuji type. Volcaniclastic deposits originating from Mt. Taranaki are highly variable ranging from basaltic to rhyolitic in composition with some of the earliest recognised deposits being the Okawa and Motunui formations (Alloway, 1989). These deposits have been dated to c. 100-120ka (Alloway et al., 2005). Throughout the Quaternary, vast quantities of tephra were ejected with coarser materials ranging from blocks to $64 \mathrm{~mm}$ being deposited within $15 \mathrm{~km}$ of the source vent (Neall, 1972). Finer ash material has been 
dispersed at wide distances with tephra sourced from Mt. Taranaki found in Kaipo Bog, Te Urewera National Park (Lowe et al., 1999), Pukaki Crater, Auckland (Lowe et al., 2008), and Lake Tutira, Hawkes Bay (Eden and Froggatt, 1996).

There are significant differences in the petrology and tectonic setting of Mt. Taranaki and Mt. Ruapehu. Taranaki eruptives are relatively potassism rich while Ruapehu eruptives are generally lower in potassium (Price et al., 1999). Phenocryst assemblages from Holocene-aged Taranaki eruptives are dominated by plagioclase, hornblende, and clinopyroxene. Mt Ruapehu eruptives however, are sparse in hornblende, while orthopyroxene is common (Graham and Hackett, 1987).

\subsubsection{Distal rhyolitic tephra marker beds}

Widespread tephras are often used as stratigraphic marker points. They can provide the key to understanding the relationships of cover-bed sequences at sites where the stratigraphies and ages are not well known.

In this study, a prominent silicic tephra was macroscopically observed inter-bedded within volcanic loess and interpreted to be of Last Glacial Maximum (LGM) age. It was identified as the Kawakawa/Oruanui Tephra (KoT) on the basis of major element chemistry of glass shards. The largest and most widespread late Pleistocene silicic airfall tephra (fig. 5), the Kawakawa/Oruanui Tephra is a product of the Oruanui super-eruption from the Taupo Volcanic Centre. It is currently aged at 25.4ka BP by Vandergoes et al. (2013) and is used as a key chronostratigraphic marker in terrestrial and marine deposits throughout New Zealand. It is found extensively within North Island cover bed successions (Auckland, Sandiford et al., 2001; East Cape, Vucetich \& Pullar, 1969; Taranaki-Wanganui, Alloway et al., 1995; Pillans and Wright, 1992; Wairarapa, Palmer, 1982), as well as multiple South Island successions and offshore marine environments. Its widespread distribution enables the inter-regional alignment of proxy records, which facilitates comparisons between New Zealand climate records. 


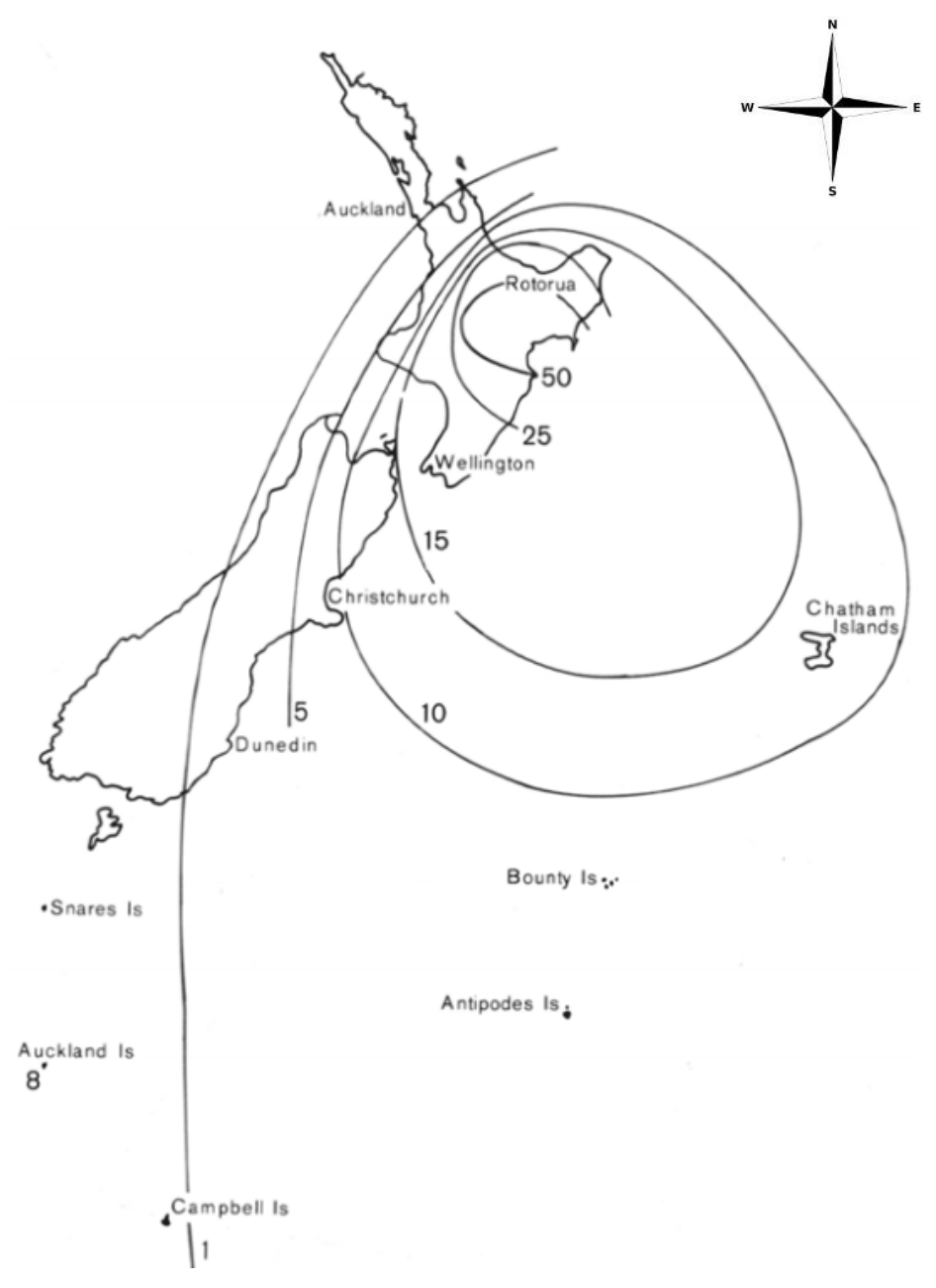

Figure 5. Distribution of the Kawakawa/Oruanui Tephra. Contours represent cm depth of deposited tephra (Campbell, 1986).

The Rotoehu tephra is a widespread, distal tephra from Okataina VC found widely throughout the North Island. Its occurrence at $64 \pm 4 \mathrm{ka}$, right on the boundary between MIS 4 and 3, makes it a very important time-stratigraphic marker. It is easily identified throughout central North Island on the basis of glass chemistry and mineralogy.

\subsubsection{Tectonics in the Karioi area}

South of Ruapehu crater, rift-bounding faults define a $10^{\circ} \mathrm{E}$-trending graben axis, slightly oblique to the main trend of the Taupo Rift around Tongariro Volcano. This southern sector of the Tongariro Domain is named the Mt Ruapehu Graben. The graben is closed to the south by northeastsouthwest and east-west faults, indentified as the Ohakune-Raetihi and the Karioi fault sets, respectively (Villamor and Berryman, 2006). 
The $24 \mathrm{~km}$ width Karioi Fault set is a northeast-southwest trending fault set defined by the Snowgrass, Shawcroft, Karioi, and Wahianoa Faults, which cut across the southern margin of the Mt Ruapehu Graben (Villamor et al., 2006).

The Karioi Fault (fig. 6) has progressively tilted the Karioi section eastward, as shown in fig. 2. It is a $22 \mathrm{~km}$ long fault which comprises a main trace that splits into two scarps. It is a normal dip-slip fault and has a summed late Quaternary displacement rate across both strands as an estimated $0.4 \pm 0.1 \mathrm{~mm} / \mathrm{yr}$ (Villamor et al., 2006).

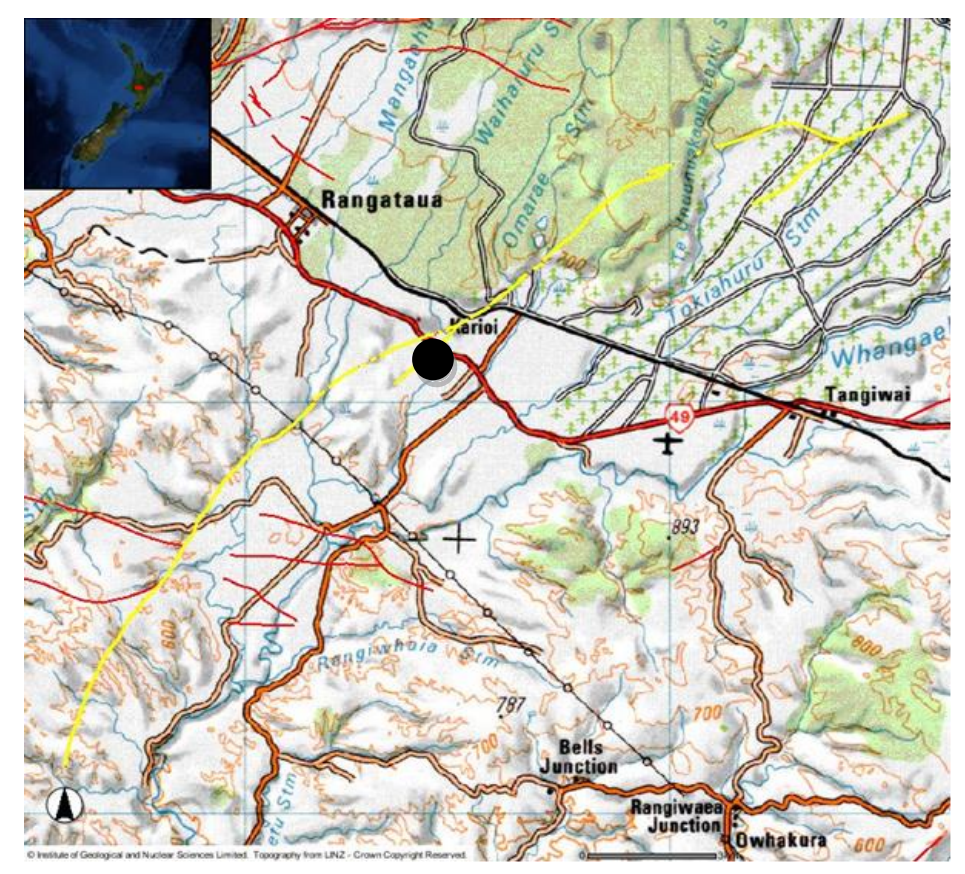

Figure 6. Map showing the extent of the Karioi Fault (yellow). The black dot marks the location of the Karioi section. Image sourced from GNS.

\subsubsection{Summary}

This chapter outlined the climate, vegetation, volcanic, and tectonic factors that have contributed to the depositional architecture of the Karioi section, as well as enabled the evaluation of the relative importance of this local to regional scale data. Due to the location of the Karioi site on the southwestern flank of Mt. Ruapehu, these are all important factors to consider for interpreting an environmental reconstruction. 


\section{Previous work completed at Karioi as a prelude to this study}

\subsection{Introduction}

In 2003, a freshly cut road side section of organic-rich sediments at Karioi was assessed by Dr Matt McGlone as having the potential to produce a continuous palynological record for MIS 5, informally referred to as the last interglacial (sensu lato) but which includes a sequence of stadials and interstadials. Included in this period is MIS 5e, of particular interest in this record, as this substage is more formally referred to as the Last Interglacial (sensu stricto) denoting the last period when Earth's temperatures matched or exceeded those reached during the current Interglacial. At an altitude of $600 \mathrm{~m}$, well away from the coast, the site is unusual. Previous New Zealand pollen records that cover MIS 5 tend to be found on the coast or at low elevation and are often discontinuous due to erosion by the sea, fluvial processes, or volcanic impacts (e.g Airedale Reef, Newnham and Alloway, 2004).

Preliminary pollen work was undertaken by $\mathrm{Dr}$ McGlone, resulting in a $10 \mathrm{~cm}$ resolution spreadsheet of pollen counts (unpublished) which was kindly made available by Dr McGlone to inform this study. All interpretations and figures associated with this pollen data were produced during the course of this study.

In addition, stratigraphic data and geochemical analysis (including back-scatter images) of tephra from within the Karioi section was undertaken and made available by Dr Brent Alloway (VUW), and is presented below. This was deemed essential to this work for establishing possible chronostratigraphic markers. Especially in relation to the rhyolitic tephra noted towards the top of the organic sequence, implications of which will be explored in this chapter. 


\subsection{Why is this likely to be a Last Interglacial site?}

Pollen curves, generated in this study, for four key tree taxa are presented (fig. 7) from data provided by Dr McGlone.

As the sediment age is beyond radiocarbon dating, the age of the pollen record must be inferred from stratigraphic criteria and by comparison with the MIS record. The Karioi section consists of a sequence of layered, organic, pollen-bearing sediments which contain an interglacial signature (as discussed below), overlain by a sequence of fluviatile, loessial and paleosol beds which contain the Kawakawa/Oruanui Tephra (dated at 25.4ka BP by Vandergoes et al., 2013).

As shown in figure 7, the sediments from $765 \mathrm{~cm}$ to $915 \mathrm{~cm}$ show a dominance (35\%) of Dacrydium cupressinum, with less than $5 \%$ of pollen from Fuscospora. As discussed in section 2.1.1.3, Fuscospora pollen is the most widely wind dispersed pollen type in New Zealand (McGlone et al., 1983). The lack of Fuscospora pollen in the percentages is therefore most likely due to limited numbers of beech trees growing in the vicinity of the Karioi site. At present, Dacrydium cupressinum is dominant in the Karioi area; however, beech trees are found in high numbers where drainage is poor, and form completely pure stands from an elevation of 975 m.a.s.l. on the western and southern slopes of Mt. Ruapehu (Wardle, 1984). The low numbers of Fuscospora pollen and other cool climate indicators in the Karioi pollen record from $765-915 \mathrm{~cm}$ depth (fig. 7) are therefore a good indication for a possibly warmer than present climate, as has previously been suggested for MIS 5e (Kukla et al., 2002).

The $765 \mathrm{~cm}$ depth in the Karioi section records an abrupt drop in podocarp pollen, in particular Dacrydium cupressinum, and Dacrycarpus dacrydioides (a drop in pollen of $25 \%$ and $16 \%$ respectively) (fig. 7). This drop coincides with a rapid increase in Fuscospora, and Libocedrus pollen (an increase of $65 \%$ and $27 \%$ respectively) (fig. 7). This change is seen in other records such as at Airedale Reef, Taranaki (Newnham and Alloway, 2004) where pollen records interpreted as MIS 5e are characterised by podocarp forest, followed by a more extensive Fuscospora forest that marked the onset of cooling associated with MIS $5 \mathrm{~d}$. Similar responses can be found in pollen analysis completed on a marine core in the Tasman Sea, off the west coast of the South Island (Ryan et al. 2012). Moar and Suggate (1996) reviewed pollen data from several sites across the HokitikaWestpost area, South Island, and noted that at a regional level, MIS $5 e$ is characterised by podocarp 
forests that resemble the present day optimum, followed by a change to more extensive Fuscospora forest during MIS $5 d$. Fuscospora remains dominant throughout MIS $5 \mathrm{~d}$ to $5 \mathrm{a}$, but a temporary return of Dacrydium cupressinum is noted in MIS 5c. By comparison to these other New Zealand pollen records, with consideration of the stratigraphic context, and in particular the overlying Kawakawa/Oruanui Tephra, it seems likely that changes in the Karioi pollen assemblage represent the climate fluctuations that occurred throughout MIS 5.

An older age for the sequence is discounted by the complete lack of Trisyngyne brassii in the pollen data. Trisyngyne brassii went extinct in New Zealand with the onset of the Late Pliocene-Pleistocene glaciations during the Kaikoura Orogeny (Mildenhall, 1980). 

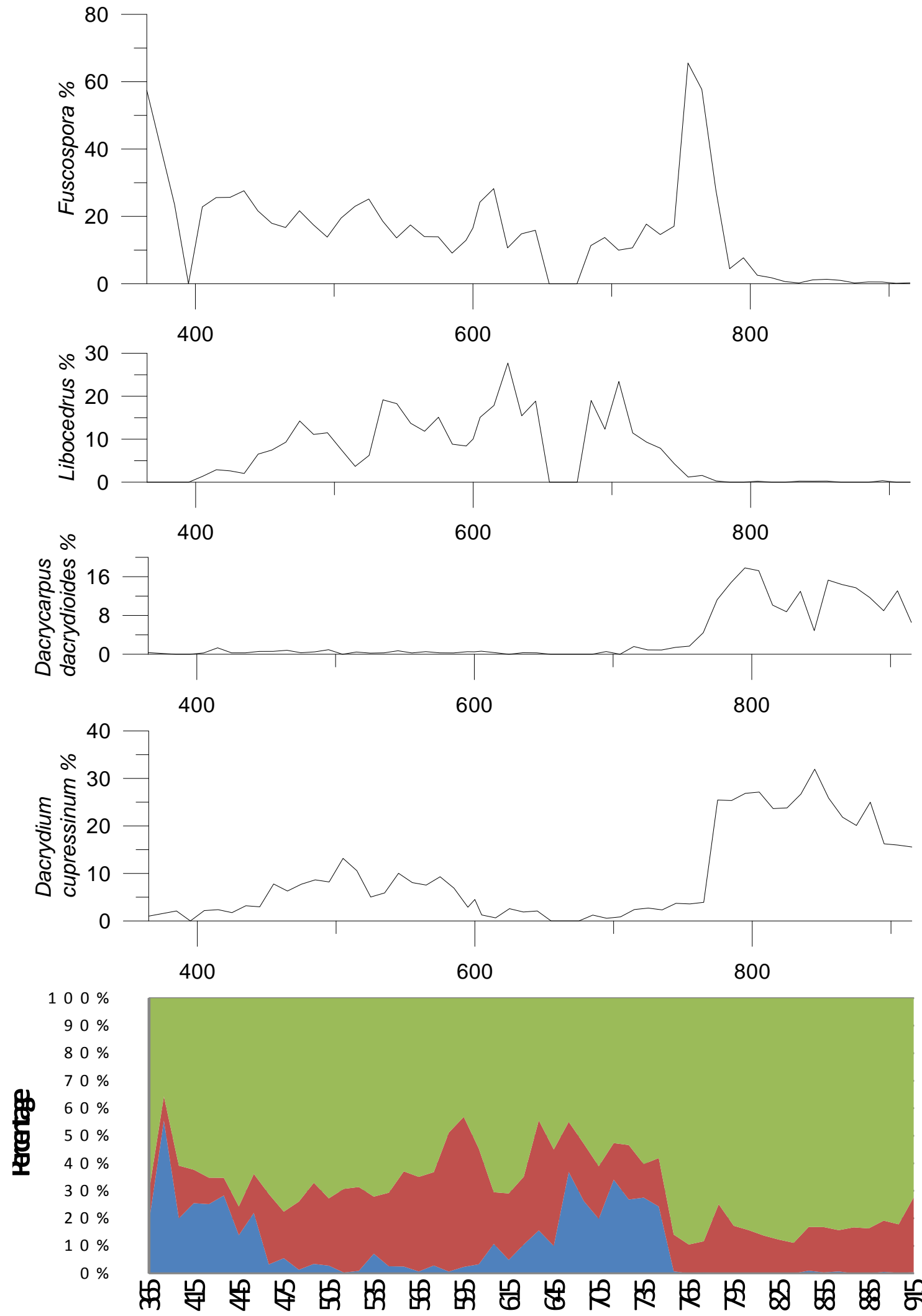

De p th (cm)

Figure 7. From the top, four pollen curves representing taxa as a \% of the dry pollen sum, and the percentage of Trees, shrubs and herbs represented as a \% plot. Raw counts from Dr Matt McGlone (unpublished).

Trees

Shrubs

Herbs 


\subsection{The reasoning behind the current study}

As outlined in chapter two of this thesis, volcanic impact can change vegetation assemblages and create interference with the climate record otherwise inferred from pollen sequences. With the $10 \mathrm{~cm}$ sampling resolution at which the preliminary Karioi work by $\mathrm{Dr}$ McGlone was completed, it is possible that volcanic impact may have occurred, but not been covered by the sampling. The purpose of this study is to establish whether this happened in the Karioi pollen record to the extent that it may have interfered with climate interpretations.

An important consideration is the time represented between samples in any fine resolution study. Holocene peat accumulation rates can be used as an analogue. Maximum rates of peat accumulation during the Holocene are about $1 \mathrm{~m}$ per 1000 years (Rewi Newnham, personal communication, Feb 2014, based on radiocarbon dating and tephrochronology at Kopouatai Bog, Hauraki Plains). Such a maximum rate is unlikely to apply at Karioi, where compaction of peat will have occurred from overlying sediments. These fast peat accumulation rates tend to be in deep low-lying basins, such as Kopouatai Bog, rather than at shallow higher altitude sites such as Karioi. If the Holocene maximum rate was applied to Karioi, however, the preliminary McGlone pollen diagram would have an estimated time sampling interval of 1000 years (assuming the Dacrydium cupressinum rich interval from $765 \mathrm{~cm}-915 \mathrm{~cm}$ corresponds to 15,000 years of interglacial time). This sampling interval is probably too broad to record volcanic impact which, as discussed previously, may only be discernable for a few decades, depending on the characteristics of the event. For this study, it was decided that the finest sampling practicable sampling resolution $(0.5 \mathrm{~cm})$ would be attempted in order to establish whether vegetation disturbance following the occurrence of significant tephra fall. Using a rate of $1 \mathrm{~m}$ of peat accumulation every 1000 years, $0.5 \mathrm{~cm}$ of peat is equal to 50 years (assuming, as above, that from $765 \mathrm{~cm}-915 \mathrm{~cm}$ corresponds to 15,000 years of interglacial time). Even with this maximum sampling resolution, it is still possible that subtle volcanic impact could be missed i.e. lost through homogenisation of sediment layers. If this were the case, however, then it can be argued that the longer term climate record inferred from the pollen is unlikely to have been affected by volcanic impact. 


\subsection{Geochemical analysis of selected tephra from within the Karioi section}

This section outlines the geochemical analysis undertaken by Dr Brent Alloway to inform this study at Karioi, and covers the three selected tephra 'Big Lower Lapilli', 'Little Tephra', and 'Unknown' tephra. The reasoning's for the use of these particular tephra are explored in chapter 5.

\subsubsection{Tephra one: The 'Big Lower Lapilli'}

This $22 \mathrm{~cm}$ thick andesitic tephra has been described by Dr Brent Alloway as follows: A profuse, greyish-brown, very course to medium, pumiceous lapilli grading upwards to well-sorted, very fine pumiceous lapilli and very coarse sandy ash (personal communication, 2013).

Electron microprobe analysis was not possible for this tephra. The grains were thin walled and full of microlite (mostly micro-feldspar and titanomagnetites), making it impossible for the microprobe to get a clean sample for geochemical analysis (fig.8). It was, however, confirmed that this is an andesitic tephra, most likely originating from Mount Ruapehu, the closest andesitic volcano to the Karioi site.
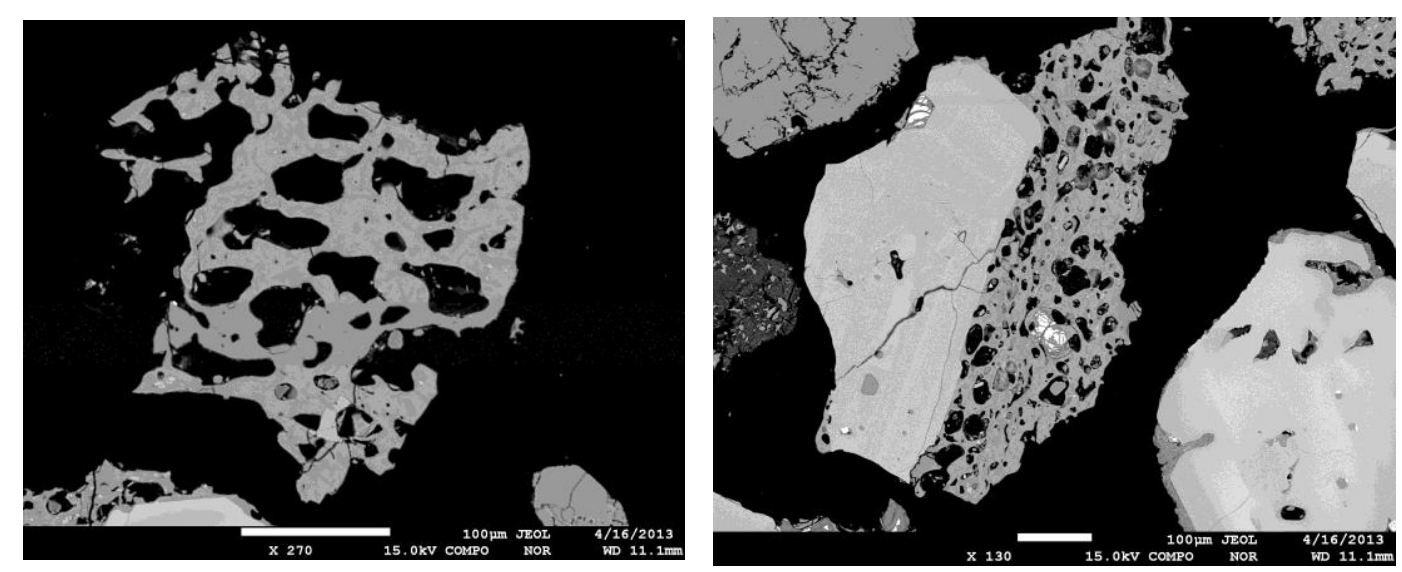

Figure 8. Two back-scattered electron images of different glass shards obtained from the 'Big Lower Lapilli' by Dr Brent Alloway. The images display the thin-walls and abundant microlites that made this sample impossible to geochemically analyse. 


\subsubsection{Tephra two: The 'Little Tephra'}

The 'Little Tephra' is a $2 \mathrm{~cm}$ thick, fine, andesitic lapilli. Electron microprobe analysis was not possible for this tephra either. The grains were thin walled and full of microlite (fig. 9) (mostly micro-feldspar and titanomagetites) and this made it impossible to get a clean sample for geochemical analysis by microprobe. It was, however, confirmed that this is an andesitic tephra (Brent Alloway, personal communication, 2013) which most likely originated from Mount Ruapehu, the closest andesitic vent to the Karioi site.
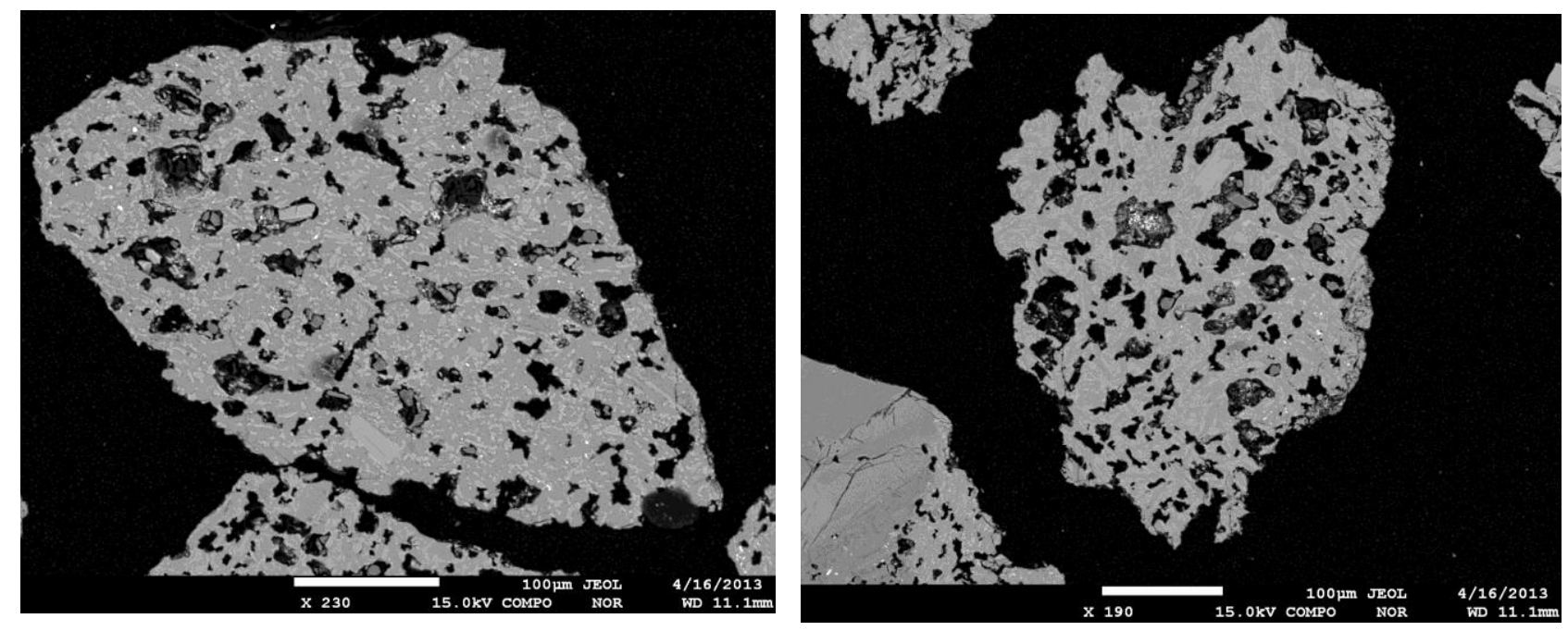

Figure 9. Two back-scattered electron images of glass shards obtained with the 'Little Tephra'. They display the abundant microlites and thin walls that made this tephra impossible to geochemically analyse.

\subsubsection{Tephra three: The 'Unknown' Tephra}

This silicic tephra is located $3.6 \mathrm{~m}$ from the top of the Karioi section (ground surface). It is $2 \mathrm{~cm}$ thick and has a discontinuous distribution. It is described as a discontinuous, greyish-white, very finepowdery volcanic ash. The 'Unknown' tephra proved to be very easy to sample using the microprobe. Being thick walled and having no microlites present, the mircoprobe gathered very clean samples that allowed clean geochemical analysis.

Due to the position of the 'Unknown' tephra at the top of the Karioi section beneath sediments which resembled glacial assemblages, it was thought it could be the Rotoehu Tephra, dated at $64 \pm 4$ ka, right on the boundary between MIS 4 and 3. The Rotoehu tephra is an important, widespread, time-stratigraphic marker, and is easily identified throughout central North Island on the basis of glass chemistry and mineralogy. Finding the Rotoehu tephra within the Karioi section would provide a definite chronostratigraphic marker to further constrain the age of the site. 

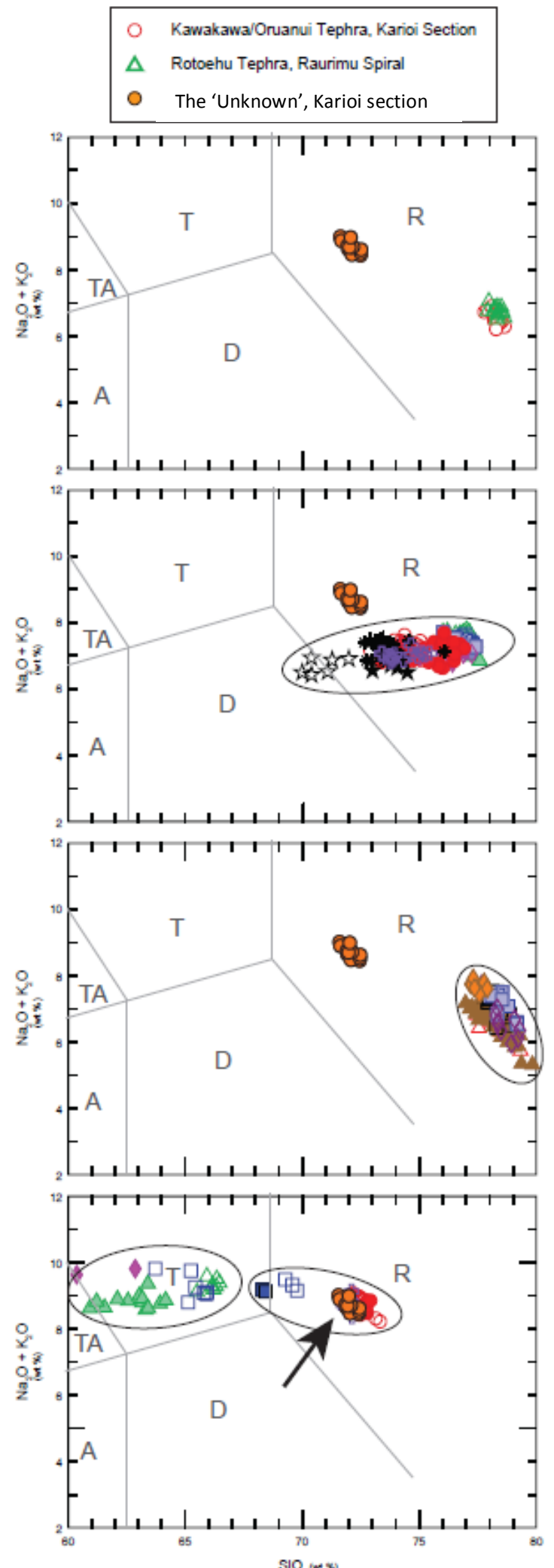

All known pre-Te Rere

Okataina VC tephra

All known pre-Oruanui

Taupo VC tephra
Late Holocene

Egmont-sourced tephra

Figure 10. Le Maitre plots showing the geochemistry of the 'Unknown' Tephra in relation to other tephra found in the vicinity of Karioi. $R=$ rhyolite, $D=$ dacite, $A=$ =andesite, $T=$ trachyte, $T a=$ trachyte-andesite. The arrow points to the three Taranaki eruptives which geochemically match the 'Unknown' tephra. Circles combine similar data points. Data and graphs courtesy of Dr Brent Alloway. 
The 'Unknown' tephra's geochemistry was plotted in a Le Maitre plot (fig. 10) (Le Maitre et al., 2002) against other known tephra from the Karioi area by Dr Brent Alloway. These tephra included the Rotoehu Tephra, the Kawakawa/Oruanui Tephra, all known pre- Te Rere eruptives from Okataina Volcanic Centre (OVC), and all known Pre- Kawakawa/Oruanui eruptives from Taupo Volcanic Centre (TVC). As figure 10 shows, the 'Unknown' did not geochemically match any of these. It does, however, highlight the 'Unknown' samples unusually high wt \% of alkali (8.5\%) compared to TVC and OVC (7\%) and squarely places it within the rhyolite sub-group of volcanic eruptives (fig. 10).

After noting the unusually high wt \% of alkali compared with TVC and OVC, a plot was then created comparing the 'Unknown' tephra to a few examples of eruptives that originated from Mt. Taranaki during the late Holocene. The results (fig. 10) showed a distinct similarity with three of the tephra originating from Mt. Taranaki, all displaying high wt \% of alkali as well as matching the 'Unknown' tephra's high wt \% (72\%) of silica. This does not mean the 'Unknown' is late Holocene in age. As the tephra is found statigraphically below the Kawakawa/Oruanui tephra, it is older than 25.4ka BP (Vandergoes et al., 2013), but further constraint of this tephra beyond its origin in the Egmont VC is not possible due to the lack of knowledge surrounding Mt. Taranaki's early activity.

\subsection{Summary}

Previous work at the Karioi site has produced the raw data for a $10 \mathrm{~cm}$ resolution pollen record apparently suitable for use as a paleoclimate proxy covering MIS 5 . The site's proximity to sources of active volcanism, however, makes it possible that at least some of the record may have been influenced by volcanism rather than climate. It was decided that a $0.5 \mathrm{~cm}$ sampling resolution around several of the tephra located within the section would be useful for identifying the extent of vegetation change is response to volcanic impacts, and therefore aid in testing the impact of this signal on the inferred climate record.

This research was supported by geochemical analysis, supplied by Dr Brent Alloway, in which, tephra from within the Karioi section have been analysed to establish provenance. It was hoped the Rotoehu would be identified, allowing for a chronostratigraphic marker within the sampled section. While this did not occur, the results gained allowed for further age constraint of the Karioi site. 


\section{Methodology}

\subsection{Introduction}

This chapter describes the sampling strategies and extraction procedures used in this study, together with specific procedures for pollen as well as geochemical analysis for selected tephra beds. Further to this, an explanation of the rationale behind the methods used will be given.

\subsection{Field site}

The Karioi Section (GR S20/242918) is a north-facing road-cut exposed on SHW-49, 7.7 km southeast of Ohakune, at an elevation of $\sim 672 \mathrm{~m}$ above sea level. The organic sequence and associated cover-beds appear to be progressively tilted eastward in the direction of the fault trace (fig. 11) and are inter-bedded by multiple andesitic tephra (of probable TgVC source) as well as a $1 \mathrm{~m}$ thick $\mathrm{d} / \mathrm{hcf}$ (lahar) deposit. Westward from the fault trace, the organic sequence is visibly truncated and unconformably overlain by a coverbed sequence that includes fluviatile sands and gravels, and volcanic loess with intervening paleosols. Kawakawa/Oruanui Tephra from the TVC is conspicuous near the base of the uppermost loess deposit (c. $2 \mathrm{~m}$ from ground surface, see figure 13: Stratigraphic Column). 


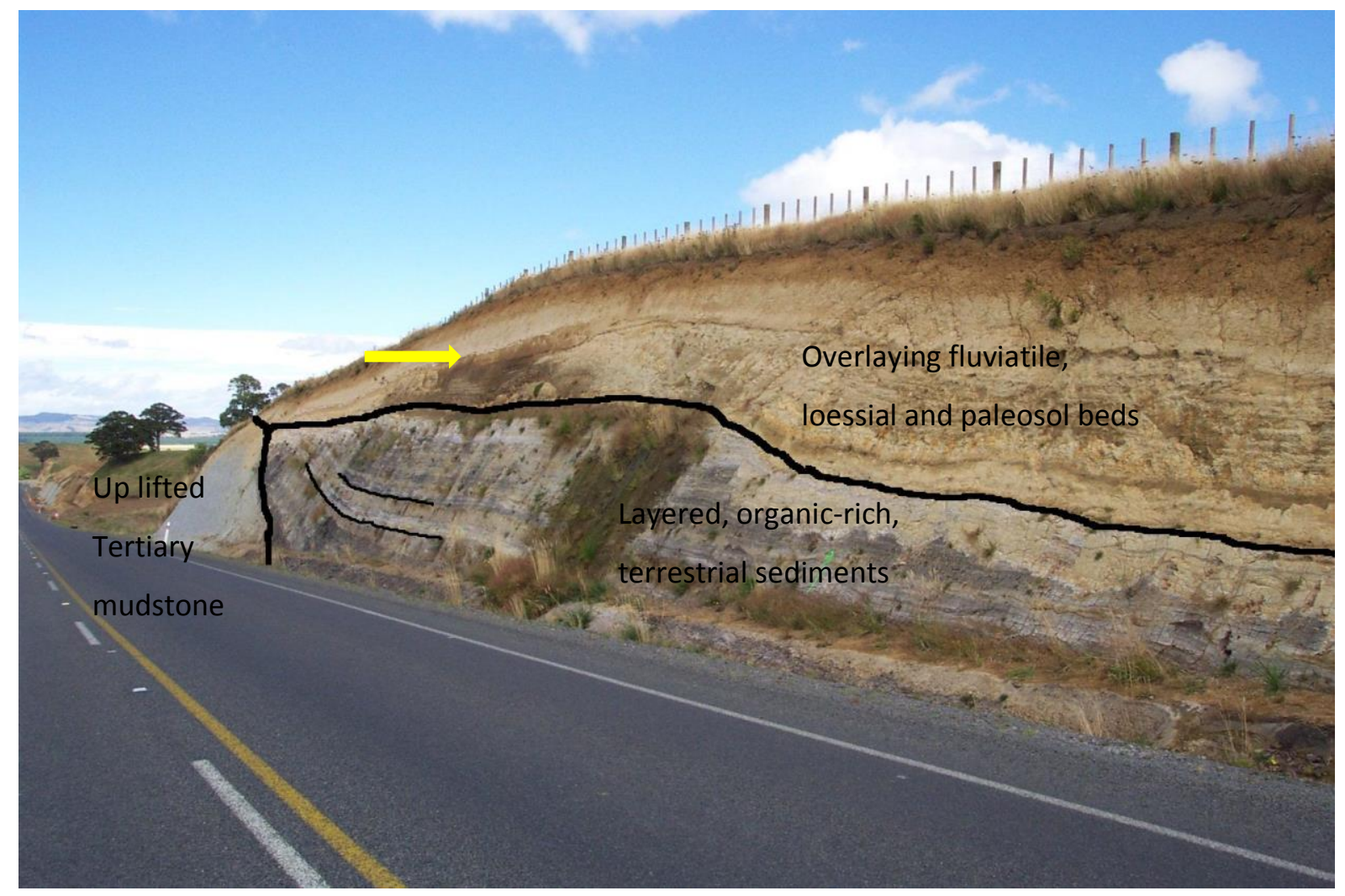

Figure 11. Eastward view of the Karioi section. Note the Tertiary-aged mudstone outcrop unconformably overlain by the woody organic rich sequence. The organic sequence is unconformably overlain by fluviatile sediments and volcanic loess containing the Kawakawa/Oruanui Tephra (indicated by the yellow arrow). Photo: Dr Brent Alloway.

\subsection{Sample collection}

As outlined in section 4.3, the preliminary McGlone pollen data has have an estimated time sampling interval of 1000 years between samples. This sampling interval is too broad to record volcanic impact, which may only be discernable for a few decades depending on the characteristics of the event. For this study, it was decided that the finest sampling resolution practicable $(0.5 \mathrm{~cm})$ would be attempted in order to establish whether vegetation disturbance after significant tephra fall had occurred. Using a rate of $1 \mathrm{~m}$ of peat every 1000 years, $0.5 \mathrm{~cm}$ of peat is equal to 50 years (assuming that from $765 \mathrm{~cm}-915 \mathrm{~cm}$ corresponds to 15,000 years of interglacial time).

This fine-resolution sampling strategy was adopted for both above and below three tephra that were selected for sampling from within the Karioi section. The three tephra were picked for their characteristics and location within the section. Thickness of the tephra was the first criterion used 
for this study, allowing for two different thicknesses of tephra to be studied; followed by tephra of different composition (e.g rhyolitic vs. andesitic). Stratigraphic position was important for establishing a wide coverage area across the section, as well as being located in parts of the section that represent different vegetation-climate settings. For these reasons, a $22 \mathrm{~cm}$ thick andesitic lapilli bed ('Big Lower Lapilli'), a $2 \mathrm{~cm}$ thick andesitic coarse, sand-textured ash ('Little Tephra'), and a $2 \mathrm{~cm}$ thick fine-sand textured rhyolitic ash ('Unknown') were chosen.

The fine resolution sampling strategy employed consisted of $0.5 \mathrm{~cm}$ interval sampling (each sample weighed $1 \mathrm{gm}$ ) for $5 \mathrm{~cm}$ both above and below each selected tephra layer. This allowed the production of a detailed record of palaeo-environmental changes following tephra deposition. For those tephra easily accessible from ground level, a monolith (a section of the outcrop, removed in its entirety for analysis elsewhere) was taken by hammering a "cookie cutter" (fig. 12) into the section, and then digging out the "cookie cutter" with a complete sample inside. This method is described in detail by Faegri and Iverson (1989). For this study, a 7cm wide, 0.055 gauge piece of galvanised steel, wrapped around a $60 \times 10 \mathrm{~cm}$ piece of $4 \times 2$ wood was used (fig. 12). These dimensions allowed for a monolith that was $60 \mathrm{~cm}$ long, $10 \mathrm{~cm}$ wide, and $5 \mathrm{~cm}$ deep, to be cut from the section. It allows for fine resolution sampling to be undertaken in the laboratory where contamination from airborne pollen can be minimised. Both the 'Big Lower Lapilli' and the 'Little Tephra' were sampled in this way. This method however, was not practical for samples located higher up the section, such as samples associated with the 'Unknown' tephra. Accessing these was difficult, so each $0.5 \mathrm{~cm}$ interval sample was dug out by hand, in the field.

A $5 \mathrm{~cm}$ sampling resolution was used across the entire section for magnetic susceptibility and losson-ignition. This was to provide an overview of the percentage of organic matter and mineral content of the sediment. This is outlined further in sections 5.4.5 and 5.5.3. 


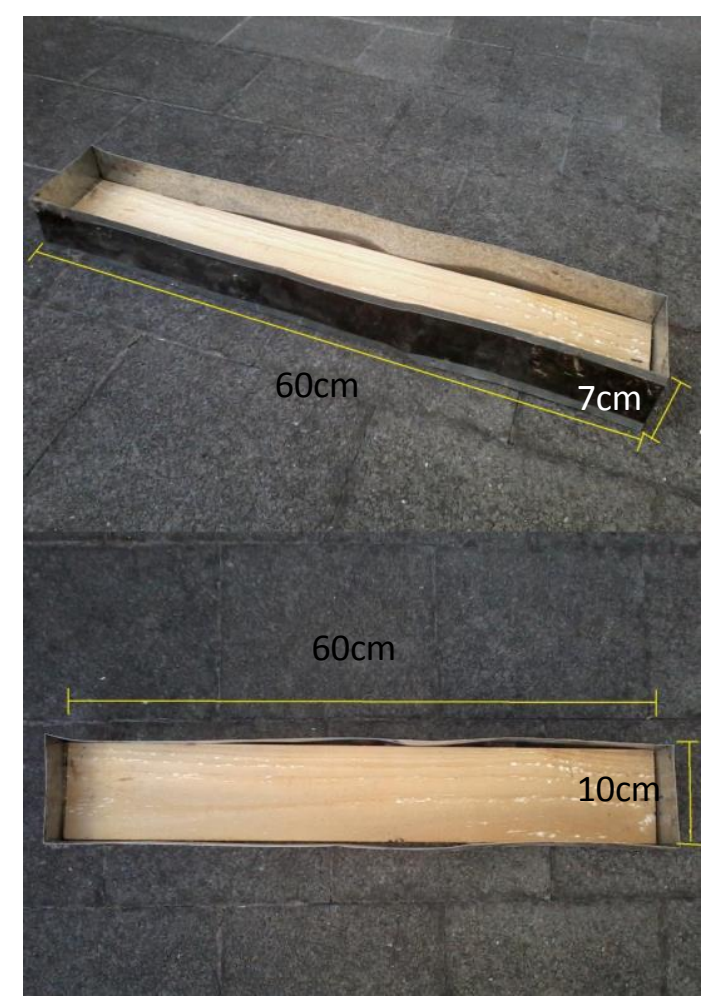

Figure 12. Image showing the dimensions of the "cookie cutter" used during sample extraction.

\subsection{Palynology}

Pollen extraction isolates pollen grains from sediment by excluding as much extraneous material as possible in order to provide a 'clean' sample which can then be analysed under the microscope. The methods employed for pollen extraction, used in this study, follow those described by Moore et al. (1991).

\subsubsection{Processing technique}

A full description of the technique followed can be found in appendix 1 of this work but the following provides a brief summary. Samples were soaked is distilled water overnight to disaggregate. The samples were then soaked in $10 \% \mathrm{HCL}$ to remove any carbonate from the sample as well as to dissolve the tablet binder from the Lycopodium tablet that was added to spike the sample for determination of pollen concentrations (see 5.4.3.2). Following this, the samples were soaked in $10 \% \mathrm{KOH}$ to neutralise humic acids and release the palynomorphs from the sediment matrix before being sieved through a $90 \mu \mathrm{m}$ mesh. Density separation was then required in order to further separate the palynomorphs from any mineral matter in the samples. Sodium polytungstate, 
with a specific gravity of 2.2, was used and the float was then decanted off. The residue is then put through Acetolysis to remove cellulose material. The remaining sample was sieved through a $6 \mu \mathrm{m}$ sieve and what was retained was poured into a test tube, ready for making into a slide for counting.

\subsubsection{Counting procedure}

Light microscopy was used to count each slide with an aim of counting 250 dry-land (species not associated with wetland environments) pollen grains per sample, in a routine approach that ensured each transect was only counted once. A 400x magnification was most commonly used; however, the 100x magnification was used if the slide was lacking in pollen numbers. The pollen grains were identified using the expert knowledge of Dr Rewi Newnham, along with Dr Newnham's type slide collection available at VUW, and relevant taxonomy literature which included Moar's (1993) 'Pollen grains of New Zealand dicotyledonous plants' and Cranwell's (1953) 'New Zealand pollen studies: The Monocotyledons'.

To avoid over-representation of any taxon, pollen grains that were fifty per cent or less complete where not tallied in the final counts for each slide. This was done with the understanding that the rest of the grain may be counted further along in the slide.

\subsubsection{Statistics}

\subsubsection{Multivariate statistical analysis}

Principal component analysis (PCA) and detrended correspondence analysis (DCA) analyses were both completed using the statistical program ' $R$ '. Pollen count data was transformed into per cent abundances and, where appropriate, rare taxa were down weighted.

PCA is a statistical procedure that uses an orthogonal_transformation to convert a set of observations of possibly correlated variables into a set of values of linearly uncorrelated variables called principal components. Put simply, it reveals the internal structure of the data in a way that best explains its variance by rotating the data set so that each successive axis displays a decreasing amount of variance. PCA columns 1 and 2 were plotted in a biplot graph to show any variance in the taxa assemblages between the samples from above and below the tephras. If a definite variance is recorded in the data, a plot of the resulting scores will reveal 'groupings' representing PCA scores 
which are statistically similar. A volcanic impact can therefore be recognised if these 'groupings' separate scores from pre- and post-tephra deposition.

DCA was used to find the main gradients in the taxa-rich data sets used in this research. DCA overcomes the tendency for the one dimensional, vegetation succession data sets, such as is used in this work, to be distorted into an arch on the second axis, allowing for a linear trend to be displayed. In this work the first DCA curve was aligned with the pollen curves to outline major changes in the taxa assemblages across the entire data set. It presented these changes on one curve, showing where vegetational assemblages varied most.

\subsubsection{Total abundance}

Exotic Lycopodium marker spore tablets (Batch number 1031; 20,848 spores per tablet) were added to each sample to determine the number of grains of pollen per gram of dry sediment (Stockmar, 1971). The absolute abundance of palynomorphs was calculated in terms of grains per gram of dry terrigenous sediment (gr. $\mathrm{g}^{-1 \mathrm{~T}}$ ) using the following formula:

Abundance=pollen counted $x$ (total Lycopodium added/number of Lycopodium counted) $\div$ dry sediment weight

\subsubsection{Relative frequency curve}

Dryland pollen percentages were calculated in the form of relative frequency curves as defined by Faegri and Iversen (1989). Pollen percentages for dryland pollen taxa were calculated as a percentage of the total dryland pollen sum (250 grains counted per slide). Pollen and spores from wetland and fern taxa were excluded from the total pollen sum. These taxa were expressed as a percentage of the particular group (e.g. wetland) plus the total dryland pollen. In this way, fluctuating values of local wetland and fern taxa do not affect the percentage values of dryland taxa, and overrepresentation of the local taxa is avoided (Moore et al., 1990). Taxa groupings were divided with reference to Moore and Irwin (1978).

Cumulative (summary) pollen percentage diagrams have been used to give a combined representation of the relative proportion of each group of taxa (e.g. podocarp-hardwoods) at each sample level. 


\subsubsection{Loss-on-Ignition}

Differential thermal analysis thermograms have shown that when a sample containing organic material is heated in a muffle furnace, the organic material begins to ignite at about $200^{\circ} \mathrm{C}$ and is completely consumed by the time the furnace temperature has reached approximately $550^{\circ} \mathrm{C}$ (Dean, 1974). Therefore, the process of loss-on-ignition (LOI) can be used to ascertain the percentage of organic matter in a sample by weighing before and after heating in the muffle furnace, as the organic content of the sample will be burned off. This was useful as a proxy for climate stability, as the amount of biomass in the catchment can be used to infer if an environment is stable, as a stable environment will incur a higher percentage of organic matter. An LOI stratigraphic plot can, therefore, infer climate in that a high LOI can be interpreted as a high percentage of biomass accumulating in the sediment, common in warm, humid environments (good for biomass expansion) and vice versa.

Samples from every $5 \mathrm{~cm}$ throughout the entire Karioi section were processed using a protocol modified from Dean (1974). The $5 \mathrm{~cm}$ sampling strategy was deemed sufficient to gain a thorough overview of the organic content across the $6 \mathrm{~m}$ thick Karioi section. Sample intervals that fell within a tephra were treated exactly the same as the more organic samples.

Crucibles were dried in an oven at $100^{\circ} \mathrm{C}$ for one hour to remove any residual moisture and placed in a desiccator to cool down for 30 minutes. The weights of each empty crucible were then determined before $0.5 \mathrm{~g}$ of sample were added to each crucible. Triplicates of each sample were processed to ensure consistency. The samples were then placed back in the oven to dry overnight at $100^{\circ} \mathrm{C}$. Samples were placed in the desiccator again to cool before the dry weight of the crucible and sample was recorded. The samples were then placed in a muffle furnace heated to $550^{\circ} \mathrm{C}$ and left to combust for two hours. At the completion of two hours the samples were again cooled in a desiccator before their final combusted weight was measured. The weight of the final combusted material was expressed as a percentage of the dry weight using the below equation:

((Dry weight - combusted weight $) \div($ dry weight - crucible weight $)) \times 100$

Tongs were always used to transfer crucibles to avoid tampering with the crucible weight by contaminating with skin oil. 
The USGS criteria for sample outliers was used to reject samples with relative standard deviations $>10 \%$. Results with a standard deviation $\geq 10 \%$ could be a result of human error or machine malfunction as well as possibly resulting from not homogenising the sample enough before processing. These results were rejected and the sample was processed again. In the course of this study, only one sample was reprocessed.

\subsubsection{Diatoms}

In preliminary work for this study, it was noted there were numerous diatom valves present in some samples preserved along with the pollen grains within the processed slides. It was decided that these could be used to further establish the paleo-environment, in particular the hydrology, which existed during tephra deposition and may show further impact from volcanic events. With the help of Dr Margaret Harper (VUW), and the text Foged (1979), diatoms from each sample (using the same slides as was used in the pollen work) were identified and their niche preferences researched. A formal count of the diatoms per slide was not under taken due to time restraints in this study; counts were completed in a presence or absence fashion and graphed accordingly.

\subsubsection{Magnetic susceptibility}

Magnetic susceptibility is a dimensionless proportionality constant that indicates the degree of magnetisation of a material in response to an applied magnetic field. For the purpose of this study, measuring the magnetic susceptibility of the Karioi section every $5 \mathrm{~cm}$ was undertaken. The $5 \mathrm{~cm}$ sampling strategy was deemed sufficient to gain a thorough overview of the magnetic susceptibility across the $6 \mathrm{~m}$ thick Karioi section. This method was completed as a useful inference for cryptotephra (not visible to the naked eye) throughout the Karioi Section, as tephra has a much stronger response to an applied magnetic field due to its ferromagnetism and titanomagnetite/ilmenite mineral content and, therefore, will record a much higher reading. Once the data was processed, it was aligned with the stratigraphic section and LOI data to further confirm the placement of tephra within this palynological study.

The lab work was undertaken using a Bartington MS2 Meter, located at Victoria University of Wellington, to induce a magnetic field around each sample, and the reading was recorded. For accuracy, three readings were taken from each sample as well as a control reading both before and 
after the sample was placed in the holder. This was to account for any drift in the magnetic field during recording. The readings were then averaged and adjusted for drift before being put through the following equation to account for the differing mass in each sample. $\chi$ is the specific susceptibility, $\mathrm{R}$ is the reading taken by the Barington MS2 Meter, and $\mathrm{m}$ is the mass of the sample:

$$
\chi=R / 10 \mathrm{~m} \quad \times 10^{-5} \mathrm{~m}^{3} \cdot \mathrm{kg}^{-1}
$$




\section{Results}

\subsection{Introduction}

The results section is split into two major parts. Part one describes the stratigraphy and results obtained in this study that relate to the whole Karioi section. This includes the results for magnetic susceptibility, Loss-on-Ignition, DCA analysis of the pollen data supplied by Dr McGlone, as well as selected pollen curves obtained from this data. Part two concerns the volcanic impact studies conducted on three discrete parts of the Karioi section. This covers high resolution pollen data, diatom identification, PCA and DCA analysis, and geochemical analysis of the tephra within each discrete section.

\subsection{Stratigraphy}

A comprehensive stratigraphic column was completed, using information provided by $\mathrm{Dr}$ Brent Alloway and the authors own observations, covering $14 \mathrm{~m}$ of vertical exposure, including $5 \mathrm{~m}$ of organic-rich sediments analysed for pollen (fig. 13). A brief description of the entire $14 \mathrm{~m}$ follows.

The base of the section consists of a massive, greenish-grey sandy clay, overlain with $1.5 \mathrm{~m}$ of weakly developed, sandy clay displaying prismatic structures, likely to be of Tertiary age (Brent Alloway, pers comm, 2013). $1.5 \mathrm{~m}$ of well-cemented, poorly sorted lithic gravels and cobbles in a matrix of poorly sorted coarse sands has then been emplaced, and trees in growth position can be seen at the lower contact (fig. 13).

The upper contact of the well cemented, poorly sorted, lithic gravels is the start of the organic-rich sediments in the section and marks where pollen sampling began. The following $1.5 \mathrm{~m}$ consists of highly carbonaceous, coarse, blocky structured deposits which are dark-grey to black in colour (fig. 13). There is a lot of preserved wood within these deposits, along with common centimetre thick ash and lapilli beds. The 'Little Tephra' is found $0.58 \mathrm{~m}$ (fig. 13) from the contact with the well-cemented, poorly sorted, lithic gravels; sampling for this tephra was undertaken as described in section 5.3. 
The highly carbonaceous deposits then grade over $5 \mathrm{~cm}$ into $20 \mathrm{~cm}$ of slightly carbonaceous, dark greyish-brown, blocky structured mud, which is overlain by a further $20 \mathrm{~cm}$ of highly carbonaceous sediments. The 'Big Lower Lapilli' is located at this point in the section, and is $22 \mathrm{~cm}$ thick (fig. 13).

Two metres of highly carbonaceous, structured mud with sand and silt inter-beds were deposited on top of the 'Big Lower Lapilli', followed by $0.5 \mathrm{~m}$ of slightly carbonaceous mud, on which, the 'Unknown' tephra is located (fig. 13), followed by $5 \mathrm{~cm}$ of highly organic sediments before another $0.20 \mathrm{~m}$ thick pumiceous lapilli is emplaced (fig. 13).

The majority of the next metre contains planar centimetre-bedded, light yellow-brown sands and silts. Thin discontinuous lenses of gravel, distinct iron concretions, as well as iron in-filled rhizomorphs are present (fig. 13). These sediments have been identified as fluvial deposits composed of clasts derived from tertiary-aged lithologies, and are followed by a distinct $22 \mathrm{~cm}$ thick paleosol, on which, the Kawakawa/Oruanui Tephra has been deposited. This is in turn overlain with $0.8 \mathrm{~m}$ of yellow-brown loess-like soil forming material with a distinct Last Glacial Maximum signature, before a $1 \mathrm{~m}$ deposit of Holocene age, strong brown, well-developed medial material. The top $0.5 \mathrm{~m}$ of the Karioi section is modern soil (fig. 13). 


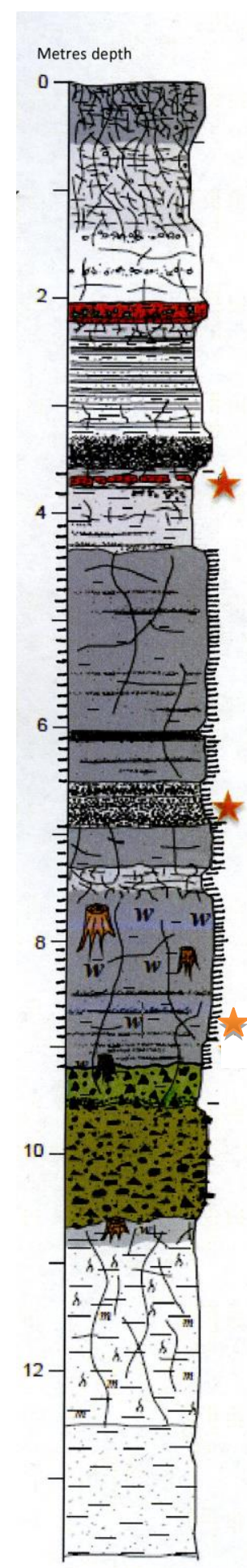

\section{Stratigraphic column of the organic rich section at Karioi, Ohakune}

Very dark greyish brown to black, well developed. Fine nut structured silt loam.

Strong brown, well developed, very fine to fine blocky structured ashy medial material, few orange-yellow fine to medium pumiceous lapilli.

Yellowish brown, weakly developed, coarse blocky structured ashy medial material.

Kawakawa Tephra

Yellowish brown to dark brown, moderately developed, medium blocky structured medial material.

Planar cm-bedded, light yellowish brown silty sands to sandy silts; thin, discontinuous lenses of sub-angularrounded gravels. Beds of gravelly Fe-concretions.

Reddish yellow-brown to strong brown, coarse to medium pumiceous lapilli grading to very coarse sandy ash. Fine grained rhyolite tephra, discontinuous. The 'Unknown' tephra.

Slightly carbonaceous, dark greyish brown, coarse blocky structured mud, $\mathrm{mm}$ - to $\mathrm{cm}$-thick fine sands to sandy silt interbeds.

Highly carbonaceous, woody, very dark grey- black, coarse blocky structured muds with wedging; common mmto $\mathrm{cm}$-thick ash and lapilli interbeds.

Profuse, shower bedded, well sorted, dark grey, scoriaceous, medium- coarse sandy ash.

Greyish brown, very coarse to medium, pumiceous lapilli grading to well sorted very fine lapilli. 'Big Lower Lapilli' Dark grey - black, highly carbonaceous mud.

Slightly carbonaceous, dark greyish brown, moderately well developed, fine to medium blocky structured mud.

Highly carbonaceous, woody, very dark grey- black, coarse blocky structured muds with wedging; common mmto $\mathrm{cm}$-thick ash and lanilli interbeds.

The 'Little Tephra'

Well cemented, massive structured, dark grey- grey, sub-angular- angular lithic gravels and cobbles, poorly sorted matrix of gravelly coarse sand. Wood rip-ups.

Slightly carbonaceous, dark greyish brown, moderately developed, coarse blocky medial material; Small trees in growth position.

Olive green, weakly developed, coarse prismatic structured sandy clay; Common, fine olive mottles, few medium pumiceous lapilli, and dispersed fine- medium sub-angular to sub-rounded gravel.

Massive, greenish grey sandy clay to clayey sand.
KEY

\begin{tabular}{|c|c|}
\hline & KEY \\
\hline & $\begin{array}{l}\text { Highly carbonaceous } \\
\text { very dark grey - black muds }\end{array}$ \\
\hline$-\theta$ & $\begin{array}{l}\text { Slightly carbonaceous } \\
\text { dark grey - dark grayish brown muds }\end{array}$ \\
\hline- & Inorganic clay to sandy clay \\
\hline & Silicic tephra \pm accretionary lapilli \\
\hline 回 & $\begin{array}{l}\text { fine to v. fine sandy ash } \\
\text { medium to coarse sandy ash } \\
\text { andesitic pumiceous lapilli }\end{array}$ \\
\hline 熎 & Andesitic debris flow deposit \\
\hline$m$ & Mottles \\
\hline & Sample location \\
\hline th & Tephra used in this study \\
\hline$\delta$ & Rhyzomorphs \\
\hline$w$ & Wood \\
\hline 蟍 & Tree stump in growth position \\
\hline
\end{tabular}

Figure 13. A stratigraphic column of the Karioi section produced in the course of this work. Tick marks on the left-hand side of the image mark the locations of sampling completed by Dr Matt McGlone. Tick marks located on the right-hand side of the image mark the locations of sampling completed in this work. Initial image supplied by Dr Brent Alloway; the image was then reworked and descriptions were added by the author of this work. 


\subsection{Analysis of the Karioi section}

DCA, LOI, and MS where carried out on samples from the entire Karioi section. These have then been plotted against vegetation, which itself is expressed as percentage abundances calculated from the data supplied by Dr McGlone (fig. 14). The data can be easily split into distinct zones according to vegetation assemblages, as shown in figure 14. These sections are outlined below.

\subsubsection{Zone one: $765 \mathrm{~cm}-915 \mathrm{~cm}$}

The plot of the first axis from the DCA shows a steady vegetation assemblage from $765 \mathrm{~cm}-915 \mathrm{~cm}$ of the Karioi record, which is matched by high levels of organic matter in the samples ranging from $20 \%$ to $90 \%$ as recorded in the LOI curve (fig. 14). The pollen assemblages during this time are dominated by Dacrydium cupressinum (25\%) and Dacrycarpus dacrydioides (16\%) (fig. 7) with tree pollen making up $80 \%$ of the total pollen sum (fig. 14).

\subsubsection{Zone two: $615 \mathrm{~cm}-765 \mathrm{~cm}$}

An abrupt change in the vegetation assemblage (as shown by the DCA curve) occurs at $765 \mathrm{~cm}$ with a rise in herb pollen (25\%), and a drop in tree pollen (60\%) (fig. 14). As discussed in section 4.2, these changes, combined with the sudden change in the axis one scores of the DCA1 curve, reflect a rapid change from podocarp-dominated forest to Fuscospora-dominated forest, which is reflected in the pollen percentage curves for both of these taxa (fig. 7). An abrupt decrease ( $85 \%$ to $55 \%$ ) is observed in overall tree pollen at the site (fig. 14), while individual pollen percentages record a sharp decrease in both Dacrydium cupressinum (20\% drop) and Dacrycarpus dacrydioides (14\% drop), and an increase in both Fuscospora (60\% rise) and Libocedrus (fig. 7).

Concurrent with these marked changes in the vegetation assemblages is a notable decrease in the LOI curve from $45 \%$ to $8 \%$ (fig. 14 ), but no change in the MS curve. This infers a change to unstable environments that are detrimental to the accumulation of biomass rather than an increase of inorganic volcanic materials in the sediment, as disruption by volcanic impact would result in a corresponding spike in the MS curve.

The LOI percentage remains low (8\%) until $715 \mathrm{~cm}$ where it rapidly increases from $10 \%$ to $35 \%$, marking an increase in biomass in the sediment, while the MS curve stays steady between 0 and $0.15 \times 10^{-6} \mathrm{~m}^{3} \cdot \mathrm{kg}^{-1}$. The deposition of the 'Big Lower Lapilli' at $675 \mathrm{~cm}$ results in an increase in the MS 
curve $\left(0.1\right.$ to $\left.0.59 \times 10^{-6} \mathrm{~m}^{3} \cdot \mathrm{kg}^{-1}\right)$ and is reflected in the low LOI curve (10\%). These two curves return back to previous levels after a further $25 \mathrm{~cm}$ (fig. 14).

\subsubsection{Zone three: $465 \mathrm{~cm}-615 \mathrm{~cm}$}

$615 \mathrm{~cm}$ records a marked drop in herb percentages to less than $5 \%$ (fig. 14). The Dacrydium cupressinum pollen curve shows a slight increase (10\%) (fig. 7), diagnostic of warmer temperatures when compared to other New Zealand pollen records for this time period. Libocedrus numbers begin to decline, and Fuscospora remains steady at about 29\% (fig. 7).

The MS of the sediment increases from 0.1 to $0.6 \times 10^{-6} \mathrm{~m}^{3} \cdot \mathrm{kg}^{-1}$, and a decrease in the LOI percentages from $20 \%$ to $3 \%$ is noted. This is the result of the deposition of coarse andesitic lapilli, $10 \mathrm{~cm}$ thick, which was identified in the stratigraphy of the section but not analysed in the volcanic impact work. The LOI percentage then rises to $60 \%$, along with a drop in the MS curve to $0.05 \times 10^{-6} \mathrm{~m}^{3} \cdot \mathrm{kg}^{-1}$ before the occurrence of several small peaks in the MS data $\left(\sim 0.3 \times 10^{-6} \mathrm{~m}^{3} . \mathrm{kg}^{-1}\right)$, which matched troughs in the LOI curve ( $20 \%)$. A final peak of $68 \%$ in the LOI curve occurs at $515 \mathrm{~cm}$, before a steady decline in biomass accumulation at Karioi for the rest of the section (fig. 14).

\subsubsection{Zone four: $465 \mathrm{~cm}-365 \mathrm{~cm}$}

$465 \mathrm{~cm}$ records the beginning of a rise in total herb pollen percentages. The DCA curve, which had been fairly constant with a score of -0.25 since the deposition of the second coarse andesitic lapilli mentioned above, drops from -0.5 to -0.85 (fig. 14). The LOI and MS curves only cover $435 \mathrm{~cm}$ $465 \mathrm{~cm}$, but a steady increasing trend in the MS can be seen. The total pollen percentage graph reports $55 \%$ herb pollen at $385 \mathrm{~cm}$ (fig. 14), the highest seen in this record for herbs, before an increase in tree pollen at the top of the sampled part of the section. 


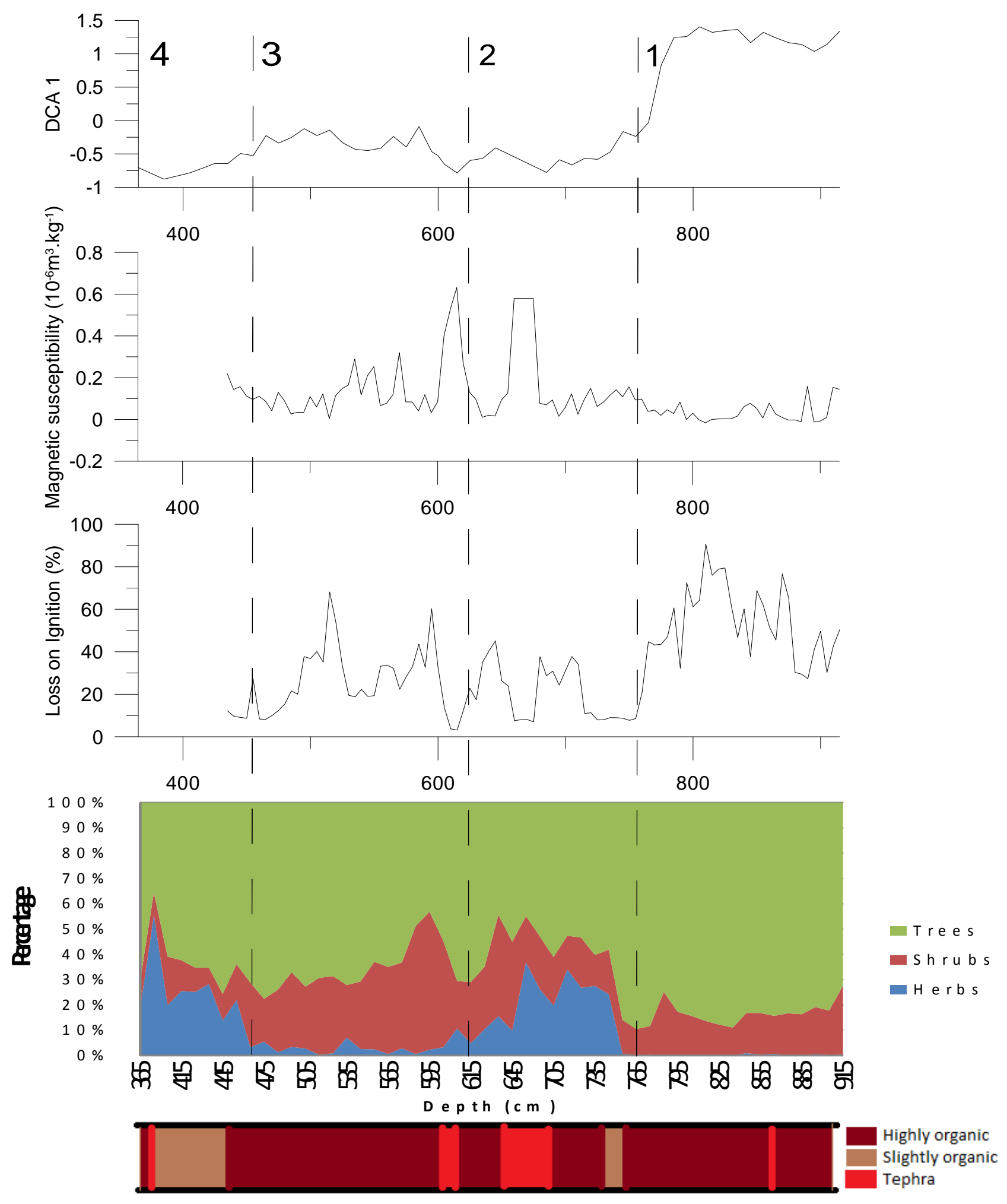

Figure 14. From the top: Stratigraphic DCA curve for the entire pollen data of the entire Karioi section calculated for data supplied by Dr McGlone. Magnetic susceptibility curve calculated in this study. Loss on Ignition curve calculated in this study. Percentages plot for vegetation type calculated from pollen data supplied by Dr McGlone. Simple stratigraphic log outlining the position of organic sediment and tephra in relation to the above graphs. Dashed lines and numbers mark the boundaries used in the above description of the section. 


\subsubsection{Summary}

The results covered above depict a Karioi section that appears to split into four sub-stages. Two substages depict a warm environment characterised by Dacrydium cupressinum forest and two substages portray cooling with an increase in Fuscospora and Libocedrus percentages (fig. 7). The cooler phases are characterised by a drop in tree pollen percentages in favour of herbs overall, which also coincides with a drop in biomass accumulation in the sediment, shown by the LOI curve (fig. 14). The lack of a concurrent rise in the MS curve points to this change in the vegetation assemblage being driven by climate, as opposed to volcanic impact. With the $765 \mathrm{~cm}$ depth already attributed to the MIS 5 e/MIS $5 \mathrm{~d}$ boundary (chapter 4 ), these vegetation assemblages have been matched to MIS $5 \mathrm{e}$, $5 d, 5 c$ and $5 b$.

The following work will concern the three discrete sections at Karioi used for high resolution analysis, here named the 'Big Lower Lapilli', the 'Unknown', and the 'Little Tephra'

\subsection{The 'Big Lower Lapilli'}

This $22 \mathrm{~cm}$ thick andesitic tephra (here named the "Big Lower lapilli") is located at $660 \mathrm{~m}$ (fig. 13). It has been described by Dr Brent Alloway as follows: A profuse, greyish-brown, very course to medium, pumiceous lapilli grading upwards to well-sorted, very fine pumiceous lapilli and very coarse sandy ash (personal communication, 2013).

\subsubsection{Vegetation}

High resolution $(0.5 \mathrm{~cm})$ pollen sampling was undertaken for $5 \mathrm{~cm}$ on either side of this tephra to ascertain the effect the deposition of the tephra had on the vegetation assemblages in the area. The resulting pollen assemblages are presented in Figure 15. 


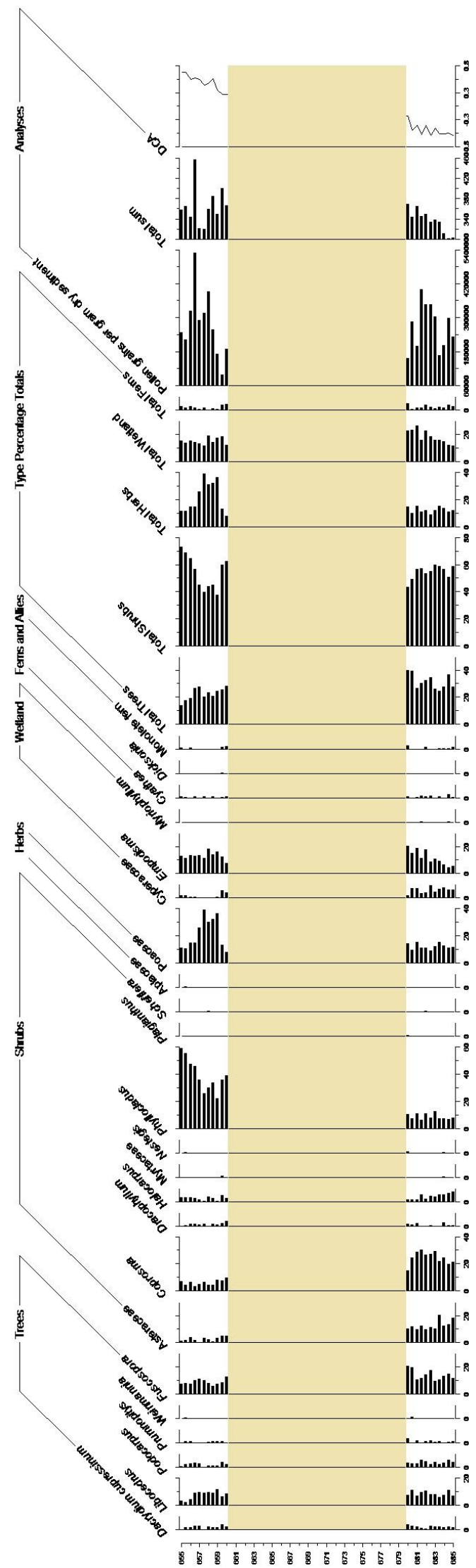

Figure 15. Pollen diagram displaying the individual pollen curves obtained in this discrete analysis with a DCA curve. The tan box represents the location of the tephra layer. 
Pre-deposition forest is dominated by Fuscospora, Libocedrus, Coprosma, and Asteraceae. With lesser but still prevalent taxa including Darcydium cupressinum, Empodisma, Phyllocladus,

Podocarpus, Cyperaceae, and Halocarpus (fig. 15). This community arrangement is found in mixedforest communities with assemblages interpreted as representing several vegetation communities in the region. These include local wetland at or near the site and regional beech forest, as well as subalpine shrub and alpine herb communities at varying distances from the site. Areas favourable for the growth of Phyllocladus and Fuscospora were likely to be dry and partially infertile, while more water logged areas are favoured by Halocarpus, Empodisma, and Cyperaceae.

Following the deposition of the 'Big Lower Lapilli' there appears to be no change in the pollen percentages for most of the tree taxa, though there is a slight decrease in Fuscopora (fig. 15). A notable change is observed in the shrub assemblages. We see a marked decrease in Asteraceae (5\%), Coprosma (15\%), and Cyperaceae (7\%) along with an increase in Phyllocladus (32\%), Poaceae (20\%), and Empodisma (15\%) (fig. 15). In an area such as Karioi, which is in proximity to high-altitude terrain containing sub-alpine vegetation, the presence of Asteraceae and Coprosma pollen most likely represents sub-alpine shrub located in the regional vicinity of the Karioi area.

Poaceae increases by $20 \%$ following tephra deposition, along with a large increase in Phyllocladus from $10 \%$ to $40 \%$ (fig. 15). Percentages this large in a pollen diagram infer the taxa must have been growing in the local vicinity of the Karioi site. As discussed in section 2.1.1.1 representation of pollen is dependant of many factors, one of which is distance from the source plant. The further away from the source, the smaller the amount of pollen from those taxa are found.

Wetland taxa pollen percentages fluctuate following the tephra. Though Empodisma percentages were already increasing prior to the tephra deposition, post-deposition sees a drop from $20 \%$ to $5 \%$, followed by a steady increase back to a stable $10 \%$ over $1 \mathrm{~cm}$. Concurrently, Cyperaceae, which had been stable prior to the eruption at $7 \%$, maintain numbers for $1 \mathrm{~cm}$ post-eruption before rapidly disappearing altogether. Myriophyllum is also present, though in small numbers (fig. 15).

To further establish the occurrence of vegetation change directly related to volcanic impact, a DCA stratigraphic curve was completed and plotted alongside the pollen curves in figure 15 . This curve records a marked change from negative to positive scores that aligns with the tephra deposition. Samples from below the tephra recorded scores between -0.8 and -0.3 , while samples from above the tephra recorded scores between 0 and 0.8 . 


\subsubsection{Principal Component Analysis}

Principal Component Analysis (PCA) was carried out for the pollen data from prior and post deposition of the 'Big Lower Lapilli' tephra to detect any notable statistical changes in the vegetation communities following tephra fall. This provides a more objective assessment of the pollen data than can be done by the eye. The results are presented in a biplot of site scores plotted against PCA axes 1 and 2. The plot displays a considerable change in site scores with those samples from below the tephra clustered together in the negative section of the PCA 1 axis, suggesting a stable vegetation environment at the time (fig. 16). Site scores from post tephra deposition record a dynamic environment, with a spread across the entire PCA 2 axis while remaining within the positive section of the PCA 1 axis. There is no overlap between site scores from pre- and post- tephra. The unstable arrangement of site scores from above the 'Big Lower Lapilli' is characteristic of a vegetation community attempting to re-establish equilibrium following a disturbance.

To further understand which taxa are driving the PCA site scores, PCA scores for three of the taxa which showed the most change in the pollen diagram (fig. 16) were plotted on the PCA graph along with the PCA site scores (fig. 16). Site scores that plot closest to these taxa scores are 'driven' by these taxa scores. They are the taxa that caused the most variation in the site scores. Samples between the depths of $655 \mathrm{~cm}$ and $656.5 \mathrm{~cm}$, and $659.5 \mathrm{~cm}$ and $660 \mathrm{~cm}$ were most influenced by Phyllocladus, while Poaceae influenced all samples between $657 \mathrm{~cm}$ and $659 \mathrm{~cm}$. All samples prior to the tephra deposition were influenced by Coprosma. The alignment of these site scores with the taxa that showed the most dramatic change in percentages following tephra deposition suggest a volcanic impact recorded in that statistical data. 


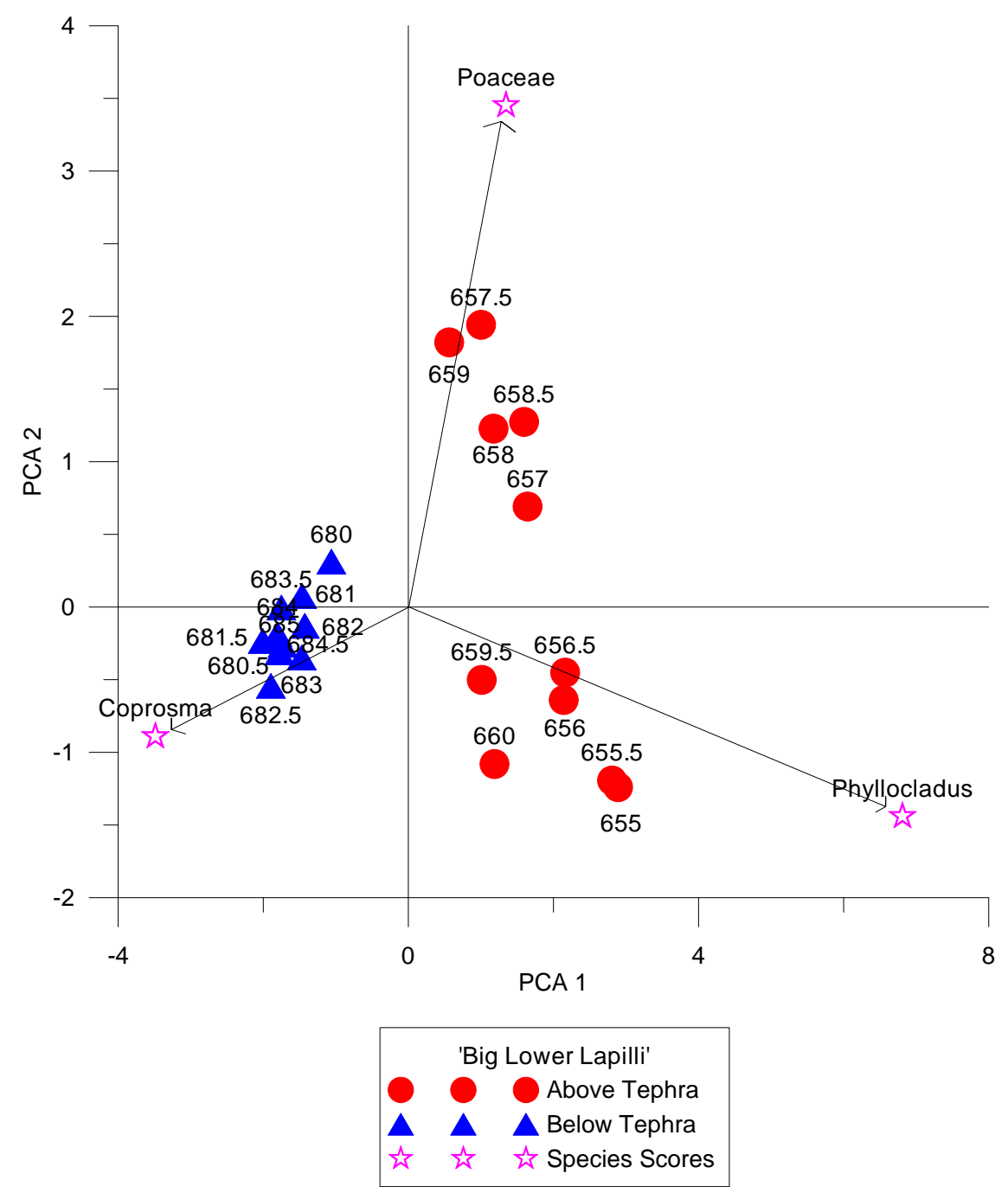

Figure 16. PCA site score plot for the 'Big Lower Lapilli' with selected species scores inset. Numbers represent depth from the top of the section.

\subsubsection{Hydrology}

Diatoms were noted throughout the samples processed both above and below the 'Big Lower Lapilli'. It was thought their presence would be useful in ascertaining the hydrological changes occurring at the site both prior and post deposition of the 'Big Lower Lapilli'. Taxa were identified with the help of Dr Margaret Harper (VUW). The result being a bar graph displaying the number of taxa found in each $0.5 \mathrm{~cm}$ sample (fig. 17).

Aulacoseira crenulata was noted as most common in samples prior to the deposition of the 'Big Lower Lapilli'. Post deposition, Aulacoseira crenulata appears to be replaced by Aulacoseira ambigua. While Aulacoseira crenulata can be found in water bodies, it also survives in wet places 
such as damp moss. Aulacoseira ambigua, however, is rarely found outside of water bodies and prefers water depths of about 2m (van Dam et al., 1994).

It is the abundance of Aulacoseira ambigua (prefers water depths of $2 \mathrm{~m}$ ) post tephra deposition, along with the abundance of taxa found in the $660 \mathrm{~cm}$ sample directly above the tephra layer, that point to this sample being fully lacustrine. Taxa also noted within this sample were Aulacoseira crenulata, Pinnularia gibba, Pinnularia microstauron, Pinnularia virdis, Hantzschia, Gomphonema, Fragilaria exigua, Cymbella, Diploneis, and Eunotia. Gomphonema, Fragilaria exigua, Cymbella, Diploneis, and Eunotia are exclusively found in this sample.

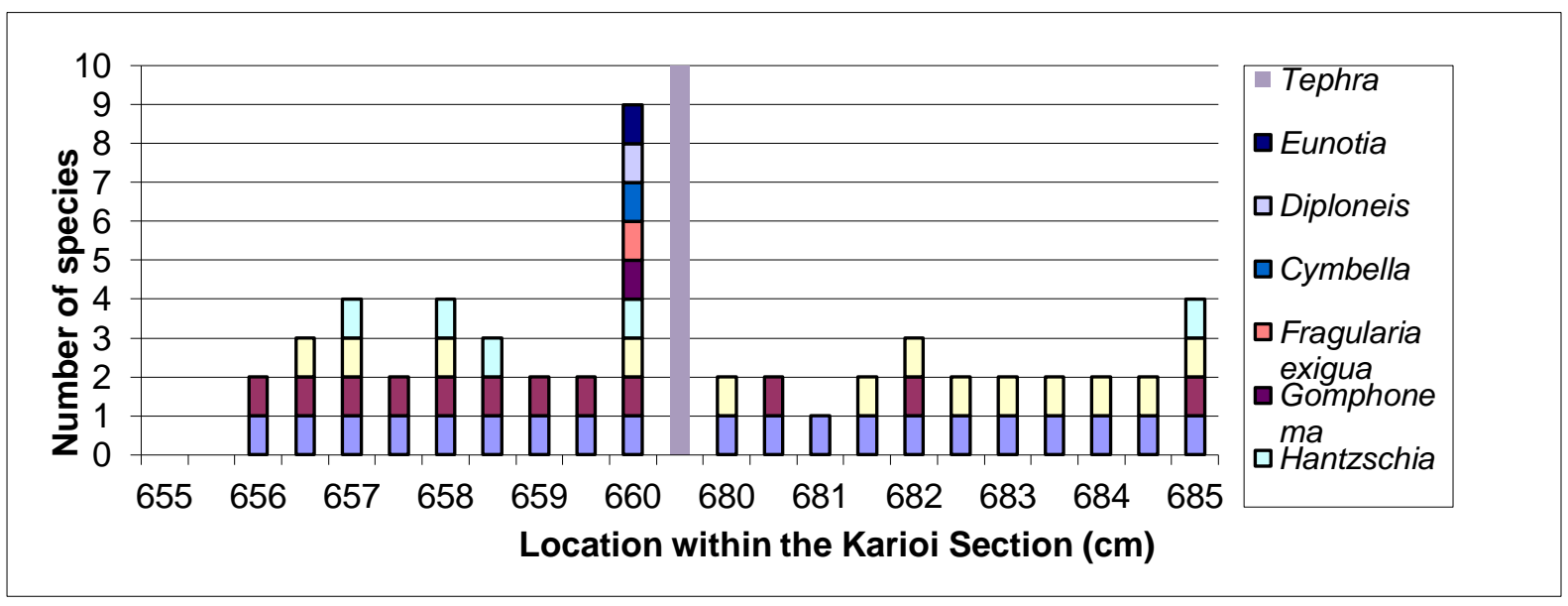

Figure 17. Graph displaying the diatom species abundances in samples on either side of the 'Big Lower Lapilli'.

\subsection{The 'Little Tephra'}

The 'Little Tephra' is a $2 \mathrm{~cm}$ thick, fine, andesitic lapilli that is located at $859 \mathrm{~cm}$ (fig. 13).

\subsubsection{Vegetation}

The vegetation (fig. 18) prior to the deposition of the 'Little Tephra' is a forest dominated by Dacrydium cupressinum (35\%), Dacrycarpus dacrydioides (15\%), and Podocarpus (23\%), with an understory of Pseudopanax (5\%), Coprosma (5\%), Phyllocladus (8\%), and the tree fern Cyathea (23\%) (fig. 18). This is a common vegetation assemblage of conifer-broadleaf forests (Wardle, 1991). As discussed in section 4, this assemblage is common in the Karioi area today; however, the pollen diagram presents very low percentages of Fuscospora $(<5 \%)$, which differs from the present day site. Percentages of sub-alpine herb pollen are very low. Taxa such as Asteraceae, Astelia, Myrsine, and 
Poaceae are very unstable in the pollen percentages and none of them rise above $2 \%$ (fig. 18).

Overall, tree taxa make up an average of $50 \%$ of the overall counts, with shrubs following with an average of $15 \%$, and herbs holding less than $5 \%$ (fig. 18 ).

Post tephra deposition, little change is seen in the pollen percentages with tree taxa remaining steady. The only notable change is the increase in Leptospermum percentages. Prior to the eruption, Leptospermum percentages were unstable and oscillated between $2 \%$ and $15 \%$ of the total assemblage. Post tephra deposition, a steady $10 \%$ is maintained for $3 \mathrm{~cm}$ before a rapid increase to $20 \%$ occurs (fig. 18). Leptospermum commonly invades freshly disturbed surfaces, so a rapid increase signifies the opening of ground space for it to colonise. There are also small increases in Pseudopanax and Coprosma where, excluding the $858 \mathrm{~cm}$ depth which records a rise to $20 \%$ for Coprosma, numbers for these two taxa stay below the $5 \%$ mark (fig. 18).

A stratigraphic curve of DCA site scores (fig. 18) does appear to detect a change in vegetation assemblage across the site. The DCA site scores fluctuate between - 0.4 and 0.1 prior to tephra deposition. Post tephra deposition, the site scores increase to 0 and then fluctuate between 0 and 0.4. There is no abrupt change in the DCA curve that coincides with the deposition of the 'Little Tephra'. Instead an increasing trend is noted for the whole section. 


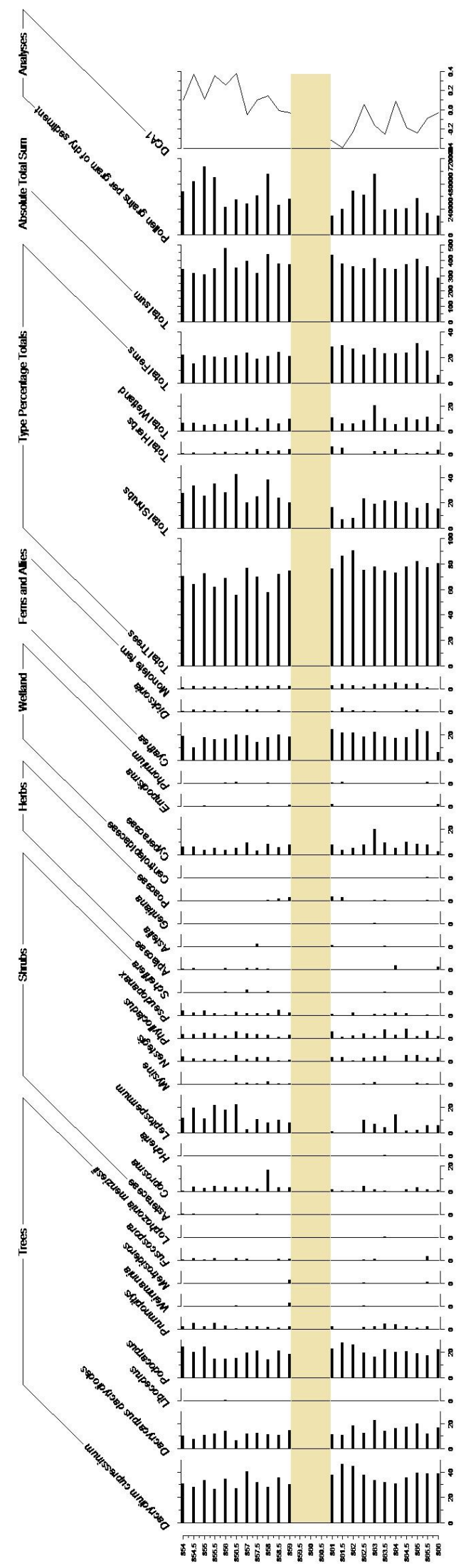

Figure 18. Pollen diagram displaying the individual pollen curves obtained in this discrete analysis against a DCA curve. The tan box represents the position of the tephra. 


\subsubsection{Principal Component Analysis}

Principal Component Analysis (PCA) results for the 'Little Tephra' are presented in a biplot of site scores plotted against PCA axes 1 and 2 (fig. 19).

Site scores for above the tephra have a small spread across the PCA 2 axis, but are contained between 1 and -1 . Their spread across the PCA 1 axis has a wider coverage, extending from -2 to 1 . In this spread, the $857 \mathrm{~cm}$ point could be seen as an outlier (fig. 19). The pollen percentages for this sample record a $10 \%$ rise in Coprosma that is not evident in any of the following samples (fig. 18).

The site scores for below the tephra also show a wide distribution with spread along the PCA 2 axis between -1.5 and 2.5 , as well as spread along the PCA 1 axis between -0.5 and -1.5 . Again this data set appears to have an outlier, with the $866 \mathrm{~cm}$ sample significantly removed from the other site scores (fig. 19). Pollen percentages from this sample also had nearly $20 \%$ more tree pollen than most of the other samples (fig. 18). Overall, the plots for pre- and post- tephra deposition show a very dynamic and unstable arrangement, especially when compared to the PCA plot for the 'Big Lower Lapilli' (fig. 16).

Taxa scores representing the taxa that made the most contribution to the pollen count were then plotted with the site scores to ascertain if these taxa were driving the statistical variation (fig. 19). Dacrydium cupressinum, Podocarpus, and Cyathea proved to have the furthest spread of scores, however, due to the distance of these points from the distribution of the site scores, it was apparent that these taxa did not drive the variation in site scores, despite having a major contribution to the pollen percentages recorded from the site (fig. 19). 


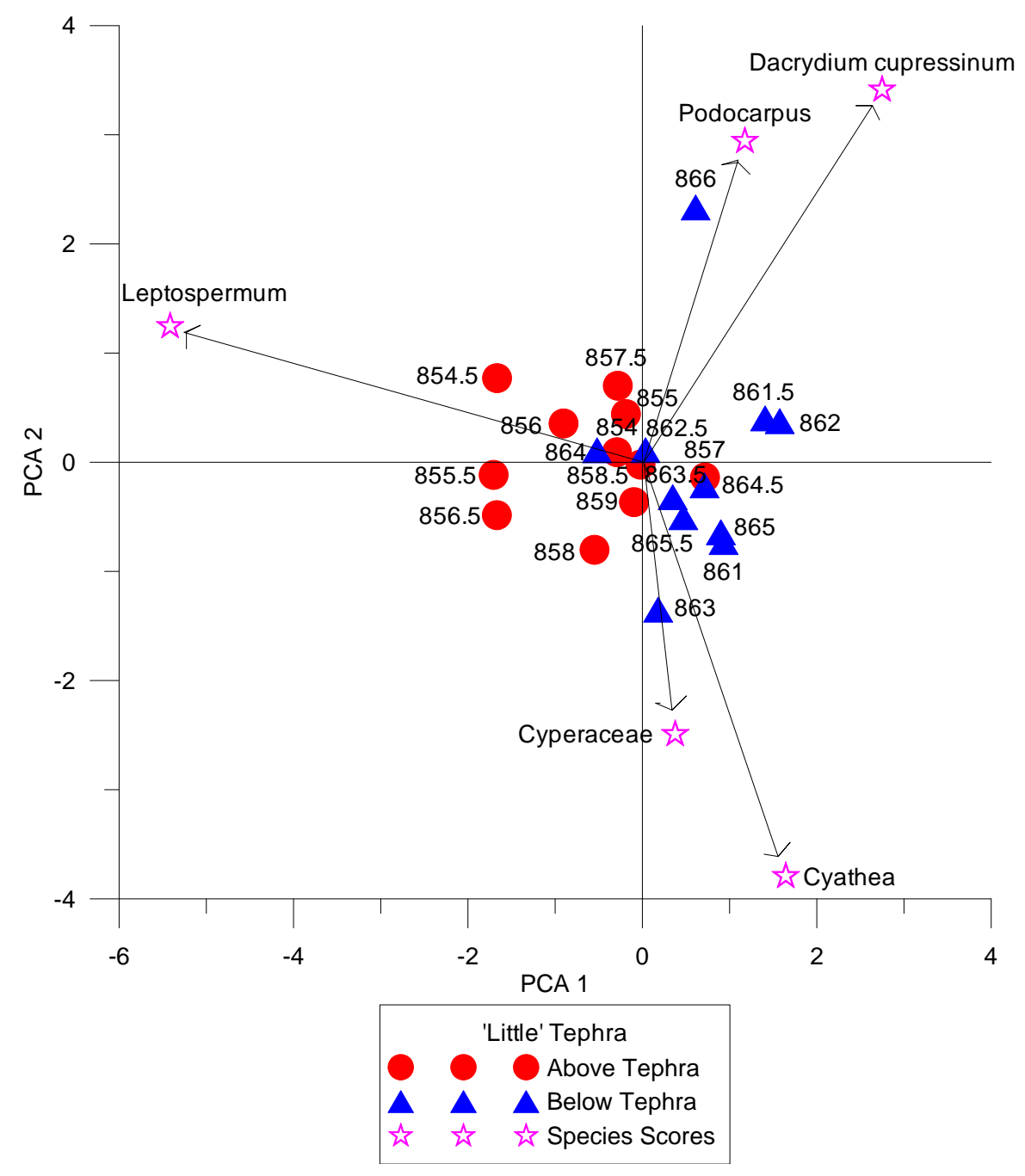

Figure 19. PCA site score plot with inserted selected species scores. Numbers represent depths in the section.

\subsubsection{Hydrology}

Diatom diversity in the samples surrounding the 'Little Tephra' was a lot lower than recorded at the 'Big Lower Lapilli' (fig. 17). Only samples from $861-863 \mathrm{~cm}$ contained any diatoms. Genera recorded in these samples included Aulacoseira, Pinnularia and Stauroneis. Stauroneis and Aulacoseira both prefer freshwater ponds and streams, though it could not be determined if any of the Aulacoseira identified where Aulacoseira ambigua, which prefers water bodies at a depth of about $2 \mathrm{~m}$.

Above the tephra, Pinnularia and Aulacoseira were noted in all samples from $854 \mathrm{~cm}$ to $859 \mathrm{~cm}$ (fig. 20). Stauroneis were noted in samples from $857.5 \mathrm{~cm}, 857 \mathrm{~cm}, 856 \mathrm{~cm}$, and $855 \mathrm{~cm}$ (fig. 20). The taxon Surirella was also noted as relatively common above the 'Little Tephra' with specimens being 
identified in all samples from $854 \mathrm{~cm}$ to $875.5 \mathrm{~cm}$ (fig. 20). Surirella also prefers freshwater ponds and slow-flowing streams, while Pinnularia is common in muddy and wetland habitats.

The total wetland taxa percentage within the pollen analysis fluctuated between $5 \%$ and $15 \%$ of the total percentages with the majority of this being attributed to Cyperaceae pollen (fig. 18). It is therefore probable that the Karioi site contained a seasonal small freshwater pond or slow moving stream.

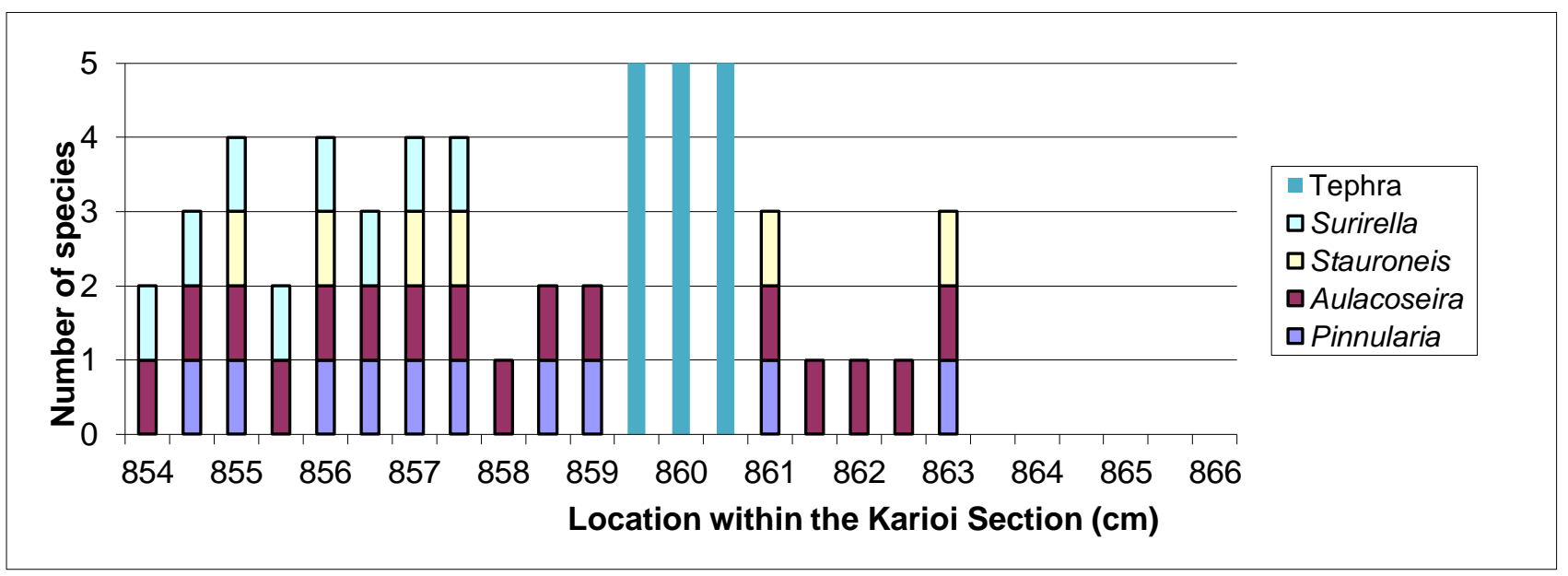

Figure 20. Graph depicting the overall species abundance in samples from either side of the 'Little Tephra'.

\subsection{The 'Unknown' Tephra}

This silicic tephra is located at $374 \mathrm{~cm}$ (fig. 13). It is $2 \mathrm{~cm}$ thick and has a discontinuous distribution. It is described as a discontinuous, greyish-white, very fine- powdery volcanic ash.

\subsubsection{Vegetation}

Pollen percentages from prior to the deposition of the 'Unknown' tephra record multiple vegetational environments within the vicinity of the Karioi section. Pollen assemblages are dominated by Fuscaspora (30\%) with an especially high count for Lophozonia menziesii (formerly Nothofagus menziesii) (15\%) (fig. 21). Podocarpus type (10\%), Asteraceae (6\%), Poaceae (20\%), Cyperaceae (20\%), Empodisma (5\%), Myriophyllum (4\%), Phyllocladus (6\%) and Halocarpus (8\%) also maintained steady percentages (fig. 21). These assemblages are interpreted as representing a 
vegetational mosaic in the region, including local wetland at or near the site, regional beech forest, subalpine shrub and alpine herb communities at varying distances from the site. The pollen assemblages above the tephra layer appear to have changed very little from those below, suggesting that none of these distinct vegetation communities in the region were affected by tephra fall to any observable extent within the time frame that the samples cover.

A stratigraphic DCA curve has been plotted beside the pollen curves (fig. 21) and this analysis has recorded some change in the pollen assemblages over time. It does, however, appear to be unrelated to any tephra impact as DCA scores on either side of the tephra layer are very similar but vary with increasing distance from deposition. 


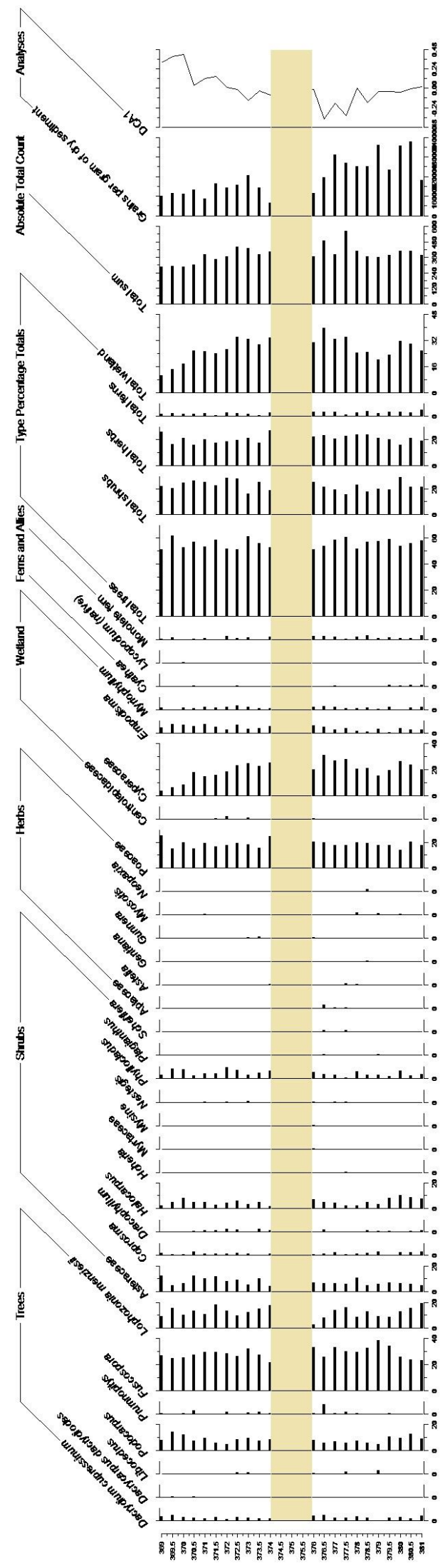

Figure 21. Pollen diagram displaying the individual pollen curves obtained in this discrete analysis against the DCA curve for the 'Unknown' tephra. The tan box represents the exact location of the tephra. 


\subsubsection{Principal Component Analysis}

Principal Component Analysis (PCA) results are presented in a biplot of site scores plotted against PCA axes 1 and 2 (fig. 22). The plot shows a scattered distribution and while there is a slight trend for a separation between the above and below site scores, there is considerable overlap centred on 0 . Site scores from prior to tephra deposition are scattered between -4 and 1 on the PCA 1 axis, and -3 and 1 on the PCA 2 axis. Site scores from post tephra deposition are spread between -2 and 3.5 on the PCA 2 axis and -1 and 2.25 on the PCA 1 axis. Both axes reveal a dynamic environment presented by the PCA site scores for the 'Unknown' tephra, but the significant overlap rules out volcanic impact as the cause for the variation.

Taxa PCA scores were plotted alongside the site scores to determine which taxa were driving this variation (fig. 22). The results show taxa variation that is not spread far from zero. Fuscospora appears to drive the samples below the tephra, while Podocarpus and Lophozonia menziesii have the largest effect on site scores above the tephra. 


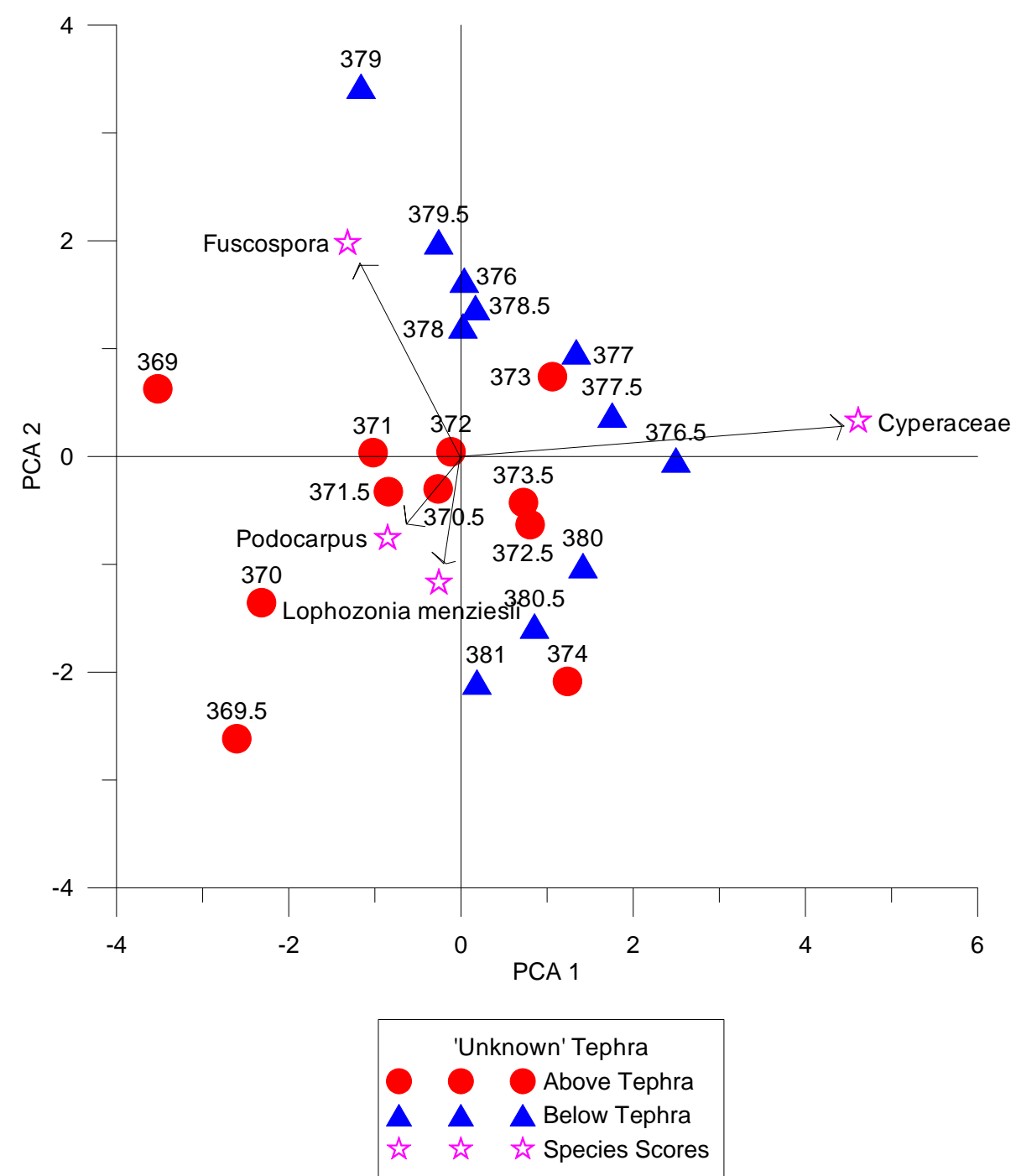

Figure 22. PCA site score plot for the 'Unknown' tephra with selected species scores plotted. Numbers represent depth of the sample.

\subsubsection{Hydrology}

Only four different diatom taxa were identified within this discrete section of the Karioi site. The most abundant was Pinnularia and Aulacoseira, though Stauroneis and Hantzschia were also noted in a couple of samples post-tephra deposition (fig. 23). The sample with the highest diversity of diatoms was from sediment $3 \mathrm{~cm}$ above the 'Unknown' tephra (fig. 23) so it appears unlikely that the deposition of the 'Unknown' tephra affected the hydrology at the Karioi site.

The site may either already be water logged or had a body of water nearby, as all four taxa identified prefer slow moving water, while Pinnularia, and certain types of Aulacoseira happily survive on 
damp ground. As there was not a change in the sedimentary layers indicating a ponding environment at the sample saite, it was concluded that there was most likely not situated directly over the sample site, though it may have periodically covered the area for short time periods. From the pollen data, the taxon Myriophyllum held at $4 \%$ abundance throughout the samples with wetland taxa as a whole consisting of an average of $20 \%$ of the total (fig. 21). Myriophyllum is currently found in the shallower, muddier areas of small streams in the vicinity of the Karioi site.

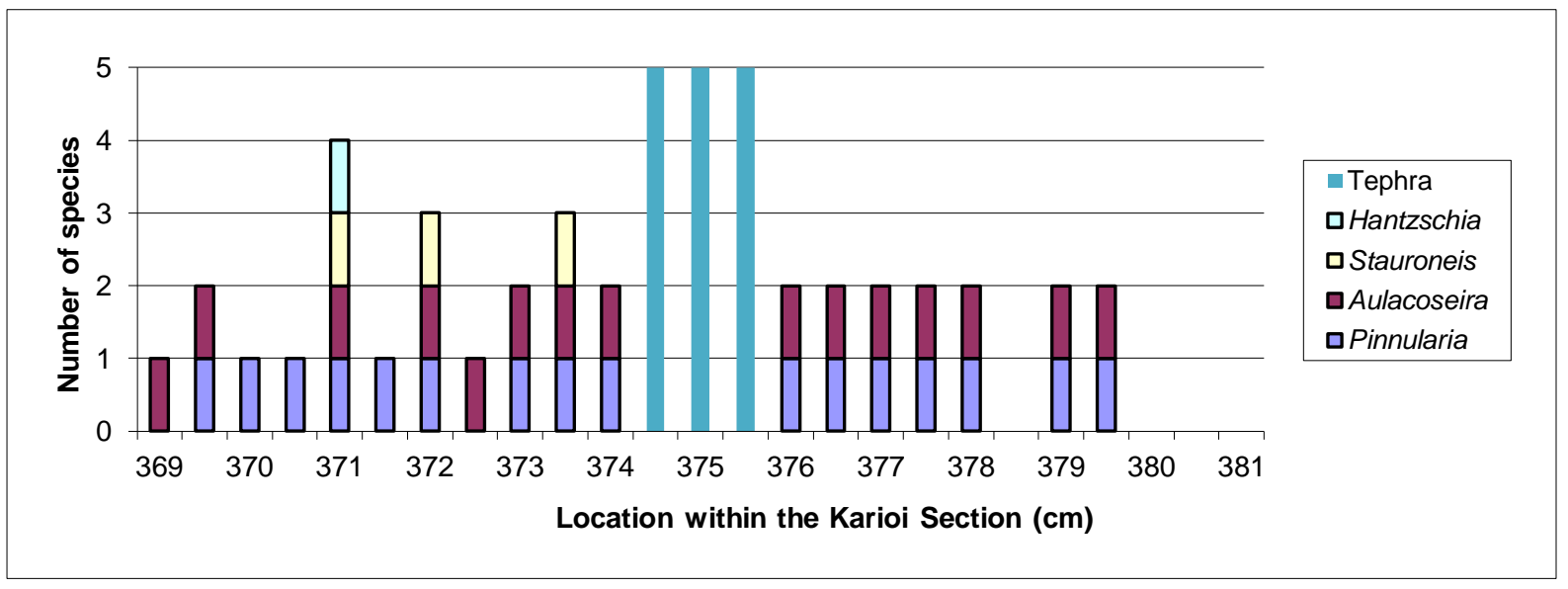

Figure 23. Graph displaying the diatom species abundance from samples surrounding the 'Únknown' tephra.

\subsubsection{Summary}

This section outlined results for possible tephra impact on the vegetation assemblages within three discrete sub-sections of the Karioi section for the period covered by the sampling strategy. The result was three high resolution analyses of tephra layers, covering different vegetation assemblages. The 'Big Lower Lapilli' displayed the largest volcanic impact, with evidence provided from the pollen record, hydrological analysis, and multivariate statistical analysis. The 'Little Tephra' displayed the possibility of a minor volcanic impact in the pollen. This was discounted in the multivariate statistical analysis. Finally the 'Unknown' tephra displayed no volcanic impact, but did appear to record variations driven by other influences. To further establish the cause of the variations within both the samples surrounding the 'Little Tephra' and those surrounding the 'Unknown' tephra, further analysis into the climate, forest dynamics, and long term vegetation and environmental trends that exist outside of volcanic impacts will need to be made, which is beyond the scope of this study. 


\section{Discussion}

\subsection{Introduction}

Research undertaken in this thesis has sought to examine the impact of distal volcanic tephra fall on palaeo-environments during MIS 5. Palynological investigations were undertaken on samples from above and below macroscopic tephra layers in an organic-rich section near Ohakune, North Island. The degree and nature of vegetation and environmental disturbance relating to tephra fall varied according to thickness of ash fall, climate and vegetation resilience. This chapter provides a discussion of these results by outlining the main findings of this research and addressing the project aims.

\subsection{Research objectives}

The research objectives for this project, outlined in chapter one, are as follows:

- To investigate possible volcanic disturbances recorded within the Karioi section and ascertain their extent.

- To consider the possible implications of these volcanic disturbances for paleoclimate reconstructions obtained from this site.

\subsection{Ascertaining volcanic impact}

In order to assess whether volcanic impacts on the vegetation were discernible in fine resolution records, the results needed to meet at least two of the following criteria:

- Notable changes to pollen taxa that appear to be directly related to the tephra layer but are of a greater magnitude than the natural ("background") variation exhibited by those taxa previously. 
- DCA stratigraphic plots show a significant change in vegetation assemblage that aligned with the tephra deposition.

- PCA of site scores show a notable difference in the sites below the tephra, when compared to those above it.

These three criteria were chosen to best portray a relevant volcanic impact to vegetation. At least two criteria needed to be met to ensure changes were the result of this volcanic impact, and not the result of other influences.

All three of the criteria outlined above were met by the deposition of the 'Big Lower lapilli', indicating a volcanic impact on the vegetation assemblages at the Karioi site during this time. A prominent change in vegetation assemblage was noted in the pollen analysis (fig. 15), specifically the increase in Phyllocladus and Poaceae, and the decrease in Coprosma. These changes are of a greater magnitude than is seen in the pollen analysis prior to tephra deposition, and the prominent changes in the percentages of these taxa are directly aligned to its deposition at the section.

The DCA statistical curve (fig. 15) displayed a marked change from negative to positive scores aligning with the tephra deposition, with samples from below the tephra recording scores between 0.8 and -0.3 , while samples from above the tephra recorded scores between 0 and 0.8 . This represented an overall change in vegetation composition at the point of tephra deposition.

The PCA plot of site scores (fig. 16) displayed a notable separation between scores from predeposition, and those from post-deposition. The graph of these results is the visual representation of a statistical variation between these two sets of samples, showing a definite difference in values between the two, which aligns with the deposition of the 'Big Lower Lapilli'.

PCA taxa scores for the taxa noted as having a considerable change in the pollen diagram were plotted on the PCA site plot (fig.16). This plot suggested an association between the large decrease in Coprosma percentages and the large increase in Phyllocladus and Poaceae percentages, with the PCA taxa scores, suggesting that these taxa drive the layout of the site scores (fig. 16).

These marked changes in the pollen percentages, along with the statistical analyses presenting a change in the data set aligning with the deposition of the 'Big Lower Lapilli', suggests that the 
vegetation assemblage changes recorded in the pollen data obtained during this discrete study, were caused by the deposition of the 'Big Lower Lapilli' onto the Karioi site.

Analysis surrounding the deposition of the 'Little Tephra' failed to give a definitive match to any of the above criteria, and this event is therefore regarded as not having had a notable impact on vegetation. While an increase is seen in the Leptospermum pollen percentages following tephra fall, it did not occur immediately after the deposition of the tephra (fig. 18); therefore, it cannot be definitively caused by volcanic impact. The DCA curve for the pollen data does display an overall increasing trend (fig. 18) and does appear to record a change in vegetation assemblage across the site with DCA site scores fluctuating between -0.4 and 0.1 prior to tephra deposition. Post tephra deposition, the site scores increase to 0 and then fluctuate between 0 and 0.4 , but no distinct change can be noted directly following the tephra deposition.

A notable overlap was apparent between the PCA scores from pre- and post- tephra deposition (fig, 19). It appears that this whole discrete section is attempting to re-establish environmental equilibrium. This is supported by the total pollen type percentage curves in figure 18 which show continuous fluctuations in the tree, shrub, and wetland type pollen percentages. It therefore may be reasonable to assume that variations in the pollen assemblages of this section have alternative influences guiding them, especially considering the increase in Leptospermum pollen percentages does not occur until well after the deposition of the 'Little Tephra' (fig. 18). The site scores showed variation across the score sample area, driven by taxa that showed fluctuating percentages unrelated to the tephra deposition (fig. 19). This pointed to general variation in the assemblages over time, rather than a distinct separation which would infer a volcanic impact influencing vegetation.

The 'Unknown' tephra returned similar results to the analysis of the 'Little Tephra'. There were no notable changes in vegetation assemblage (fig. 21). The DCA showed no significant change that aligned with the tephra deposition (fig. 21), and the PCA site plot (fig. 22) showed some variation but nothing that was considerable enough to be a definitive impact of the tephra. PCA species scores for Fuscospora appear to drive the site scores for samples below the tephra, while Podocarpus and Lophozonia menziesii have the largest effect on site scores above the tephra, which could be a result of a switch to a slightly cooler climate, rather than a volcanic impact, as these taxa had been dynamic in their percentages well before the tephra deposition (fig. 21). 
These results would be consistent with previous analysis of how tephra thickness affects vegetation (see section 2.2.2). A $2 \mathrm{~cm}$ thickness of tephra, as discussed in section 2.2 .2 .3 , would create much less impact in the way of smothering and foliage damage, than a tephra that is $22 \mathrm{~cm}$ thick. The lack of impact could also be due to other factors such as vegetation type, as larger taxa (e.g. trees) can better withstand the damage. Further work would be needed in this area to ascertain their effect on volcanic impact.

The rest of this section will therefore concentrate on the volcanic impact recorded by the 'Big Lower Lapilli'.

\subsubsection{Volcanic impact on vegetation}

Following the deposition of the 'Big Lower Lapilli', pollen percentages (fig. 15) show no change in the abundance of the tree taxa Dacrydium cupressinum, Libocedrus, and Podocarpus, while a slight decrease in Fuscopora abundance is noted. This lack of change is likely to be due to larger taxa being better equipped (i.e. stouter branches) to survive the lapilli deposition than more fragile smaller trees and shrubs. While the coarse nature of the lapilli is likely to have damaged the foliage of larger tree taxa, this would have been akin to the damage that many tree taxa incurred during the 1886 eruption of Mt Tarawera. During this eruption, large trees had leaves and small branches stripped off, but bore healthy and profuse foliage from larger surviving branches the following year (Turner, 1928); tree pollen percentages would have only been marginally affected.

Pollen percentages of smaller shrubs, including Asteraceae and Coprosma, record a definite decrease following tephra deposition (fig. 15). In an area such as Karioi, local to mountainous terrain high enough to maintain sub-alpine vegetation, Asteraceae and Coprosma most likely represent subalpine shrub assemblages within the Karioi pollen record. The location of this sub-alpine vegetation at higher altitudes, and therefore closer to the source of the eruption, would mean sub-alpine vegetation in this area would receive a thicker covering of tephra (see section 2.2.1) causing smothering and more intense foliage damage. Vegetation in the sub-alpine zone does not benefit from the protection of the forest canopy (see section 2.2.2). These sub-alpine vegetation assemblages will therefore receive more damage than those located further from the source and those within areas of standing forest, resulting in less pollen to travel to sites such as Karioi. This also explains the slight decrease in Fuscospora percentages, as Fuscospora forest dominates the higher 
altitudes on Mt. Ruapehu, which are closer to the source vent than other tree taxa such as Dacrydium cupressinum and Libocedrus, which prefer lower altitudes (Wardle, 1991). Distance from the vent and the dominant vegetation assemblage of an area, therefore, have a large effect on the pollen percentages gained from a site like Karioi. Sub-alpine assemblages are closer to the source and are more affected by volcanic impact than forest located further away. This results in a lack of change to tree pollen percentages and a marked drop in shrub and herb pollen percentages during the time frame of this discrete study.

Concurrent with the decreases of Asteraceae and Coprosma that occurred at tephra deposition, are considerable increases in Phyllocladus (30\%) and the primary coloniser Poaceae (15\%), which takes advantage of open sites and fresh surfaces (Wilmshurst et al., 1996). The increase in Poaceae is not immediate following the tephra deposition (fig. 15), and this slight pause would coincide with the time taken for herbs affected by the tephra deposition to die-back, followed by Poaceae advantageously invading these recently cleared, fresh surfaces.

Phyllocladus is a large shrub and its stature would give it an advantage over smaller plants during a volcanic event (see section 2.2.2). It is also found as a common sub-canopy component of Fuscospora forest (Wardle, 1991). While Fuscospora percentages decrease marginally (fig. 15), Phyllocladus percentages natably increase following volcanic impact. This is a likely result of initial protection by the forest canopy, followed by an increase in Phyllocladus numbers as die-back in Fuscospora opened up the canopy and allowed more sunlit.

\subsubsection{Tephra impact on hydrology}

Analyses of pollen and diatoms following the deposition of the 'Big Lower Lapilli' have outlined a picture of impeded drainage, forming an area of open water at or near the site following the tephra deposition. The total percentage of wetland taxa holds reasonably steady at about $15 \%$ (fig. 15) both pre- and post-tephra deposition. Individual wetland taxa, however, present a more dynamic record. Prior to the deposition of the tephra, the wire rush Empodisma showed increasing values. Postdeposition values then showed a decline from $20 \%$ to $5 \%$, followed by a steady increase over $1 \mathrm{~cm}$ to background levels of $10 \%$ (fig. 15). Concurrently, Cyperaceae, which had been stable prior to the eruption at $7 \%$, maintain numbers for $1 \mathrm{~cm}$ post-eruption before rapidly disappearing from the record (fig. 15). In inland areas Empodisma prefers the marshy edges of slow moving water bodies 
(Moore and Irwin, 1978), while Cyperaceae is commonly found in wet or saturated conditions. The increasing Empodisma and decreasing Cyperaceae could be due to a water body in the vicinity of the Karioi site becoming larger in size and depth following the deposition of the 'Big Lower Lapill'. The presence of Myriophyllum (fig. 15), though not in large numbers, also points to a water source close to the Karioi site, as Myriophyllum prefers the muddy, shallow edges of small deep streams (Cockayne, 1908).

An increase in the size of the water body at the Karioi site is supported by the identified diatom assemblages. Directly following tephra deposition, there was an increased diversity in fresh water diatom taxa, including Aulacoseira ambigua, Aulacoseira crenulata, Pinnularia gibba, Pinnularia microstauron, Pinnularia virdis, Hantzschia, Gomphonema, Fragilaria exigua, Cymbella, Diploneis, and Eunotia (fig. 17).

Most of the taxa noted are commonly found in deeper water environments. Fragilaria exigua and Diploneis are found in lakes and slow moving rivers, while rivers and stony streams are the preferred habitat of Hantzschia and Cymbella. Pinnularia is found in muddy wetland habitats and can survive on as little as wet moss, and Eunotia is found in all habitats.

Of particular interest was the presence of two species of Aulacoseira representing quite different depositional environments. Aulacoseira crenulata was noted as the most common in samples prior to the deposition of the 'Big Lower Lapilli' (fig. 17). This taxon is intolerant to salt and organic nitrogen, requiring nearly $100 \%$ oxygen saturation (van Dam et al., 1994). It mainly occurs in water bodies, but can be found in moist places on land. It was nearly entirely replaced by Aulacoseira ambigua following the deposition of the 'Big Lower Lapilli' (fig. 17). A. ambigua is rarely found outside of water bodies, preferring water depths of more than $2 \mathrm{~m}$.

The abundance of taxa found directly above the tephra, and especially the presence of Aulacoseira ambigua, points to the samples in the first centimetre of sediment following the tephra deposition, as being fully lacustrine. A small pool or lake may have persisted at the Karioi section for a short time, but not long enough to produce a layer in the sediment that is distinct enough to be identified during stratigraphic work. As the deposition of tephra can impede water flow, this is not an unusual occurrence. 
It is also possible that changes to the nutrient status and water chemistry at the site may have occurred due to acid pollution from the tephra, possibly explaining the drop in Aulacoseira crenulata following tephra deposition, as it is salt and organic nitrogen intolerant and requires nearly $100 \%$ oxygen saturation (van Dam et al., 1994). Cyperaceae is often highly sensitive to changes in nutrient status as well, so this could be the reason for the Cyperaceae percentages to decrease. Further work on the geochemistry of the tephra and surrounding sediment would be needed to clarify this.

Evidence from the hydrology studies of 'Little Tephra' and the 'Unknown' tephra supports the idea of a shallow water source at or near the Karioi site with diatoms being found in both analyses (figs. 20 and 23), but with a lesser taxa diversity than related to the 'Big Lower Lapilli' (fig. 17). Wetland taxa which prefer notable water bodies such as Empodisma were very low with wetland taxa as a whole reaching only $7 \%$ in the 'Little Tephra' study, and Myriophyllum near absent from the percentages (fig. 18).

In the hydrology studies of the 'Unknown' tephra, however, Empodisma and Myriophyllum were common throughout the samples with wetland taxa as a total fluctuating between $20 \%$ and $40 \%$ (fig. 21). It is therefore concluded that a small water source was maintained at or near the Karioi site, which fluctuated in size and did not remain for long enough periods over the Karioi section itself to leave a distinct lacustrine layer notable in the stratigraphy work.

Overall, pollen and diatom analysis at the Karioi site pre- and post-deposition of the 'Big Lower Lapilli' depicts a picture of a small pond or slow moving stream in the vicinity of the sample site, which increased in size following the deposition of the 'Big Lower Lapilli', as drainage in the area had been impeded.

\subsection{Critical tephra thickness}

New Zealand forests can tolerate quite high levels of tephra accumulation under stable climate conditions. Extensive, long term damage to vegetation from tephra accumulation would only occur following prolonged exposure to very thick tephra deposits, or during times were vegetation is already weakened, such as following storm damage or during harsh climatic conditions (McGlone, 1981). The tephra layers analysed from the Karioi section ranged in thickness from $2 \mathrm{~cm}$ (the 'Unknown' tephra, the 'Little Tephra') to 22cm (the 'Big Lower Lapilli'). Tephra impacts were 
observed above only the 'Big Lower Lapilli'. As this tephra has a similar geochemical make up to the 'Little Tephra' (originating from the same eruptive source) which had no clear signs of volcanic impact in the pollen record, the thickness of the tephra layer seems to be a critical factor in volcanic impact on vegetation.

With the deposition of the $22 \mathrm{~cm}$ 'Big Lower Lapilli', there would have been a high rate of foliage damage for larger trees as the canopy would be the first surface of contact in forested communities and would provide some protection to smaller sub-canopy taxa (Giles, 1999) within the vicinity of Karioi. The smothering of the smaller shrubs in the alpine zone, closer to the source vent and not protected by a forest canopy, however, would have been a common occurrence. Antos et al. (1985) found that following the 1980 eruption of Mount St. Helens, buried herbaceous taxa representing all morphological categories could penetrate $0-12 \mathrm{~cm}$ of tephra, while at sites buried by $15 \mathrm{~cm}$ or more, few individuals survived. The deposition of a $22 \mathrm{~cm}$ tephra would therefore have been too thick for the smaller herbaceous taxa to survive.

\subsection{Recovery patterns of vegetation affected by tephra}

According to published literature, the rate of recovery of vegetation from volcanic impact varies significantly depending on tephra thickness, current climate patterns, and age of the forest. For example, the speed of re-vegetation back to pre-eruption composition following the 1850 BP Taupo eruption varied between 120- 225 (radiocarbon) years (Wilmshurst et al., 1996). While following the eruption of Mt Tarawera in 1886 it took 70 years for bare surfaces to progress to grass-herb-lichen assemblages (Burke, 1974) and a further 15 years for Coriaria scrub to develop (Clarkson et al., 1983). While in locations where forest was only partly damaged, Weinmannia racemosa and Beilschmiedia tawa re-sprouted from epicormic buds within a year of the disturbance and continued growing as normal (Clarkson, 1990).

The pollen curves that represent the vegetation assemblages from above and below the deposition of the 'Big Lower Lapilli' (fig. 15) show no change in the tree percentages, but a distinct change was evident in the shrub percentages, interpreted as volcanic impact in this study. These changes are not present in previous palynology data from the site (McGlone, unpublished), and so it appears that volcanic disturbance is recorded within the time frame of high resolution $(0.5 \mathrm{~cm})$ pollen analysis, but not at a $10 \mathrm{~cm}$ sampling resolution. As previously discussed in section 4 , if the Holocene maximum 
peat accumulation rate was applied to Karioi, the preliminary pollen diagram (McGlone, unpublished) would have an estimated time sampling interval of 1000 years per sample. Under the same assumptions, $0.5 \mathrm{~cm}$ of peat is equal to 50 years. Using this accumulation rate means that the total $5 \mathrm{~cm}$ of sediment analysed above the 'Big Lower Lapilli' covered a maximum of 500 years. This should be ample time to see vegetation assemblages returning to pre-eruption states if the $1850 \mathrm{BP}$ Taupo or the $1886 \mathrm{Mt}$ Tarawera eruption is used as analogues. If Mt. Taranaki is used as an analogue, however, this time frame could be greatly extended as the ability of Weinmannia racemosa to re-sprout from epicormic buds within a year of the disturbance allowed it to gain forest dominance within 50 years of the Burrell eruption of c. 1655 AD (Druce, 1964) where it hadn't previously played a large role in the forest assemblage. This dense growth of Weinmannia proved to hinder the re-establishment of other vegetation, preventing the pre-eruption vegetation from gaining a foothold in the disrupted area. It has only been in the 100 years since c. 1888, as Weinmannia trees have come to the end of their natural life, that ground has opened up allowing for forest to return to its pre-eruption state (McGlone et al., 1988). The re-generation of pre-eruption forest is therefore not only dependent of the amount of tephra impact, but also on the type of vegetation that re-establishes following impact.

The pollen percentages following the deposition of the 'Big Lower Lapilli' show a return to pre eruption levels for the herb and shrub total percentages after $3 \mathrm{~cm}$ of sediment accumulation (fig. 15). Using the above peat accumulation rate, this would be about 300 years after the deposition of the tephra, similar to the forest recovery time following the 1655 AD Burrell eruption (McGlone et al., 1988; Deuce, 1964).

\subsection{Implications for the vegetation and environment at Karioi in the light of this study on volcanic disturbance}

In light of this study on volcanic disturbance, implications for the vegetation and associated environment at the Karioi site are outlined in this section, with reference to data supplied by Dr Matt McGlone. In particular it will look at the vegetational environments in the vicinity of the Karioi site and how this affects the pollen spectra preserved in the sediment, as well as the implications of sampling resolution as related to this study. 
Fluctuations in the pollen data appeared to conform to the five-fold substage for MIS 5 outlined by Newnham and Alloway (2004) and are as follows:

\subsubsection{MIS 5e: $765 \mathrm{~cm}-915 \mathrm{~cm}$}

Vegetation assemblages between $765 \mathrm{~cm}$ and $915 \mathrm{~cm}$, corresponding to MIS 5e (fig. 7), are dominated by Dacrydium cupressinum, Dacrycarpus dacrydioides and other podocarps. The discrete study surrounding the 'Little Tephra' (fig. 18) at a sampling resolution of $0.5 \mathrm{~cm}$ outlines a vegetation assemblage for this time period as follows. A forest canopy dominated by Dacrydium cupressinum, Dacrycarpus dacrydioides, and selected Podocarpus, with an understory of Pseudopanax, Coprosma, Phyllocladus, and the tree fern Cyathea. There is a near complete lack of Fuscospora in the pollen percentages (fig. 18). Fuscospora pollen is one of New Zealand's most highly wind-dispersed pollen types (McGlone and Topping, 1983) with pollen found in high abundances $60 \mathrm{~km}$ downwind from the source forest (Newnham, 1990). Low numbers of Fuscospora pollen recorded within the lower section at Karioi would therefore infer an absence of Fuscospora forest anywhere near the vicinity of where the samples were taken.

Today, sites at a similar elevation as the Karioi section, in the North Island, are described by Wardle (1991) as Dacrydium cupressinum dominant, however, Fuscospora trees are still found in high numbers where drainage is poorer, and form completely pure stands from an elevation of 975 m.a.s.l. on the western and southern slopes of Mt. Ruapehu (Wardle, 1984), less than $2 \mathrm{~km}$ from Karioi.

Similar vegetation assemblages to those recorded at the Karioi site during MIS 5e are currently found at an elevation of $200 \mathrm{~m}$ above sea level (400m lower in elevation than Karioi) in lowland-tomontane Central Westland, South Island, where Wardle (1991) describes mixed podocarp stands occupying recent flats that grade into dense stands of Dacrydium cupressinum/Dacrycarpus dacrydioides forest on terraces of intermediate age, where drainage is poor.

A density survey completed on conifer-broadleaf forest in the South Island by McKelvey (1984) indicates that Dacrydium cupressinum was most commonly found on flat to undulating older terraces at about 200m.a.s.l. while the preferred niche of Dacrycarpus dacrydioides was found to be on wet, recent alluvial sites at about 100m.a.s.l. Giles et al. (1999) also noted that Dacrydium 
cupressinum/Dacrycarpus dacrydioides forests prefer moist swampy ground, characteristic of mild, stable temperatures, and high rainfall (Lintott and Burrows, 1973).

Low relative abundances of Fuscospora, and high relative abundances of Dacryium cupressinum therefore suggest a warmer climate than present day, further supported by the low relative abundances of sub-alpine shrub and herb pollen (fig. 24). A warmer climate would restrict the ecological zone of sub-alpine herbs to higher elevations than those which currently occur within the Mt. Ruapehu landscape (currently above $\sim 1200$ m.a.s.I.). The sub-alpine taxa Asteraceae, Astelia, Mysine, and Poaceae are very unsteady in the pollen percentages, barely individually increasing above $2 \%$ (fig. 18). These pollen taxa are found in present interglacial flora assemblages in the vicinity of Karioi (Cockayne, 1908), but a warmer climate resulting in this ecological niche being pushed to higher elevations, further from the Karioi site, would result in lower percentages of these pollen types reaching Karioi. Overall, the proportion of tree taxa is greatest (up to $~ 50 \%$ ), followed by shrubs ( $15 \%$ ), with herbs less dominant ( $5 \%)$ throughout MIS 5e (fig. 24). These percentages are a good indication for the possibility of a warmer climate than present, as has previously been suggested for MIS 5e (Kukla et al., 2002).

\subsubsection{MIS $5 \mathrm{~d}: 615 \mathrm{~cm}-765 \mathrm{~cm}$}

$765 \mathrm{~cm}$ records a rapid change from podocarp forest, to Fuscospora forest (fig. 24) characteristic of the change from MIS 5 e to $5 \mathrm{~d}$ previously recorded in other paleo-vegetation archives from the New Zealand region (Newnham and Alloway, 2004; Ryan et al. 2012; Moar and Suggate, 1996).

Fuscospora proportions increase from less than $5 \%$, to up to $50 \%$, and maintain this percentage for the next $25 \mathrm{~cm}$ before dropping down to an average of $15 \%$ for the next $125 \mathrm{~cm}$ of the Karioi record (fig. 24). This change is clearly seen in the DCA curve (fig. 24) as well as the LOI curve (fig. 24) which records a rapid drop in the biomass accumulation, continuing for the next $50 \mathrm{~cm}$ of sediment, indicating a change to unstable environments. This rapid drop does not coincide with a volcanic impact as there is no change in the MS for the same depths (fig. 24); therefore, this drop noted in the DCA and LOI curve has been attributed to a climatic event.

MIS $5 d$ sees a dominance of shrubland in the Karioi area with shrubs maintaining an average of $40 \%$ of the total pollen percentages (fig. 24), while tree pollen makes up only half that. This is typical of a colder climate as the treeline drops and tree taxa that prefer warmer climates recede coastward. 
$0.5 \mathrm{~cm}$ sampling resolution pollen analysis completed on sediment either side of 'Big Lower Lapilli' (fig. 15), which is found from $660 \mathrm{~cm}-680 \mathrm{~cm}$ within the MIS $5 \mathrm{~d}$ zone (fig. 24), show a forest composition dominated by shrubland with the main shrub taxa present being Phyllocladus, Asteraceae, and Coprosma as well as the canopy trees Fuscospora and Libocedrus. These taxa suggest a forest community found in mixed forests, representative of several vegetation communities from the study region. These include local wetland, at or near the site, and regional beech forest, as well as subalpine shrub and alpine herb communities at varying distances from the site. This analysis also recognised a volcanic impact to vegetation with a notable increase in Phyllocladus and Poaceae. While Coprosma and Asteraceae decreased in abundance. This changes were not recorded in the $10 \mathrm{~cm}$ resolution sampling resolution used for the original work undertaken at Karioi.

The presence of Libocedrus in the pollen spectra, with percentages that steadily increase during this time (0-15\%) (fig. 7) indicate a climate of high rainfall (Lintott and Burrows, 1973), with cooler temperatures and stormier conditions (McGlone, 1985). Fuscospora pollen percentages form a major element within MIS $5 \mathrm{~d}$. This taxon forms a major element in most New Zealand forests and is particularly prominent in the montane regions between $600 \mathrm{~m}$ and 1300 m.a.s.l. (Cockayne, 1908; Wardle, 1991). Of the five sub-species recognised in New Zealand, three are currently common in the vicinity of the Karioi site. Fuscospora taxa tend to increase in abundance along environmental gradients that lead away from moist, mild, fertile optimums (Wardle, 1984). They are most prevalent at high altitudes in drier regions (Wardle, 1984) tolerating greater temperature extremes, lower rainfall, and periodic drought (Lintott and Burrows, 1973). MIS 5d is therefore a period of cooler, more variable climate conditions than MIS 5e, maintaining a dominance of shrubland (fig. 24), with Fuscospora prominent at higher elevations, and Libocedrus in the wetter, poorly drained, areas with infertile soils.

\subsubsection{MIS 5c: $615 \mathrm{~cm}-465 \mathrm{~cm}$}

Libocedrus abundances decrease from $25 \%$ to $10 \%$ at $615 \mathrm{~cm}$, simultaneous with increases in Dacrydium cupressinum (5\%-10\%) (fig. 7). This increase is interpreted as the beginning of MIS 5c (Moar and Suggate, 1996) (fig. 24). This time period is characterised by slightly warmer temperatures than MIS $5 d$ and is marked by a return of Dacrydium cupressinum (Moar and Suggate, 1996). This increase is characteristic of an increase in overall temperatures and is recorded in other 
climate records for this period (Newnham and Alloway, 2004). Temperatures were still much lower than that of the present day optimum, however, as the colder temperature indicator Fuscospora is still prevalent in the pollen percentages (fig. 24), and while Dacrydium cupressinum values increase from near zero to $15 \%$ during this time (fig. 24), this is still much lower than those recorded in the section attributed to MIS 5e (fig. 24). During MIS $5 \mathrm{c}$ the DCA curve has a slight, but steady increasing trend, while the LOI curve (fig. 24) presents steady rises and falls that can be matched to peaks in the MS curve (fig. 24) representing volcaniclastic layers deposited within the sediment. These are attributed to increasing volcanic minerals in the sediment rather than climatic variation affecting the biomass accumulation in the sediment. Overall, MIS $5 \mathrm{c}$ sees a return of the warm indicator Dacrydium cupressinum. Herb taxa decline and shrub and tree taxa increase in number (an increase of $40 \%$ and $20 \%$ respectively) (fig. 24 ) marking a return to slightly warmer temperatures than those attributed to MIS 5 d. Fuscospora is still prevalent (20\%) (fig. 24), so temperatures did not reach those associated with MIS 5e.

\subsubsection{MIS 5b: $465 \mathrm{~cm}-365 \mathrm{~cm}$}

Vegetation assemblages from $465 \mathrm{~cm}$ to $365 \mathrm{~cm}$ of the Karioi section represent an increase in Fuscospora (10\%), and a drop in both Libocedrus (fig. 7) and Dacrydium cupressinum (fig. 24) (5\% and $7 \%$ respectively). This section has been attributed to MIS 5b. The 'Unknown' tephra is located at $370 \mathrm{~cm}$ (fig. 24). Discrete analysis ( $0.5 \mathrm{~cm}$ resolution) around this tephra (fig. 21$)$ identify tree taxa as the dominant vegetation type ( $40 \%$ ), with wetland taxa contributing a further $15 \%$ of the total vegetation type identified. Fuscospora dominates the site with a strong presence of the typically under-represented (McKellar, 1973) Lophozonia menziesii (10\%) (fig. 21), suggesting a stand in close proximity of the Karioi site. Currently, L. menziesii and Fuscospora are prevalent on the southern side of Mt Ruapehu and can occur on mid slopes with stands sometimes up to $500 \mathrm{~m}$ thick, with an upper limit of 1100-1200m.a.s.I. (Wardle, 1984); this is barely $200 \mathrm{~m}$ higher in altitude than the Karioi site. At lower altitudes, scattered Dacrydium cupressinum and other podocarps can emerge from between the dominant Fuscospora forest as a secondary forest inhabitant, and this is represented in MIS $5 d$ by the low relative abundances of Dacrydium cupressinum. At $20 \mathrm{~cm}$, within MIS $5 b$, records show the highest values of herb pollen (50\%) observed at Karioi, occurring concurrently with increasing tree pollen percentages (fig. 24). These vegetation changes correspond with increasing values recorded in the oxygen isotope curve (fig. 24), a result of increasing sea surface temperatures (fig. 24). MIS $5 \mathrm{~b}$ is therefore associated with a return to the cooler, more unstable temperatures of MIS 5d. 


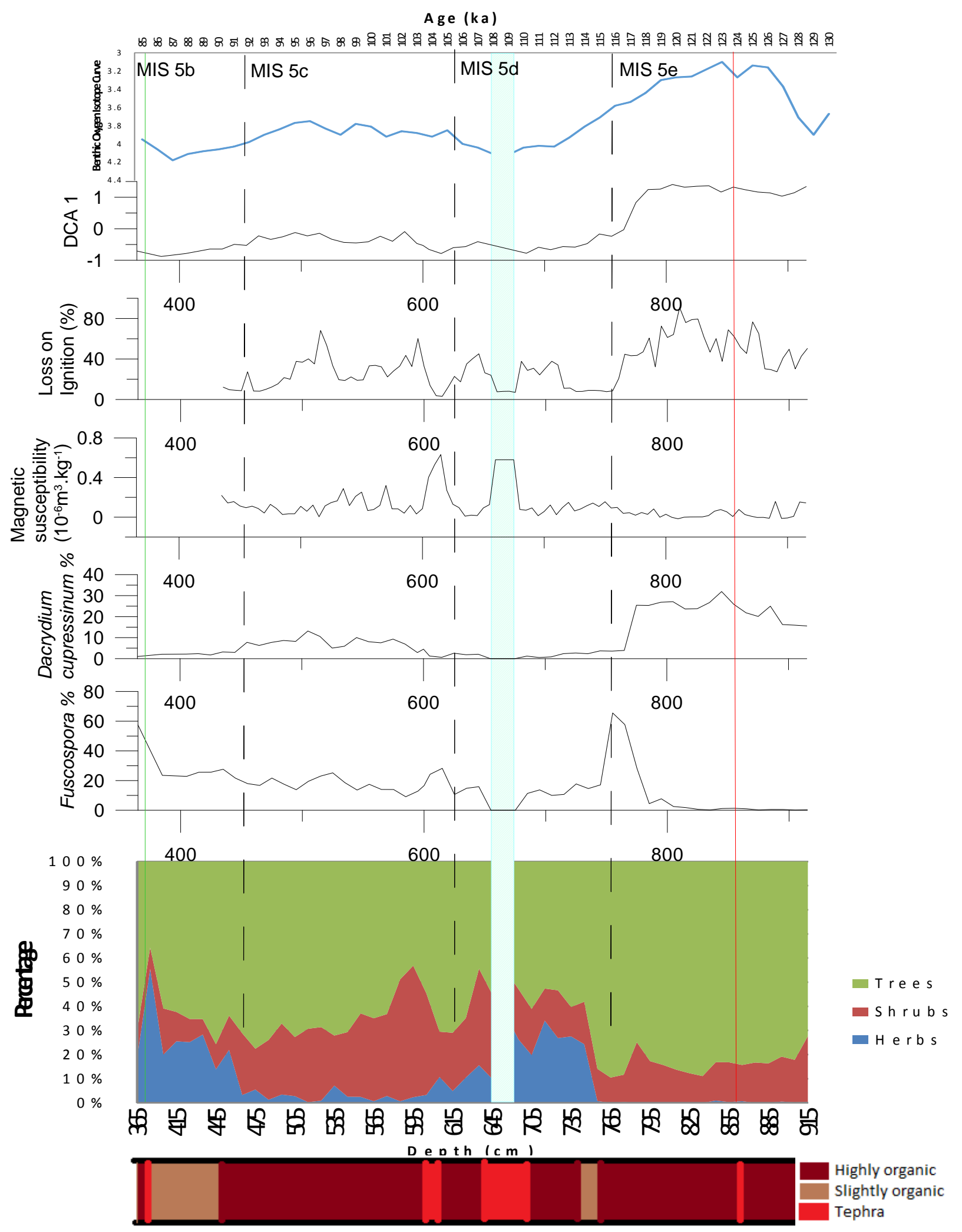

Figure 24. From the top: Benthic $\delta 180$ curve (Lisiecki and Raymo, 2005). DCA1 curve from data supplied by Dr McGlone. Loss-on-Ignition curve. Magnetic susceptibility curve. Dacrydium cupressinum pollen relative abundance curve from data supplied by Dr McGlone. Fuscospora pollen relative abundance curve from data supplied by Dr McGlone. Percentage plot for total vegetation type from data supplied by Dr McGlone. Simple stratigraphic log outlining the main organic content and tephra location at the section. Red line= 'Little Tephra', Blue forward slash line= 'Big Lower Lapilli', Green line= 'Únknown' tephra. Dashed lines denote MIS boundaries. Bottom x=axis= depth (cm), Top x-axis=Age (ka). 


\subsection{Summary}

\begin{tabular}{|l|l|l|l|l|l|l|l|}
\hline Tephra & Thickness & Source & $\begin{array}{l}\text { Estimate } \\
\text { age }\end{array}$ & $\begin{array}{l}\text { Baseline } \\
\text { vegetation }\end{array}$ & $\begin{array}{l}\text { Vegetation } \\
\text { impact }\end{array}$ & Diatoms & $\begin{array}{l}\text { Overall } \\
\text { impact }\end{array}$ \\
\hline $\begin{array}{l}\text { 'Big Lower } \\
\text { Lapilli' }\end{array}$ & $22 \mathrm{~cm}$ & $\begin{array}{l}\text { Mt. } \\
\text { Ruapehu }\end{array}$ & MIS 5d & $\begin{array}{l}\text { Shrubland } \\
\text { and } \\
\text { Fuscopora } \\
\text { forest }\end{array}$ & $\begin{array}{l}\text { Increase in } \\
\text { herbs }\end{array}$ & $\begin{array}{l}\text { 2m of } \\
\text { water } \\
\text { after } \\
\text { eruption }\end{array}$ & $\begin{array}{l}\text { Large } \\
\text { impact }\end{array}$ \\
\hline 'Unknown' & $2 \mathrm{~cm}$ & $\begin{array}{l}\text { Mt. } \\
\text { Taranaki }\end{array}$ & MIS 5b & $\begin{array}{l}\text { Lophozonia } \\
\text { menziesii } \\
\text { forest }\end{array}$ & No change & $\begin{array}{l}\text { Slight } \\
\text { ponding } \\
\text { near site }\end{array}$ & impact \\
\hline $\begin{array}{l}\text { 'Little } \\
\text { Tephra' }\end{array}$ & $2 \mathrm{~cm}$ & $\begin{array}{l}\text { Mt. } \\
\text { Ruapehu }\end{array}$ & MIS 5e & $\begin{array}{l}\text { Dacrydium } \\
\text { cupressinum } \\
\text { forest }\end{array}$ & No change & $\begin{array}{l}\text { Slight } \\
\text { ponding } \\
\text { near site }\end{array}$ & $\begin{array}{l}\text { No } \\
\text { impact }\end{array}$ \\
\hline
\end{tabular}

Figure 25. Table summarising the location, age, characteristics, and environment surrounding each discrete sub-section sampled in this work. 


\section{Conclusions}

In the course of this study, investigations were undertaken to assess the palaeo-environmental impacts from volcanic tephra deposition, through pollen analysis of an organic-rich section of sediment, $\sim 7 \mathrm{~km}$ south-east of Ohakune, on the low south-western flanks of Mount Ruapehu. Fineresolution pollen analysis and diatom identification immediately below and above tephra layers within this site provided an adequate method for the reconstruction and assessment of vegetation impacts immediately following tephra fall. Loss-on-ignition and magnetic susceptibility were used to infer environmental stability, and volcanic-rich sediment throughout this section.

The research objectives for this work were phrased as two questions, as outlined in chapter one, and will be answered here:

1) Has deposition of volcanic ash caused any impact on vegetation that can be observed in the Karioi pollen record, and to what extent?

2) If so, what are the implications of any volcanic disturbances for reconstructing paleoclimate from the Karioi pollen record?

\subsection{Question One}

Has deposition of volcanic ash caused any impact on vegetation that can be observed in the Karioi pollen record, and to what extent?

Three discrete analyses were completed in this study. Analyses of sediment surrounding the 'Unknown' and 'Little' Tephra revealed no significant impact to the pollen spectra following the tephra deposition. Pollen spectra surrounding the 'Big Lower Lapilli', however, showed definitive signs of volcanic impact on vegetation. As outlined in section 7, all three of the necessary criteria used to confirm a volcanic impact to vegetation were met. A notable change in vegetation assemblage occurred with an abrupt increase in Poaceae and Phyllocladus along with a decrease in Coprosma and Asteraceae. Most notable in the pollen spectra was an increase in the total abundance of herb taxa, while tree taxa abundance remained steady. Statistical analysis also 
showed a significant variation in the data immediately following the tephra deposition, with the DCA stratigraphic plot showing a marked change following tephra deposition, and a PCA plot of site scores which revealed a distinctive split between scores from before and after tephra deposition were attributed to the deposition of the 'Big Lower Lapilli'. Hydrological changes were also noted at the site. Prior to tephra deposition, diatom assemblages consisted of taxa that predominantly lived in damp places but did not necessarily require a significant amount of water. Post deposition, however, a significant increase in the abundance of Aulacoseira ambigua occurs. This taxon prefers water depths of about $2 \mathrm{~m}$ which suggests that the tephra deposition has impeded drainage at the Karioi site allowing a significant pool of water to exist.

Now that a volcanic impact has been established, the question then becomes what was the estimated length of time for these vegetation communities to recover from this impact? As outlined in section 4.3 , each $0.5 \mathrm{~cm}$ sample taken for these discrete analyses covers an estimated 50 years of vegetational history. The pollen diagram for the 'Big Lower Lapilli' (fig. 15) shows that the pollen spectra took $3 \mathrm{~cm}$ to return to pre-tephra deposition assemblages, which is equivalent to 300 years. A $0.5 \mathrm{~cm}$ sampling resolution is, therefore, ideal for detecting volcanic impact in other sites similar to Karioi.

In summary, the deposition of tephra affected vegetation following the deposition of the 'Big Lower Lapilli', but not following the 'Unknown' or 'Little' tephra's. Change in pollen spectra following the deposition of the 'Big Lower Lapilli' resemble a change in climate, inferred by an increase in shrub and herb percentages recorded in the pollen diagram. For this to be a climate influenced event, however, the increase in shrub and herb abundance should be concurrent with a decrease in tree pollen abundance. This seen at $765 \mathrm{~cm}$ depth in the Karioi record where the MIS 5e/MIS5d boundary records a turn to cold temperatures by a large decrease in tree pollen, and an increase in herb pollen. Results from this study conclude that tree pollen percentages are not affected by tephra to the same extent as shrubs and herbs, with very minimal change recorded in their pollen percentages following tephra impact at a $0.5 \mathrm{~cm}$ sampling resolution. Volcanic impact can therefore be distinguished and separated from change in climate, at a $0.5 \mathrm{~cm}$ sampling resolution, at sites such as Karioi, by identifying the changing relationships in the pollen percentages of trees, shrubs, and herbs. 


\subsection{Question Two}

What are the implications of any volcanic disturbances for reconstructing paleoclimate from the Karioi pollen record?

It has been established that volcanism impacted vegetational assemblages at the Karioi site on at least one occasion, but that these impacts are only recorded by a $0.5 \mathrm{~cm}$ sampling resolution and had recovered within $\sim 300$ years. Such shorter term changes were not able to be detected at the centennial-millennial scale sampling resolution $(10 \mathrm{~cm})$ previously applied at this site. This coarser sampling resolution could contain as long as 1000 years between each sample and, therefore, could contain several volcanic events that had affected the vegetation assemblages at the time, and there would still be enough time left for the vegetation to recover back to pre-eruption assemblages without a distinct change being noticed in the $10 \mathrm{~cm}$ record.

Such a coarse resolution sampling interval may, however, be appropriate for determining longer term changes, for example in relation to Milanković Cycles. Although there are some untested assumptions about sediment accumulation rates in the foregoing discussion, on the basis of these assumptions it is concluded that volcanic impact is unlikely to have distorted the climate interpretations to be drawn from the long term $(10 \mathrm{~cm}$ resolution) Karioi pollen record.

The results presented in this work, however, determined that volcanic impact must be evaluated at sites like Karioi where the stratigraphy indicates volcanic processes have occurred. As short-lived volcanic impact could be misinterpreted as abrupt climate change, it is important that additional fine resolution analyses are conducted around prominent tephra layers to evaluate this possibility.

\subsection{Concluding statements}

Conclusions reached from this research are related to the fundamental aims of the project which are outlined in chapter one.

- Volcanic impact to vegetation assemblages can be distinguished from changes in climate by comparing how the percentages of trees, shrubs, and herbs change in relation to each other. 
- The timescale in which it takes vegetation to recover from volcanic impact is well within the millennial timescale that influences climate change, with recovery patterns of vegetation affected by deposition of the 'Big Lower Lapilli' calculated to have taken 300 years.

- The severity of volcanic impact on vegetation depends on the thickness of the tephra. The critical tephra thickness was confirmed to be within $2 \mathrm{~cm}$ and $22 \mathrm{~cm}$, above which discernible vegetation and environmental impacts occurred.

- The impact of tephra fall on individual taxa was inconsistent, but the overall trend was for tree taxa to be less affected than herbs and shrubs, consistent with the conclusions that size of the vegetation affected by tephra plays a large role in its survival.

- The organic-rich section at Karioi presents a record spanning MIS 5e to MIS 5b. Vegetation assemblages indicate a period that has warmer temperatures than current day, attributed to the Last Interglacial, followed by a succession of stadial, interstadial, stadial. This aligns with the five-fold subdivision outlined for MIS 5, the result of pronounced orbital oscillations that indicate a global climate returning to glacial conditions. 


\section{References}

Antos, J.A; Zobel, D.B (1985) Plant form, developmental plasticity. And survival following burial by volcanic tephra. Canadian Journal of Botany. Vol. 63(12). Pp. 2083-2090.

Alloway, B.V; McComb, P; Neall, V; Vucetich, C; Gibb, J; Sherburn, S; Stirling, M (2005) Stratigraphy, age, and correlation of voluminous debris-avalanche events from an ancestral Egmont Volcano: Implications for coastal plain construction and regional hazard assessment. Journal of the Royal Society of New Zealand. Vol. 35(1\&2). Pp. 229-267.

Alloway, B.V; Neall, V. E; Vucetich, C. G (1995) Late Quaternary tephrostratigraphy of northeast and central Taranaki, New Zealand. Journal of the Royal Society of New Zealand. Vol. 25. Pp. 385-458.

Alloway, B.V (1989) The Late Quaternary cover bed stratigraphy and tephrochronology of northeastern and central Taranaki, New Zealand. PhD Thesis. Massey University, Palmerston North, New Zealand.

Batten, D.J; Dutta, R.J (1997) Ultrastructure of exine of gymnospermous pollen grains from Jurassic and basal Cretaceous deposits in north-western Europe and implications for botanical relationships. Review of Paleobotany and Palynology. Vol. 99(1). Pp. 25-54.

Birks, H. H; Birks, H. J. B. (2005) Reconstructing Holocene climates from pollen and plant macrofossils. In: A. Mackay, R.W. Battarbee, H.J.B. Birks and F. Oldfield (eds), Global change in the Holocene, Hodder Arnold, London, pp. 342-357.

Blong, R.J (1984) Volcanic Hazards: A Source book on the Effects of Eruptions. Academic Printer Australia. North Ryde.

Burke, W.D (1974) Regeneration of podocarps on Mt Tarawera, Rotorua. New Zealand Journal of Botany. Vol. 12. Pp. 9-26.

Burnham, R (1994) Plant deposition in modern volcanic environments. Transactions of the Royal Society, Edinburgh: Earth Sciences. Vol. 84. Pp. 275-281.

Campbell, I.B (1986) New occurrences and distribution of Kawakawa Tephra In South Island, New Zealand. New Zealand Journal of Geology and Geophysics. Vol. 29. Pp. 425-435.

Campbell, N.A; Reece, J.B; Urry, L.A; Cain, M.L; Wasserman, S.A; Minorsky, P.V; Jackson, R.B (2008) Biology. Eighth Edition. Pearson Benjamin Cummings. San Fransico.

Clarkson, B.R; Clarkson, B.D (1983) Mt Tarwera. 2. Rates of change in the vegetation and flora of the high domes. New Zealand Journal of Ecology. Vol. 6. Pp 107-119.

Clarkson, B.D (1990) A review of vegetation development following recent (<450 years) volcanic disturbance in North Island, New Zealand. New Zealand Journal of Ecology. Vol. 14. Pp. 59-71. 
Clarkson, B.D; Clarkson, B.R (1994) Vegetation decline following recent eruptions on White Island (Whakaari), Bay of Plenty, New Zealand. New Zealand Journal of Botany. Vol. 32. Pp. 21-36.

Cockayne, L (1908) New Zealand Department of Lands Report on a Botanical Survey of the Tongariro National Park. Government Printer. Wellington.

Collins, N.J (1969) The effects of volcanic activity on the vegetation of Deception Island. British Antarctic Survey Bulletin. Vol. 21. Pp. 79-94.

Cook, R.J; Barron, J.C; Papendick, R.I; Williams, G. J (1981) Impact on Agriculture of the Mount St. Helens Eruptions. Science. Vol. 211(4477). Pp. 16-22.

Cranwell, L.M (1953) New Zealand pollen studies: The Monocotyledons. Bulletin of the Auckland Institute and Museum No. 3. Harvard University Press. Cambridge, Massachusetts.

Cronin, S.J; Hedley, M.J; Smith, R.G; Neall, V.E (1997) Impact of Ruapehu ash fall and pasture nutrient status 1, October 1995 eruptions. New Zealand Journal of Agriculture Research. Vol. 40. Pp. 383-395.

Cronin, S.J; Hodgson, K.A; Neall, V.E; Palmer, A.S; Lecointre, J.A (1997a) 1995 Ruapehu lahars in relation to the late Holocene lahars of Whangaehu River, New Zealand, N. Z. Geology and Geophysics. Vol. 40. Pp. 507-520.

Dahlgren, R.A; Ugolini, F.C (1989) Effects of Tephra Addition on Soil Processes in Spodosols in the Cascade Range, Washington, U.S.A. Geoderma. Vol. 45. Pp. 331-355.

Davis, M. B. (1963) On the theory of pollen analysis. American Journal of Science. Vol. 261. Pp 897912.

Dean, W.E (1974) Determination of Carbonate and organic matter in calcareous sediments and sedimentary rocks by loss on ignition: Comparison with other methods. Journal of Sedimentary Petrology. Vol. 44(1). Pp 242-248.

de Lisle, J. F (1962) Climate and weather . In: Bay of Plenty Region. Chapter 4. Natural Resources Survey Part II. Government Printer, Wellington. Pp. 45-56.

Delusina, I (2007) Relevance of Palynological Data for Reconstruction of Abrupt Climatic Change in the Neotropics Region, Based on Marine Sediments from the Cariaco Basin, Caribbean Sea. American Geophysical Union, Spring Meeting 2007.

Diaz, F; Jimenez, C.C; Tejedor, M (2005) Influence of the thickness and grain size of tephra mulch on soil water evaporation. Agricultural Water Management. Vol. 74. Pp. 47-55.

Druce, A.P (1964) The Vegetation. In: Egmont National Park Handbook, $2^{\text {nd }}$ Ed. Egmont National Park Board, New Plymouth. Pp. 51-55.

Edan, D.N; Froggatt, P.C (1996) A 6500 year old history of tephra deposition recorded in the sediments of Lake Tutira, eastern North Island, New Zealand. Quaternary International. Vol. 34-36. Pp. 55-64. 
Egan, D; Howell, E.A. (2001) The Historical Ecology Handbook: a Restorationist's Guide to Reference Ecosystems. Island Press, Washington. D. C., USA.

Faegri, K; Iverson, J (1989) Textbook of pollen analysis $4^{\text {th }}$ edition. John Wiley \& Sons, Chichester.

Firth, C.R; McGuire, W.J. (eds) 1999. Volcanoes in the Quaternary. Geological Society, London, Special publications. Vol. 161. Pp. 11-26.

Foged, N (1979) Diatoms in New Zealand, The North Island. Strauss and Gramer GmbH, Germany.

Frenzen, P.M; Franklin, J.F (1985) Establishment of Conifers from seeds on tephra deposited by the 1980 eruptions of Mount Saint Helens, Washington.

Gibbs, H. S (1968) Volcanic ash soils in New Zealand. New Zealand DSIR Information Series- No. 65. Government Printer. Wellington.

Giles, T.M (1999) Volcanic emissions and distal palaeoenvironmental impacts in New Zealand. Thesis for the Doctorate of Philosophy. University of Plymouth, Devon, England.

Giles, T.M; Newnham, R.M; Lowe, D.J; Munro, A.J (1999) Impact of tephra fall and environmental change: a 1000 year record from Matakana Island, Bay of Plenty, North Island, New Zealand. In:

Gamble, J.A; Price, R.C; Smith, I.E.M; McIntosh, W.C; Dunbar, N.W (2003) ${ }^{40}$ AR/ $/{ }^{39}$ AR geochronology of Magmatic activity, magma flux and hazards at Ruapehu Volcano, Taupo Volcanic Zone, New Zealand. Journal of Volcanology and Geothermal Research. Vol. 120. Pp. 271-287.

Gomez-Romero, M; Lindig-Cisneros, R; Galindo-Vallejo, S (2006) Effect of tephra depth on vegetation development in areas affected by volcanism. Plant Ecology. Vol. 183. Pp. 207-213.

Graham, I.J; Hackett, W.R (1987) Petrology of calc-alkaline lavas from Ruapehu volcano and related vents, Taupo Volcanic Zone, New Zealand. Journal of Petrology. Vol. 28. Pp. 531 - 567.

Gregg, D. R (1960) The Geology of the Tongariro Subdivision: New Zealand Geological Survey. New Zealand Department of Scientific and Industrial Research. Bulletin 40. Pp. 151.

Hackett, W.R; Houghton, B (1989) A facies model for a Quaternary andesitic composite volcano: Ruapehu, New Zealand. Bulletin of Volcanology. Vol. 51. Pp. 51-68.

Healy, I, 1992: Central Volcanic Region. In: Soons, I M. and Selby, M. J. (eds) Landforms of New Zealand. Second edition, Longman Paul. Pp. 256-287.

Houghton, B.F; Wilson, C. J. N; McWilliams, M. O; Lanphere, M. A; Weaver, S. D; Briggs, R. M; Pringle, M. S (1995) Chronology and dynamics of a large silicic magmatic system: Central Taupo Volcanic Zone, New Zealand. Geology. Vol. 23(1) Pp. 13-16.

Huntley, B (1990) Studying global change: the contribution of Quaternary palynology. Palaeogeography, Palaeoclimatology, Palaeoecology. Vol. 82. Pages 53-61. 
Inbar, M; Ostera, H. A; Parica, C. A; Remesal, M. B; Salani,F. M (1995) Environmental assessment of 1991 Hudson volcano eruption ashfall effects on southern Patagonia region, Argentina.

Environmental Geology. Vol. 25. Pp. 119-125.

Keigler, R; Thouret, J; Hodgson, K.A; Neall, V.E; Lecointre, J.A; Procter, J.N; Vronin, S.J (2011) The Whangaehu Formation: Debris-avalanche and lahar deposits from ancestral Ruapehu Volcano, New Zealand. Vol. 133. Pp. 57-79.

Kent, M; Owen, N.W; Dale, P; Newnham, R.M; Giles, T.M (2001) Studies of vegetation burial: a focus for biogeography and biogeomorphology? Progress in Physical Geography. Vol. 25(4). Pp. 455-482.

Kukla, G.J; Bender, M.L; de Beaulieu, J; Bond, G; Broecker, W.S; Cleveringa, P; Gavin, J.E; Herbert, T.D; Imbria, J; Jouzel, J; Keigwin, L.D; Knudsen, K; McManus, J.F; Merkt, J; Muhs, D.R; Müller, H;

LeGuern, F; Garrec, J.P (1988) Atmospheric contribution of volcanic sulphur vapour and its influence on the surrounding vegetation. Journal of Volcanology and Geothermal Research. Vol. 35 Pp. 173178.

Le Maitre, R.W; Streckeison, A; Zanettin, B; Le Bas, M.J; Bonin, B; Bateman, P; Bellieni, Dudek, A; Efremova, S; Keller, J; Lamare, J; Sabine, P.A; Schmid, R; Sorenson, H; Wolley, A.R (2002) Igneous Rocks: A Classification and Glossary of terms, recommendations of the International Union of Geological Sciences, sub-commission of the systematics of Igneous Rocks. Cambridge University Press.

Lisiecki, L.E; Raymo, M.E (2005) A Pliocene-Pleistocene stack of 57 globally distributed benthic $\delta^{18} \mathrm{O}$ records. Paleoceanography. Vol. 20(1).

Lintott, W.H; Burrows, C.J (1973) A Pollen Diagram and Macrofossils from Kettlehole Bog Cass, South Island, New Zealand. New Zealand Journal of Botany. Vol. 11. Pp. 269-282.

Lowe, D.J; Shane, P.A.R; Alloway, B.V; Newnham, R.M (2008) Fingerprints and age models for widespread New Zealand tephra marker beds erupted since 30,000 years ago: a framework for NZINTIMATE. Quaternary Science Reveiws. Vol. 27. Pp. 95-126.

Lowe, D.J; Newnham, R.M; Ward, C.M (1999) Stratigraphy and Chronology of a 15 ka sequence of multi-sourced silicic tephras in a montane peat bog, eastern North Island, New Zealand. New Zealand Journal of Geology and Geophysics. Vol. 42. Pp. 565-579.

Macdonald, G. M (1988) Methods in Quaternary ecology \#2. Palynology. Geoscience Canada. Vol. 15. Pp. 29-42.

Magill, C; Wilson, T; Okada, T (2013) Observations of tephra fall impacts from the 2011 Shinmoedake eruption, Japan. Earth Planets Space. Vol. 65. Pp. 677-698.

Marcos, M. A; Mancini, M. V. (2011) Modern pollen and vegetation relationships in north eastern Patagonia (Golfo San Matías, Río Negro). Review of Paleobotany and Palynology. Vol. 171. Pp. 19-26.

McGlone, M.S; Neall, V.E; Clarkson, B.D (1988) The effect of recent volcanic events and climatic changes on the vegetation of Mt Egmont (Mt Taranaki), New Zealand. New Zealand Journal of Botany. Vol. 26. Pp. 123-144. 
McGlone, M.S. (1985): Biostratigraphy of the Last Interglacial-Glacial cycle, Southern North Island, New Zealand. Botany Division, DSIR, Christchurch.

McGlone, M.S; Topping, W.W (1983) Late Quaternary vegetation, Tongariro region, central North Island, New Zealand. New Zealand Journal of Botany. Vol. 21. Pp. 53-76.

McGlone, M.S (1981) Forest fire following Holocene tephra fall. Pp. 80-86 in Howorth, R, et al.(eds), Proceedings of tephra workshop. Department of Geology Publication 20, Victoria University of Wellington, Wellington.

McGlone, M. S; Topping, W. W (1977) Aranuian (post-glacial) pollen diagrams from the Tongariro region, North Island, New Zealand. New Zealand Journal of Botany. Vol. 15. Pp. 749-760.

McKellar, M.H (1973) Dispersal of Nothofagus pollen in eastern Otago, South Island, New Zealand. New Zealand Journal of Botany. Vol. 11. Pp. 305-310.

Mildenhall, D.C (1980) New Zealand Late Cretaceous and Cenozoicplant biogeography: A contribution. Palaeogeography, Palaeoclimatology, Palaeoecology. Vol. 31. Pp. 197-233.

Moar, M.T; Suggate, R.P (1996) Vegetation history from the Kaihinu (Last) Interglacial to the present: West Coast, South Island, New Zealand. Quaternary Science Reviews. Vol. 15. Pp. 521-547.

Moar, N.T (1993) Pollen grains of New Zealand dicotyledonous plants. Manaaki Whenua Press. Lincoln, NZ.

Moar, N.T. (1970) A new pollen diagram from Pyramid Valley Swamp. Records of the Canterbury Museum. 8: 455-461.

Moore, L.B; Irwin, J.B (1978) The Oxford book of New Zealand Plants. Oxford University Press, Wellington.

Moore, P.D; Webb, J.A; Collinson, M.E (1990) Pollen Analysis. Blackwell Scientific Publications, London.

Neall, V.E (1972) Tephrachronology and tephrastratigraphy of western Taranaki (N108-109)New Zealand. New Zealand Journal of Geology and Geophysics. Vol. 15. Pp. 507-557.

Newnham, R; Alloway, B (2004) A terrestrial record of Last Interglacial climate preserved by voluminous debris avalanche inundation in Taranaki, New Zealand. Journal of Quaternary Science. Vol. 19(3). Pp. 299-314.

Newnham, R.M; Lowe, D.J; Williams, P.W (1999) Quaternary environmental change in New Zealand: a review. Progress in Physical Geography. Vol. 23(4). Pp. 567-610.

Newnham, R.M; Lowe, D.J; Wigley, G.N.A (1995) Late Holocene palynology and palaeovegetation of tephra-bearing mires at Papamoa and Waihi Beach, western Bay of Plenty, North Island, New Zealand. Journal of the Royal Society of New Zealand. Vol. 25(2). Pp. 283-300. 
Newnham, R.M (1990) Late Quaternary palynological investigations into the history of vegetation and climate in northern New Zealand. PhD thesis, University of Auckland.

Palmer, A.S (1982) Kawakawa Tephra in Wairarapa, New Zealand, and its use for correlating Ohakea Loess. New Zealand Journal of Geology and Geophysics. Vol. 25. Pp. 305-315.

Pérez, F.L (2000) The influence of surface volcaniclastic layers from Haleakala (Maui, Hawaii) on soil water conservation. Catena. Vol. 38. Pp. 301-332.

Pérez, F.L (2009) The role of tephra covers on soil moisture conservation at Haleakala's crater (Maui, Hawai'i). Catena. Vol.79. Pp. 191-205.

Pillans, B; Wright, I (1992) Late Quaternary tephrostratigraphy from the southern Havre Trough Bay of plenty, northeast New Zealand. New Zealand Journal of Geology and Geophysics. Vol. 35 Pp. 129-143.

Poore, R.Z; Porter, S.C; Seret, G; Shackleton, N.J; Turner, C; Tzedakis, P.C; Winograd, I.J (2002) Last Glacial Climates. Quaternary Research. Vol. 58. Pp. 2-13.

Price, R.C; Gamble, J.A; Smith, I.E.M; Stewart, R.B; Eggins, S; Wright, I.C (2005) An integrated model for the temporal evolution of andesites and rhyolites and crustal development in New Zealand's North Island. Journal of Volcanology and Geothermal Research. Vol. 140. Pp. 1-24.

Price, R.C; Stewart, R.B; Woodhead, J.D; Smith, I.E.M (1999) Petrogenesis of high-K arc magmas: evidence from Egmont Volcano, North Island, New Zealand. Journal of Petrology. Vol. 40. Pp. 167 197.

Raymo, M.E; Huybers, P (2008) Unlocking the Mysteries of the Ice Ages. Nature. Vol. 451. Pp. 284285.

Ryan, M.T; Dunbar, G.B; Vandergoes, M.J; Neil, H.L; Hannah, M.J; Newnham, R.M; Bostock, H; Alloway, B.V (2010) Vegetation and climate in Southern Hemisphere mid-latitudes since 210 ka: new insights from marine and terrestrial pollen records from New Zealand. Quaternary Science Reviews. Vol. 48. Pp. 80-98.

Sandiford, A; Alloway, B; Shane, P (2001) A 28,000 - 6,600 cal yr record of local and distal volcanism preserved in a paleolake, Auckland, New Zealand. New Zealand Journal of Geology and Geophysics. Vol. 44. Pp. 323-336.

Skiba, U; Cresser, M.S; Derwent, R.G; Futty, D.W (1989) Peat acidification in Scotland. Nature. Vol.337. Pp. 68-69.

Soons, J.M; Selby, M.J (1992) Landforms of New Zealand, Second Edition. Longman Paul Limited. Auckland.

Stockmarr, J (1971) Tablets with spores used in absolute pollen analysis. Pollen and Spores. Vol. 13(4). Pp. 165-621. 
Tanaka, H; Kawamura, K; Nagao, K; Houghton, B (1997) K-Ar ages and paleosecular variation of direction and intensity from Quaternary lava sequences in the Ruapehu volcano, New Zealand. Journal of Geomagmatism and Geoelectricity. Vol. 49. Pp. 587-599.

Traverse, A (2008) Paleopalynology. Second Edition. Springer. Dordrecht, The Netherlands.

Tschudy, R.H; Scott, R.A (1969) Aspects of Palynology. John Wiley and Sons Inc. New York, USA.

Turner, E.P (1928) A brief account of the re-establishment of vegetation of Tarawera mountain since the eruption of 1886. Royal Society of New Zealand Transactions and Proceedings. Vol. 59. Pp. 60-66

Ugolini, F. C; Zasoski, R J (1979) Soils derived from tephra. In: Sheets, P. D. \& Grayson, D. K (eds) Volcanic Activity and Human Ecology; Academic Press. Orlando, Florida. Chapter 4: 83-124.

van Dam, H; Mertens, A; Sinkeldam, J ( 1994) A coded checklist and ecological indicator values of freshwater diatoms from The Netherlands. Netherlands Journal of Aquatic Ecology Vol. 28. Pp. 117133.

Vandergoes, M.J; Hogg, A.G; Lowe, D.J; Newnham, R.M; Denton, G.H; Southon, J; Barrell, D.J.A; Wilson, C.J.N; McGlone, M.S; Allen, A.S.R; Almond, P.C; Petchey, F; Dabell, K; Dieffenbacher-Krall, A.C; Blaauw, M (2013) A revised age for the Kawakawa/Oruanui tephra, a key marker for the Last Glacial Maximum in New Zealand. Quaternary Science Reviews. Vol. 74. Pp. 195- 201.

Vandergoes, M.J; Newnham, R.M; Preusser, F; Hendy, C.H; Lowell, T.V; Fitzsimons. S.J; Hogg, A.G; Kasper, H.U; Schluchter (2005) Regional insolation forcing of late Quaternary climate change in the Southern Hemisphere. Nature. Vol. 436. Pp. 242-245.

Villamor, P; Berryman, K.R (2006) Late Quaternary geometry and kinetics of faults at the southern termination of the Taupo Volcanic Zone, New Zealand. New Zealand Journal of Geology and Geophysics. Vol. 49. Pp. 1-21.

Vucetich, C.G; Pullar, W.A (1969) Stratigraphy and chronology of late Pleistocene volcanic ash beds in central North Island, New Zealand. New Zealand Journal of Geology and Geophysics. Vol. 12. Pp. 784-837.

Wardle, P (1991) Vegetation of New Zealand. Cambridge University Press, Cambridge.

Wardle, J (1984) The New Zealand Beeches: Ecology, Utilisation and Management. The Caxton Press. Christchurch.

Wilmshurst, J.M; McGlone, M.S; Leathwick, J.R; Newnham, R.M (2007) A pre-deforestation pollenclimate calibration model for New Zealand and quantitative temperature reconstructions for the past 18000 years BP. Journal of Quaternary Science. Vol. 22(5). Pp. 535-547.

Wilmshurst, J.M; McGlone, M.S (1996) Forest disturbance in the central North Island, New Zealand, following the 1850 BP Taupo eruption. The Holocene. Vol. 6. Pp. 399-411.

Wilson, C.J.N; Houghton, B.F; McWilliams, M.O; Lanphere, M.A; Weaver, S.A; Briggs, R.M (1995) Volcanic and structural evolution of Taupo Volcanic Zone, New Zealand: a review. Journal of Volcanology and Geothermal Research. Vol. 68. Pp. 1-28. 


\section{Appendices}

\subsection{Palynological processing technique}

Modified from Moore et al. 1991.

1. Processing

a. 1 gram of sample is placed in $9 \mathrm{mls}$ of distilled water and left to soak overnight in $15 \mathrm{ml}$ test tubes for the sample to disaggregate.

b. Vortex and then centrifuge the samples at 4000rpm for 5 minutes and decant the liquid.

c. Add one Lycopodium (marker spores) tablet to each $15 \mathrm{ml}$ test tube. Fill the test tube up to $5 \mathrm{mls}$ with $10 \% \mathrm{HCL}$ and place in a $70^{\circ} \mathrm{C}$ water bath for 5 minutes. This will remove the tablet binder $\left(\mathrm{CaCO}_{3}\right)$ as well as any carbonate that is in the sample. Centrifuge (4000rpm, $5 \mathrm{mins}$ ) and decant the supernatant followed by a water wash with distilled water (distilled water up to $10 \mathrm{mls}$, vortex, centrifuge, decant).

Notes: All acid steps should be undertaken in the fume hood. All acid needs to be decanted into a labelled waste acid beaker for proper disposal.

d. Fill $10 \% \mathrm{KOH}$ in each test tube up to $10 \mathrm{mls}$, stir and place in a $70^{\circ} \mathrm{C}$ water bath for 10 minutes, stirring occasionally before centrifuging and decanting. This will neutralise humic acids and release the polynomorphs from the matrix material as well as removing any $\leq 3 \mu \mathrm{m}$ particles.

e. Complete a water wash with distilled water and sieve the remaining sample through a $90 \mu \mathrm{m}$ mesh into labelled beakers. Use distilled water to break apart the sample and ensure that any pollen stuck to larger material is washed off and through the mesh. Centrifuge into $50 \mathrm{ml}$ test tubes and then transfer back into $15 \mathrm{ml}$ test tubes. Decant the excess water.

f. Add 5-6mls of Sodium Polytungstate (SPT) heavy liquid separation with a specific gravity of 2.2 to each test tube. Try to ensure minimal distilled water is left in the test tubes as water changes the specific gravity of SPT. Vortex before centrifuging at 2000rpm before leaving overnight for material to fully settle out. 
g. Decant the light fraction of the samples into labelled beakers by first pouring and then pipetting and make the volume up to $100 \mathrm{mls}$ with distilled water. Mix thoroughly before centrifuging back into $15 \mathrm{ml}$ test tubes. Collect the decanted SPT/water mix for recovery.

h. Complete a water wash followed by a wash with glacial acetic acid. Glacial acetic acid dehydrates the sample ready for acetolysis. Do not add water. Acetolysis acid mix reacts violently on contact with water.

i. Acetolysis: Make up a 9:1 ratio of acetic anhydrite: sulphuric acid and fill to $5 \mathrm{mls}$ in each test tube (for 8 test tubes $36 \mathrm{mls}$ of acetic anhydrite to $4 \mathrm{mls}$ sulphuric acid should be right).

j. Stir samples and leave in a $96^{\circ} \mathrm{C}$ water bath for 5 minutes, stirring occasionally. Acetolysis removes cellulose material. Centrifuge and decant into waste acid beaker before completing a wash in glacial acetic acid followed by two washes in distilled water.

k. Sieve the samples through a $6 \mu \mathrm{m}$ mesh and wash what is left on top of the mesh into $15 \mathrm{ml}$ test tubes. Use lots of water pressure in this stage to ensure all the silts are washed off the pollen grains and through the mesh.

2. Staining:

a. Centrifuge samples and decant off as much of the water as possible.

b. Add two drops of safranin ( $2 \mathrm{gm}$ in $200 \mathrm{ml}, 50 \% \mathrm{EtOH}$ then $200 \mathrm{ml} \mathrm{H} 2 \mathrm{O}$ ) into each test tube and fill up to $10 \mathrm{mls}$ with distilled water. Vortex, centrifuge and decant.

c. Complete two water washes and decant.

3. Slide making:

a. Label slides with site name and sample depth.

b. Homogenise the sample using the vortex and while the sample is suspended, transfer 1 drop of the organic matter ( $>6 \mu \mathrm{m}$ ) onto a warmed glass slide that has 1 drop of glycerine jelly on it. Mix together carefully, avoiding material near the outer limits of the slide and leave for about a minute for the water from the sample to evaporate.

c. Once the water has evaporated (this can be checked by holding a cover slip over the sample to see if it "fogs up", carefully lower a cover slip on with toothpick.

d. Leave to dry overnight before removing excess gel from around the edges with a toothpick and sealing with clear nail polish.

Note: Duplicate copies of slides were made in this study. 


\subsection{Diatom Plate}
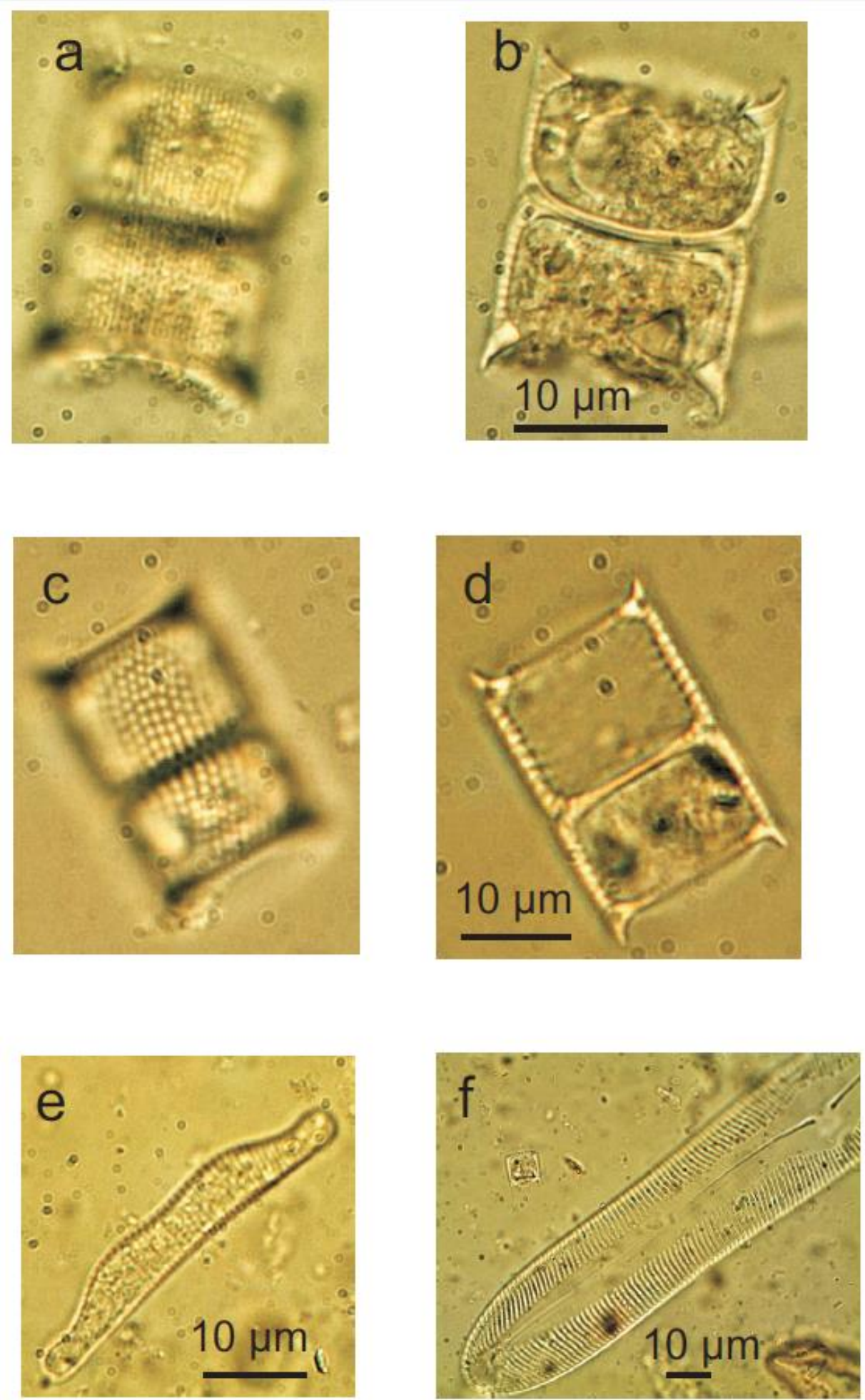

Figures a and b: Aulacoseira crenulata: $a$, surface view; $b$, optical section; (note fine pores).

Figures $\mathrm{c}$ and d: Aulacoseira ambigua: a, surface view; b, optical section;. (note u-shaped indentation in sulcus).

Figure e is Eunotia cf. pectinalis. Figure $\mathrm{f}$ is Pinnularia cf. microstauron (only half of valve in photo). 


\subsection{Raw pollen data}

Raw pollen counts: Above the 'Little Tephra'

\begin{tabular}{|c|c|c|c|c|c|c|c|c|c|c|c|}
\hline Sample \# & 76 & 75 & 74 & 73 & 72 & 71 & 70 & 69 & 68 & 67 & 66 \\
\hline Depth from top $(\mathrm{cm})$ & 0 & 0.5 & 1 & 1.5 & 2 & 2.5 & 3 & 3.5 & 4 & 4.5 & 5 \\
\hline \multicolumn{12}{|l|}{ Name } \\
\hline Dacrydium cupressinum & 80 & 72 & 79 & 72 & 129 & 71 & 113 & 82 & 92 & 98 & 84 \\
\hline Dacrycarpus dacrydioides & 27 & 20 & 26 & 33 & 53 & 18 & 34 & 32 & 37 & 31 & 41 \\
\hline Libocedrus & 0 & 0 & 0 & 0 & 3 & 2 & 0 & 0 & 0 & 0 & 0 \\
\hline Podocarpus & 63 & 52 & 57 & 41 & 55 & 40 & 55 & 55 & 47 & 58 & 52 \\
\hline Prumnopitys & 6 & 13 & 6 & 14 & 11 & 3 & 8 & 6 & 6 & 4 & 7 \\
\hline Weinmannia & 0 & 0 & 0 & 1 & 1 & 3 & 0 & 0 & 0 & 0 & 8 \\
\hline Metrosideros & 0 & 0 & 0 & 0 & 0 & 0 & 0 & 1 & 2 & 2 & 8 \\
\hline Fuscospora & 3 & 5 & 2 & 5 & 1 & 6 & 4 & 1 & 2 & 4 & 5 \\
\hline Asteraceae & 2 & 2 & 0 & 0 & 1 & 0 & 0 & 3 & 0 & 1 & 0 \\
\hline Coprosma & 3 & 10 & 7 & 13 & 15 & 10 & 11 & 7 & 55 & 10 & 10 \\
\hline Dracophyllum & 0 & 0 & 0 & 0 & 0 & 0 & 0 & 0 & 0 & 1 & 0 \\
\hline Griselinia & 1 & 0 & 0 & 0 & 0 & 0 & 0 & 0 & 0 & 2 & 0 \\
\hline Halocarpus & 1 & 0 & 0 & 0 & 0 & 0 & 0 & 0 & 0 & 0 & 0 \\
\hline Leptospermum & 31 & 51 & 27 & 58 & 67 & 58 & 9 & 28 & 27 & 29 & 23 \\
\hline Mysine & 1 & 0 & 0 & 2 & 2 & 4 & 5 & 2 & 8 & 3 & 3 \\
\hline Nestegis & 11 & 6 & 5 & 5 & 5 & 13 & 6 & 9 & 12 & 3 & 4 \\
\hline Phyllocladus & 9 & 9 & 11 & 11 & 9 & 15 & 12 & 9 & 10 & 4 & 9 \\
\hline Plagianthus & 2 & 1 & 1 & 0 & 0 & 0 & 0 & 0 & 0 & 0 & 0 \\
\hline Pseudopanax & 10 & 6 & 10 & 6 & 4 & 8 & 6 & 5 & 7 & 13 & 7 \\
\hline Schefflera & 0 & 1 & 0 & 0 & 3 & 2 & 8 & 1 & 5 & 0 & 0 \\
\hline Apiaceae & 2 & 4 & 1 & 1 & 5 & 1 & 4 & 4 & 4 & 2 & 2 \\
\hline Astelia & 0 & 0 & 0 & 0 & 1 & 1 & 1 & 6 & 1 & 1 & 1 \\
\hline Epacrid & 0 & 0 & 0 & 1 & 0 & 0 & 0 & 0 & 0 & 0 & 0 \\
\hline Gentiana & 0 & 0 & 0 & 0 & 0 & 0 & 0 & 0 & 1 & 0 & 0 \\
\hline Myosotis & 0 & 0 & 0 & 2 & 0 & 0 & 1 & 1 & 0 & 0 & 0 \\
\hline Poaceae & 1 & 0 & 0 & 0 & 1 & 1 & 0 & 0 & 3 & 6 & 8 \\
\hline Centrolepidaceae & 0 & 0 & 0 & 0 & 0 & 1 & 1 & 0 & 0 & 0 & 0 \\
\hline Cyperaceae & 19 & 18 & 10 & 16 & 17 & 16 & 31 & 9 & 31 & 18 & 26 \\
\hline
\end{tabular}




$\begin{array}{llllllllllll}\text { Empodisma } & 0 & 1 & 2 & 0 & 1 & 2 & 0 & 0 & 3 & 1 & 4 \\ \text { Gleichenia } & 0 & 0 & 0 & 0 & 0 & 1 & 0 & 0 & 0 & 0 & 0 \\ \text { Phormium } & 0 & 0 & 1 & 1 & 4 & 5 & 1 & 0 & 3 & 0 & 0 \\ \text { Cyathea } & 64 & 32 & 55 & 56 & 79 & 68 & 73 & 46 & 74 & 74 & 66 \\ \text { Dicksonia } & 3 & 7 & 5 & 6 & 6 & 2 & 7 & 7 & 3 & 5 & 1 \\ \text { Lycopodium NZ } & 0 & 1 & 0 & 2 & 0 & 0 & 0 & 0 & 0 & 0 & 0 \\ \text { Monolete fern } & 6 & 8 & 6 & 7 & 9 & 3 & 9 & 8 & 10 & 11 & 9 \\ \text { Dactylanthus taylorii } & 0 & 0 & 0 & 0 & 0 & 0 & 0 & 0 & 0 & 0 & 1 \\ \text { Spiked Lycopodium } & 35 & 26 & 20 & 27 & 76 & 44 & 55 & 36 & 32 & 28 & 23 \\ \text { Total sum } & 345 & 319 & 311 & 353 & 482 & 354 & 399 & 322 & 443 & 381 & 379 \\ \text { Dry sum } & 253 & 252 & 232 & 265 & 366 & 256 & 277 & 252 & 319 & 272 & 272\end{array}$


Raw pollen counts: Below the 'Little Tephra'

\begin{tabular}{|c|c|c|c|c|c|c|c|c|c|c|c|}
\hline Sample \# & 55 & 56 & 57 & 58 & 59 & 60 & 61 & 62 & 63 & 64 & 65 \\
\hline Depth from top (cm) & 7 & 7.5 & 8 & 8.5 & 9 & 9.5 & 10 & 10.5 & 11 & 11.5 & 12 \\
\hline \multicolumn{12}{|l|}{ Name } \\
\hline Dacrydium cupressinum & 109 & 119 & 114 & 96 & 86 & 80 & 80 & 95 & 105 & 97 & 100 \\
\hline Dacrycarpus dacrydioides & 34 & 29 & 47 & 33 & 58 & 36 & 42 & 46 & 53 & 30 & 43 \\
\hline Podocarpus & 66 & 71 & 66 & 50 & 42 & 56 & 52 & 55 & 51 & 44 & 58 \\
\hline Prumnopitys & 7 & 0 & 0 & 5 & 6 & 12 & 11 & 7 & 4 & 7 & 1 \\
\hline Weinmannia & 0 & 0 & 0 & 2 & 1 & 0 & 0 & 0 & 0 & 0 & 0 \\
\hline Metrosideros & 0 & 1 & 0 & 2 & 0 & 0 & 2 & 0 & 1 & 4 & 1 \\
\hline Fuscospora & 2 & 1 & 1 & 3 & 4 & 0 & 0 & 1 & 2 & 9 & 2 \\
\hline Lophozonia menziesii & 1 & 0 & 0 & 0 & 0 & 2 & 0 & 0 & 0 & 0 & 0 \\
\hline Asteraceae & 0 & 0 & 0 & 0 & 0 & 1 & 0 & 0 & 0 & 0 & 0 \\
\hline Coprosma & 6 & 3 & 3 & 12 & 5 & 3 & 1 & 6 & 9 & 5 & 4 \\
\hline Dracophyllum & 2 & 0 & 0 & 0 & 0 & 1 & 0 & 1 & 1 & 1 & 0 \\
\hline Halocarpus & 0 & 0 & 0 & 0 & 1 & 0 & 0 & 0 & 0 & 0 & 0 \\
\hline Hoheria & 0 & 0 & 0 & 0 & 0 & 2 & 0 & 0 & 0 & 0 & 0 \\
\hline Leptospermum & 4 & 2 & 0 & 26 & 19 & 12 & 37 & 6 & 7 & 15 & 16 \\
\hline Mysine & 2 & 0 & 1 & 3 & 5 & 0 & 0 & 2 & 4 & 2 & 1 \\
\hline Nestegis & 11 & 9 & 3 & 8 & 10 & 12 & 2 & 14 & 14 & 8 & 10 \\
\hline Phyllocladus & 16 & 4 & 7 & 10 & 5 & 18 & 8 & 20 & 6 & 15 & 5 \\
\hline Plagianthus & 0 & 0 & 1 & 0 & 0 & 0 & 0 & 0 & 0 & 0 & 1 \\
\hline Pseudopanax & 5 & 1 & 7 & 1 & 4 & 4 & 7 & 5 & 2 & 3 & 2 \\
\hline Schefflera & 2 & 0 & 0 & 0 & 0 & 2 & 1 & 0 & 0 & 0 & 1 \\
\hline Apiaceae & 1 & 1 & 0 & 1 & 1 & 1 & 9 & 1 & 0 & 0 & 7 \\
\hline Astelia & 5 & 0 & 0 & 0 & 1 & 2 & 1 & 1 & 1 & 1 & 1 \\
\hline Cruciferae & 0 & 1 & 0 & 0 & 0 & 0 & 0 & 0 & 0 & 0 & 0 \\
\hline Epacrid & 0 & 1 & 0 & 0 & 0 & 0 & 0 & 0 & 0 & 1 & 0 \\
\hline Epilobium & 0 & 0 & 0 & 0 & 0 & 0 & 0 & 1 & 0 & 0 & 0 \\
\hline Gentiana & 0 & 0 & 0 & 0 & 2 & 0 & 0 & 0 & 1 & 1 & 0 \\
\hline Gunnera & 1 & 2 & 0 & 0 & 0 & 1 & 0 & 0 & 0 & 0 & 0 \\
\hline Myosotis & 0 & 1 & 1 & 0 & 0 & 0 & 0 & 0 & 0 & 0 & 0 \\
\hline
\end{tabular}




\begin{tabular}{llllllllllll} 
Poaceae & 11 & 8 & 0 & 0 & 2 & 2 & 1 & 0 & 1 & 2 & 1 \\
Centrolepidaceae & 0 & 0 & 1 & 0 & 0 & 0 & 0 & 0 & 0 & 3 & 0 \\
Cyperaceae & 27 & 11 & 16 & 23 & 65 & 27 & 16 & 31 & 26 & 24 & 9 \\
Empodisma & 7 & 2 & 0 & 1 & 0 & 0 & 0 & 1 & 1 & 0 & 6 \\
Myriophyllum & 0 & 1 & 0 & 0 & 0 & 2 & 0 & 0 & 1 & 0 & 1 \\
Phormium & 3 & 4 & 1 & 1 & 1 & 0 & 0 & 1 & 0 & 5 & 0 \\
Cyathea & 99 & 80 & 76 & 61 & 80 & 62 & 60 & 63 & 94 & 77 & 18 \\
Dicksonia & 4 & 13 & 6 & 4 & 4 & 1 & 1 & 6 & 8 & 2 & 0 \\
Lycopodium NZ & 0 & 1 & 1 & 1 & 0 & 0 & 0 & 0 & 1 & 0 & 0 \\
Monolete fern & 13 & 16 & 11 & 7 & 14 & 13 & 17 & 15 & 18 & 6 & 0 \\
Spiked Lycopodium & 50 & 32 & 18 & 38 & 30 & 61 & 59 & 62 & 49 & 72 & 65 \\
Total sum & 438 & 382 & 363 & 350 & 416 & 352 & 348 & 378 & 411 & 362 & 288 \\
\hline Dry sum & 285 & 254 & 251 & 252 & 252 & 247 & 254 & 261 & 262 & 245 & 254
\end{tabular}


Raw pollen counts: Above the 'Big Lower Lapilli'

\begin{tabular}{|c|c|c|c|c|c|c|c|c|c|c|c|}
\hline Sample \# & 21 & 20 & 19 & 18 & 17 & 16 & 15 & 14 & 13 & 12 & 11 \\
\hline Depth from top (cm) & 0 & 0.5 & 1 & 1.5 & 2 & 2.5 & 3 & 3.5 & 4 & 4.5 & 5 \\
\hline \multicolumn{12}{|l|}{ Name } \\
\hline Dacrydium cupressinum & 2 & 6 & 5 & 11 & 8 & 1 & 7 & 7 & 5 & 10 & 7 \\
\hline Dacrycarpus dacrydioides & 1 & 1 & 2 & & & & & & & 1 & 1 \\
\hline Libocedrus & 10 & 7 & 12 & 34 & 25 & 24 & 28 & 29 & 30 & 17 & 24 \\
\hline Podocarpus & 3 & 7 & 8 & 13 & 8 & 1 & 4 & 4 & 4 & 10 & 7 \\
\hline Prumnopitys & 1 & 4 & 4 & 2 & 1 & 1 & 3 & 5 & 4 & 4 & 2 \\
\hline Weinmannia & & 3 & & 2 & & & 1 & & & 1 & 2 \\
\hline Fuscospora & 22 & 23 & 21 & 39 & 30 & 27 & 23 & 19 & 20 & 22 & 36 \\
\hline Asteraceae & 5 & 6 & 11 & 7 & 1 & 10 & 7 & 4 & 9 & 14 & 14 \\
\hline Coprosma & 20 & 13 & 18 & 14 & 14 & 18 & 13 & 14 & 21 & 20 & 28 \\
\hline Dracophyllum & 2 & 3 & 6 & 8 & 4 & 5 & 2 & 6 & 4 & 7 & 11 \\
\hline Griselinia & & & & & & & & & 1 & & \\
\hline Halocarpus & 10 & 11 & 10 & 11 & 5 & 3 & 11 & 9 & 3 & 13 & 8 \\
\hline Hoheria & & & & & & & 1 & 1 & & & \\
\hline Myrtaceae & 1 & & 1 & 1 & & & 1 & 1 & & 4 & 2 \\
\hline Mysine & & 2 & & & & & & & & & \\
\hline Nestegis & & 3 & & & & & & & & 1 & 1 \\
\hline Phyllocladus & 160 & 156 & 128 & 170 & 93 & 68 & 84 & 102 & 57 & 91 & 108 \\
\hline Plagianthus & & & & & & & & & & & 1 \\
\hline Schefflera & 1 & 1 & & & & & 3 & & 1 & 1 & \\
\hline Apiaceae & & 3 & & 1 & & & 2 & & & & \\
\hline Epacrid & 1 & & & & & & & & & & \\
\hline Poaceae & 31 & 31 & 40 & 56 & 67 & 102 & 84 & 98 & 92 & 34 & 23 \\
\hline Cyperaceae & 6 & 7 & 4 & 5 & & & 2 & 1 & 4 & 18 & 13 \\
\hline Empodisma & 43 & 39 & 44 & 59 & 41 & 35 & 64 & 50 & 51 & 39 & 25 \\
\hline Gleichenia & 1 & 1 & 1 & & & & & & & 1 & 2 \\
\hline Myriophyllum & & & & 1 & & & & & & & \\
\hline Sphagnum & & & & & & & & 1 & & & \\
\hline Cyathea & 4 & 3 & 2 & 6 & 1 & 4 & & 4 & 2 & 3 & 5 \\
\hline Dicksonia & 1 & 1 & 1 & 1 & 2 & 1 & & & & 3 & \\
\hline
\end{tabular}




\begin{tabular}{llllllllllll} 
Monolete fern & 4 & 2 & 5 & & & & 2 & 1 & 1 & 5 & 8 \\
\hline Spiked Lycopodium & 30 & 34 & 22 & 18 & 23 & 21 & 19 & 31 & 42 & 83 & 40 \\
\hline Total sum & 359 & 367 & 345 & 459 & 323 & 321 & 361 & 387 & 351 & 402 & 368 \\
Dry sum & 270 & 280 & 266 & 369 & 256 & 260 & 274 & 299 & 251 & 250 & 275
\end{tabular}

\section{Raw pollen counts: Below the 'Big Lower Lapilli'}

\begin{tabular}{|c|c|c|c|c|c|c|c|c|c|c|c|}
\hline Sample \# & 22 & 23 & 24 & 25 & 26 & 27 & 28 & 29 & 30 & 31 & 32 \\
\hline Depth from top (cm) & 25 & 25.5 & 26 & 26.5 & 27 & 27.5 & 28 & 28.5 & 29 & 29.5 & 30 \\
\hline \multicolumn{12}{|l|}{ Name } \\
\hline Dacrydium cupressinum & 11 & 8 & 7 & 5 & 3 & 8 & 8 & 7 & 5 & 7 & 6 \\
\hline Dacrycarpus dacrydioides & 1 & & & & & 1 & 1 & & & 1 & \\
\hline Libocedrus & 21 & 30 & 20 & 28 & 29 & 22 & 23 & 18 & 21 & 30 & 19 \\
\hline Podocarpus & 10 & 8 & 9 & 17 & 13 & 7 & 12 & 7 & 9 & 15 & 11 \\
\hline Prumnopitys & 10 & 2 & 6 & 2 & 4 & 5 & 3 & 5 & 1 & 3 & 4 \\
\hline Weinmannia & 1 & 4 & 1 & 1 & & 2 & & 2 & 2 & & 1 \\
\hline Fuscospora & 57 & 52 & 29 & 35 & 38 & 48 & 28 & 30 & 36 & 39 & 32 \\
\hline Asteraceae & 29 & 32 & 27 & 36 & 26 & 31 & 30 & 57 & 33 & 35 & 49 \\
\hline Coprosma & 42 & 65 & 78 & 88 & 71 & 74 & 84 & 61 & 65 & 51 & 57 \\
\hline Dracophyllum & 6 & 4 & 7 & 1 & 2 & 3 & 1 & 1 & 8 & 3 & 3 \\
\hline Halocarpus & 6 & 6 & 5 & 16 & 7 & 13 & 12 & 16 & 15 & 18 & 20 \\
\hline Hoheria & & & & & & & & 1 & & & \\
\hline Myrtaceae & & 2 & 2 & & & & 2 & 1 & 3 & 2 & \\
\hline Mysine & 1 & & & & & & & & 1 & & \\
\hline Nestegis & 4 & & & 2 & 1 & 1 & & 1 & 3 & 1 & 1 \\
\hline Phyllocladus & 30 & 20 & 30 & 20 & 31 & 23 & 37 & 22 & 20 & 19 & 22 \\
\hline Plagianthus & 3 & & 2 & 1 & & 2 & 2 & 1 & 2 & 1 & 1 \\
\hline Pseudowintera & & & & & 1 & 1 & & & & & \\
\hline Schefflera & & 1 & & & 3 & & 2 & 1 & & 1 & 1 \\
\hline Epacrid & 1 & & & & & & & & 1 & & \\
\hline Epilobium & & & & & & & & & & & 1 \\
\hline Gunnera & & 2 & & & 2 & & 1 & & 1 & & \\
\hline Poaceae & 41 & 26 & 42 & 33 & 31 & 25 & 35 & 43 & 35 & 29 & 32 \\
\hline Cyperaceae & 7 & 26 & 27 & 12 & 15 & 32 & 16 & 22 & 24 & 19 & 18 \\
\hline
\end{tabular}




\begin{tabular}{llllllllllll} 
Empodisma & 75 & 54 & 70 & 41 & 62 & 30 & 37 & 31 & 22 & 14 & 18 \\
Gleichenia & & 1 & & & & & & 1 & & 1 & \\
$\begin{array}{l}\text { Myriophyllum } \\
\text { Cyathea }\end{array}$ & & & & 3 & 1 & 1 & 1 & & 1 & 3 & \\
Dicksonia & 4 & 1 & 3 & 6 & 5 & 6 & 2 & 4 & 2 & 8 & 3 \\
Monolete fern & 2 & & & & & 1 & & & & & \\
Spiked Lycopodium & 9 & 2 & 2 & & 6 & & 2 & 3 & 3 & 3 & 5 \\
Total sum & 49 & 25 & 38 & 18 & 21 & 20 & 23 & 41 & 32 & 21 & 27 \\
Dry sum & 371 & 346 & 367 & 347 & 351 & 336 & 339 & 335 & 313 & 303 & 304 \\
\hline
\end{tabular}


Raw pollen counts: Above the 'Unknown' tephra

\begin{tabular}{|c|c|c|c|c|c|c|c|c|c|c|c|}
\hline Sample \# & 54 & 53 & 52 & 51 & 50 & 49 & 48 & 47 & 46 & 45 & 44 \\
\hline Depth from top (cm) & 0 & 0.5 & 1 & 1.5 & 2 & 2.5 & 3 & 3.5 & 4 & 4.5 & 5 \\
\hline \multicolumn{12}{|l|}{ Name } \\
\hline Dacrydium cupressinum & 10 & 12 & 7 & 6 & 6 & 8 & 4 & 9 & 7 & 6 & 6 \\
\hline Dacrycarpus dacrydioides & 1 & 2 & & 2 & & & 2 & 2 & 1 & 1 & \\
\hline Libocedrus & & & & & & & & 4 & 4 & & \\
\hline Podocarpus & 22 & 37 & 30 & 18 & 28 & 17 & 14 & 26 & 28 & 21 & 24 \\
\hline Prumnopitys & 3 & 1 & 2 & 7 & 2 & 1 & 5 & 1 & 4 & 6 & 3 \\
\hline Metrosideros & & & & & & & & & 1 & & \\
\hline Fuscospora & 71 & 62 & 60 & 63 & 85 & 79 & 77 & 77 & 94 & 76 & 59 \\
\hline Lophozonia menziesii & 25 & 40 & 25 & 32 & 32 & 50 & 37 & 29 & 38 & 43 & 49 \\
\hline Asteraceae & 33 & 13 & 17 & 29 & 31 & 32 & 23 & 28 & 17 & 29 & 13 \\
\hline Coprosma & 6 & 3 & 2 & 7 & 5 & 4 & 5 & 6 & 4 & 2 & 5 \\
\hline Dracophyllum & 2 & 2 & 1 & 3 & 4 & 4 & 7 & 6 & 1 & 7 & 5 \\
\hline Halocarpus & 7 & 13 & 20 & 12 & 15 & 9 & 13 & 19 & 11 & 14 & 6 \\
\hline Hoheria & & & & & 1 & & & & & 1 & \\
\hline Leptospermum & & & & & & & 1 & & & & \\
\hline Mysine & & & & & & & & & & 1 & \\
\hline Nestegis & 1 & & & 1 & 3 & & 3 & & 5 & 2 & \\
\hline Phyllocladus & 8 & 20 & 18 & 6 & 13 & 11 & 25 & 20 & 10 & 14 & 18 \\
\hline Plagianthus & 1 & 1 & 1 & 1 & 1 & 1 & & & & & 2 \\
\hline Pseudopanax & & & & & & & & 2 & & & \\
\hline Schefflera & & & & 1 & & & & 1 & & & 2 \\
\hline Apiaceae & & & & & & & & & 2 & & \\
\hline Astelia & & & & & & & & & & 1 & 3 \\
\hline Chenopodiaceae & & & & & & & & & & & 1 \\
\hline Epilobium & & 1 & & & & & & & & & \\
\hline Gunnera & 1 & 1 & 1 & 1 & & 2 & 1 & & 3 & 4 & 2 \\
\hline Myosotis & & & 1 & & 3 & & 1 & & 2 & & \\
\hline Neopaxia & & & & & & & & 1 & 1 & & \\
\hline Poaceae & 66 & 39 & 48 & 35 & 56 & 45 & 49 & 57 & 54 & 43 & 66 \\
\hline Centrolepidaceae & 1 & & 1 & & 1 & 4 & 9 & & 7 & & 2 \\
\hline
\end{tabular}




\begin{tabular}{|c|c|c|c|c|c|c|c|c|c|c|c|}
\hline Cyperaceae & 12 & 20 & 25 & 56 & 59 & 56 & 70 & 104 & 110 & 90 & 104 \\
\hline Empodisma & 13 & 21 & 19 & 18 & 28 & 18 & 11 & 31 & 16 & 17 & 24 \\
\hline Gleichenia & & & 1 & & & & & 1 & & & \\
\hline Myriophyllum & 6 & 2 & 6 & 5 & 10 & 7 & 9 & 16 & 11 & 7 & 7 \\
\hline Phormium & & & & & & & & 1 & & 1 & \\
\hline Cyathea & 2 & 1 & 1 & 2 & 2 & 1 & & 3 & & 1 & 2 \\
\hline Dicksonia & & & 1 & & & & & & & & \\
\hline Lycopodium NZ & & & 2 & & & 1 & & & & & \\
\hline Monolete fern & 3 & 5 & 1 & 3 & 5 & 1 & 8 & 4 & 6 & 2 & 7 \\
\hline Spiked Lycopodium & 37 & 32 & 33 & 29 & 56 & 27 & 33 & 36 & 27 & 34 & 78 \\
\hline Total sum & 331 & 328 & 323 & 337 & 446 & 378 & 407 & 484 & 464 & 423 & 488 \\
\hline Dry sum & 257 & 247 & 233 & 224 & 285 & 263 & 267 & 288 & 287 & 271 & 264 \\
\hline
\end{tabular}

\section{Raw pollen counts: Below the 'Unknown' tephra}

\begin{tabular}{|c|c|c|c|c|c|c|c|c|c|c|c|}
\hline Sample \# & 33 & 34 & 35 & 36 & 37 & 38 & 39 & 40 & 41 & 42 & 43 \\
\hline Depth from top (cm) & 7 & 7.5 & 8 & 8.5 & 9 & 9.5 & 10 & 10.5 & 11 & 11.5 & 12 \\
\hline \multicolumn{12}{|l|}{ Name } \\
\hline Dacrydium cupressinum & 10 & 14 & 6 & 9 & 11 & 7 & 1 & 8 & 9 & 6 & 12 \\
\hline Dacrycarpus dacrydioides & 1 & & & 2 & 1 & & & & 2 & 1 & 2 \\
\hline Libocedrus & 2 & 1 & & 8 & 1 & 2 & 9 & 2 & 2 & & 1 \\
\hline Podocarpus & 21 & 18 & 18 & 23 & 24 & 17 & 15 & 31 & 27 & 37 & 26 \\
\hline Prumnopitys & 3 & 22 & 2 & 8 & 3 & 1 & 1 & 3 & & & 1 \\
\hline Metrosideros & & & & & & 1 & & & & & \\
\hline Fuscospora & 84 & 76 & 85 & 113 & 91 & 89 & 111 & 99 & 72 & 68 & 64 \\
\hline Lophozonia menziesii & 8 & 25 & 37 & 61 & 28 & 37 & 28 & 26 & 38 & 45 & 54 \\
\hline Quintinia & & & & & & 1 & & & & & \\
\hline Asteraceae & 19 & 21 & 18 & 24 & 34 & 14 & 18 & 21 & 20 & 18 & 15 \\
\hline Coprosma & 3 & 4 & 7 & 5 & 5 & 6 & 10 & 2 & 8 & 7 & 9 \\
\hline Dracophyllum & 1 & 6 & 1 & 1 & 2 & 4 & 3 & 3 & 1 & 3 & 4 \\
\hline Halocarpus & 19 & 15 & 12 & 10 & 9 & 14 & 11 & 24 & 30 & 26 & 22 \\
\hline Hoheria & & & & 3 & & & & & 1 & & \\
\hline Leptospermum & 3 & & & 1 & & & & & & & \\
\hline Mysine & 2 & & & & & & 1 & & 1 & & \\
\hline
\end{tabular}




\begin{tabular}{|c|c|c|c|c|c|c|c|c|c|c|c|}
\hline Nestegis & 2 & & 2 & 4 & & & 2 & & 1 & & \\
\hline Phyllocladus & 14 & 11 & 9 & 5 & 19 & 9 & 10 & 7 & 19 & 8 & 10 \\
\hline Plagianthus & 1 & 3 & 1 & & 2 & & 3 & & & & \\
\hline Schefflera & & 4 & & 6 & & 2 & & & & & \\
\hline Apiaceae & & 10 & 3 & 5 & & & & 2 & 2 & 1 & 1 \\
\hline Astelia & 1 & & & 7 & 3 & 2 & 2 & 2 & & & \\
\hline Cruciferae & & & 3 & & & & & & & & \\
\hline Epacrid & & & & 1 & 1 & & & 1 & & & \\
\hline Epilobium & & & & 2 & & & & & & & \\
\hline Gentiana & 1 & & & & 1 & 3 & & & & & \\
\hline Gunnera & 2 & & 1 & & & & 2 & & & 1 & 2 \\
\hline Myosotis & & & & 2 & 7 & 1 & 5 & & 3 & & \\
\hline Neopaxia & & & & & & 5 & & 2 & & 1 & \\
\hline Poaceae & 52 & 58 & 46 & 68 & 62 & 54 & 52 & 52 & 40 & 58 & 50 \\
\hline Centrolepidaceae & 3 & 1 & 2 & & & & & & & & \\
\hline Cyperaceae & 75 & 151 & 103 & 160 & 86 & 78 & 56 & 75 & 108 & 98 & 75 \\
\hline Empodisma & 23 & 25 & 12 & 25 & 8 & 5 & 13 & 3 & 17 & 13 & 11 \\
\hline Gleichenia & 2 & & & & & & & & 2 & 3 & 1 \\
\hline Myriophyllum & 10 & 16 & 9 & 10 & 6 & 8 & 4 & 9 & 2 & 9 & 9 \\
\hline Cyathea & & 1 & 3 & 1 & 1 & 1 & 2 & 4 & 3 & 4 & 5 \\
\hline Dicksonia & & & & 1 & & & & 1 & & & \\
\hline Monolete fern & 8 & 9 & 7 & 3 & 9 & 10 & 5 & 6 & 5 & 5 & 10 \\
\hline Trilete fern & 1 & 1 & & 1 & & 1 & & & 2 & & \\
\hline Spiked Lycopodium & 40 & 32 & 16 & 27 & 21 & 19 & 13 & 21 & 15 & 14 & 27 \\
\hline Total sum & 411 & 524 & 403 & 596 & 435 & 391 & 377 & 404 & 430 & 426 & 411 \\
\hline Dry sum & 249 & 288 & 251 & 368 & 304 & 269 & 284 & 285 & 276 & 280 & 273 \\
\hline
\end{tabular}




\subsection{Loss-on-Ignition, Magnetic Susceptibility, and DCA raw data for the Karioi section.}

Listed against depth. The deepest point aligns with the cemented lithic gravels as described in figure 10.

$\begin{array}{rlll}\text { Depth(cm) } & \text { LOI \% } & \chi & \text { XCA1 } \\ 365 & & & -0.70505 \\ 370 & & & \\ 375 & & & \\ 380 & & & \\ 385 & & & -0.87768 \\ 390 & & & \\ 395 & & & \\ 400 & & & \\ 405 & & & -0.78641 \\ 410 & & & \\ 415 & & & -0.71588 \\ 420 & & & \\ 425 & & & -0.64266 \\ 430 & & & \\ 435 & 12.18088 & 0.219415 & -0.64387 \\ 440 & 9.617613 & 0.143552 & \\ 445 & 9.112426 & 0.156951 & -0.49397 \\ 450 & 8.710066 & 0.112994 & \\ 455 & 27.34085 & 0.095749 & -0.52637 \\ 460 & 8.338175 & 0.111209 & \\ 465 & 8.216856 & 0.087603 & -0.22524 \\ 470 & 10.01965 & 0.041903 & \\ 475 & 12.39961 & 0.129604 & -0.33663 \\ 480 & 15.46855 & 0.088141 & \\ 485 & 21.58348 & 0.026566 & -0.25233 \\ 490 & 19.99813 & 0.034325 & \\ 495 & 37.71281 & 0.034014 & -0.12081 \\ 500 & 36.80203 & 0.109453 & \\ 505 & 40.11142 & 0.059791 & -0.225 \\ 510 & 35.11058 & 0.121897 & \\ 515 & 68.17371 & 0.00438 & -0.14408 \\ 520 & 53.59695 & 0.114155 & \\ 525 & 33.35983 & 0.147516 & -0.33052 \\ 530 & 19.51138 & 0.165125 & \\ 535 & 18.79699 & 0.288994 & -0.43201 \\ 540 & 22.26562 & 0.116959 & \\ 545 & 18.9834 & 0.20954 & -0.4486\end{array}$




\begin{tabular}{|c|c|c|c|}
\hline 50 & 19.37137 & 0.25294 & \\
\hline 55 & 33.21314 & 0.066199 & -0.4135 \\
\hline & 33.731 & 0.077864 & \\
\hline 55 & 32.25688 & 0.119048 & -0.2376 \\
\hline & 22.35252 & 0.319962 & \\
\hline 75 & 28.1913 & 0.083912 & -0.39705 \\
\hline 0 & 32.95035 & 0.083799 & \\
\hline 85 & 43.53909 & 0.040494 & -0.09024 \\
\hline 90 & 32.63615 & 0.118881 & \\
\hline 95 & 60.20289 & 0.03222 & -0.466 \\
\hline 00 & 32.78761 & 0.085767 & -0.5275 \\
\hline 05 & 13.71429 & 0.401951 & -0.6554 \\
\hline 10 & 3.703704 & 0.529972 & \\
\hline 15 & 3.136155 & 0.631436 & -0.7850 \\
\hline 20 & 12.5812 & 0.271474 & \\
\hline 25 & 22.79947 & 0.130407 & -0.598 \\
\hline 30 & 17.39551 & 0.096363 & \\
\hline 35 & 35.07282 & 0.010331 & -0.5657 \\
\hline 640 & 40.40554 & 0.020387 & \\
\hline 45 & 45.11991 & 0.016584 & -0.40938 \\
\hline 650 & 26.32687 & 0.092864 & \\
\hline 55 & 23.94477 & 0.126874 & \\
\hline 660 & 7.6 & 0.579791 & \\
\hline 665 & 8.021713 & 0.579791 & \\
\hline 70 & 8.1 & 0.579791 & \\
\hline 675 & 7 & 0.579791 & \\
\hline 680 & 37.63676 & 0.078201 & \\
\hline 685 & 28.75845 & 0.06986 & -0.7767 \\
\hline 690 & 30.85349 & 0.093333 & \\
\hline 695 & 24.30407 & 0.015075 & $-0.5874 \varepsilon$ \\
\hline 700 & 31.1507 & 0.057351 & \\
\hline 705 & 37.73836 & 0.12261 & -0.6639 \\
\hline 710 & 34.15751 & 0.025253 & \\
\hline 715 & 11.00404 & 0.096154 & -0.5655 \\
\hline 720 & 11.27167 & 0.149549 & \\
\hline 725 & 7.89378 & 0.06281 & -0.5807 \\
\hline 730 & 7.997118 & 0.082873 & \\
\hline 735 & 9.001447 & 0.115132 & -0.4704 \\
\hline 740 & 8.984263 & 0.1421 & \\
\hline 745 & 8.707124 & 0.1082 & -0.1652 \\
\hline 750 & 7.721118 & 0.156082 & \\
\hline 755 & 8.531432 & 0.093168 & -0.2379 \\
\hline 760 & 20.76309 & 0.097911 & \\
\hline 765 & 44.74433 & 0.038377 & -0.0297 \\
\hline & 43.22457 & 0.044952 & \\
\hline
\end{tabular}




$\begin{array}{rrrr}775 & 43.53448 & 0.019943 & 0.832902 \\ 780 & 47.08819 & 0.046729 & \\ 785 & 60.67416 & 0.02849 & 1.246 \\ 790 & 32.21671 & 0.08307 & \\ 795 & 72.52678 & 0 & 1.25864 \\ 800 & 61.27213 & 0.029536 & \\ 805 & 64.24542 & -0.00186 & 1.404483 \\ 810 & 90.75342 & -0.01582 & \\ 815 & 76.00321 & 0 & 1.321362 \\ 820 & 78.91459 & 0.00244 & \\ 825 & 79.44803 & 0.002971 & 1.349481 \\ 830 & 61.70886 & 0.003187 & \\ 835 & 46.79782 & 0.016077 & 1.364838 \\ 840 & 60.12843 & 0.060322 & \\ 845 & 37.69231 & 0.077031 & 1.16711 \\ 850 & 68.82291 & 0.054317 & \\ 855 & 61.90937 & 0.006954 & 1.321801 \\ 860 & 51.55039 & 0.078125 & \\ 865 & 45.50393 & 0.026123 & 1.23762 \\ 870 & 76.66232 & 0.009881 & \\ 875 & 65.14727 & -0.0028 & 1.166444 \\ 880 & 30.30303 & -0.00214 & \\ 885 & 29.50291 & -0.01075 & 1.140784 \\ 890 & 27.34085 & 0.158582 & \\ 895 & 41.02886 & -0.01258 & 1.036035 \\ 900 & 49.63459 & -0.00765 & \\ 905 & 30.22284 & 0.009025 & 1.142001 \\ 910 & 42.70319 & 0.153374 & \\ 915 & 50.38835 & 0.144231 & 1.340272\end{array}$




\subsection{Eiganvalues - supplementary to the statistical analysis}

The 'Big Lower Lapilli'

Eigenvalues

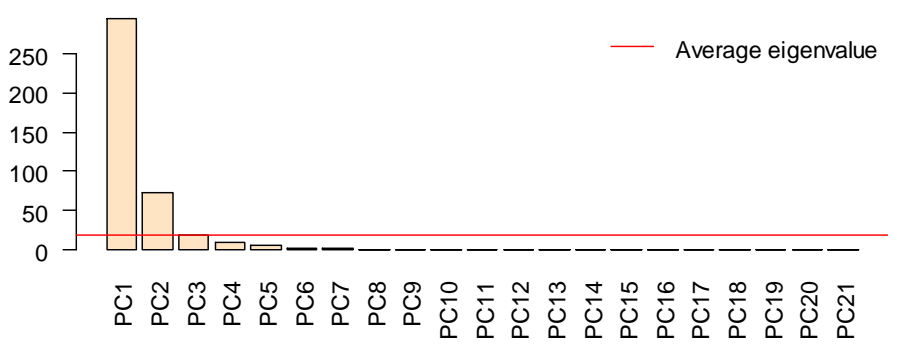

$\%$ variation

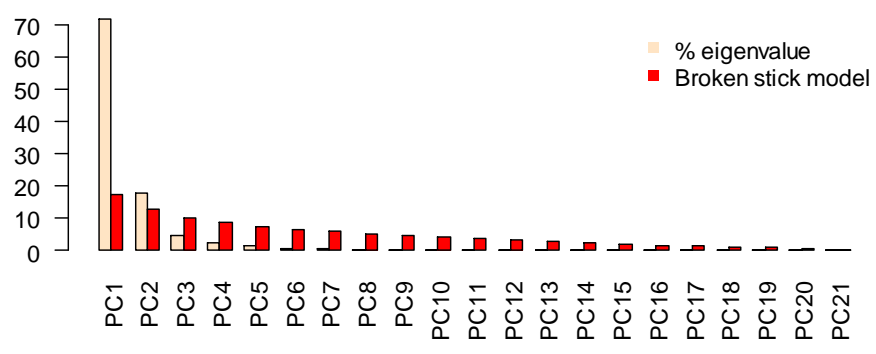

The 'Little' Tephra

Eigenvalues

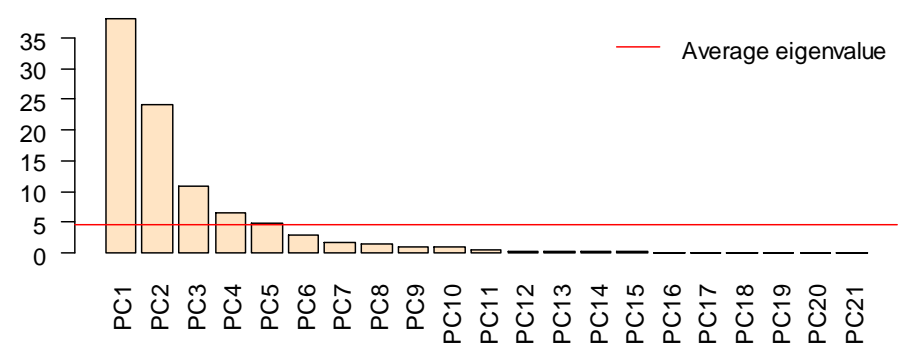

$\%$ variation

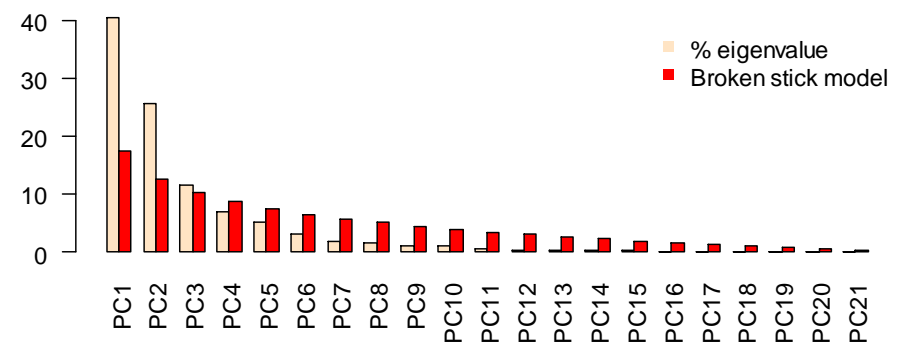




\section{The 'Unknown' Tephra}

Eigenvalues

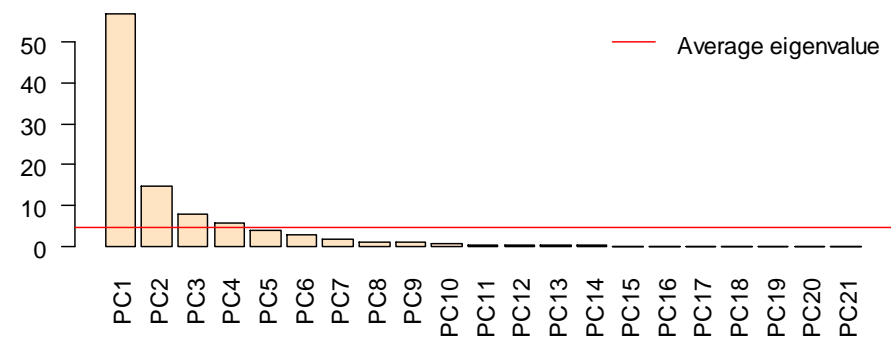

$\%$ variation

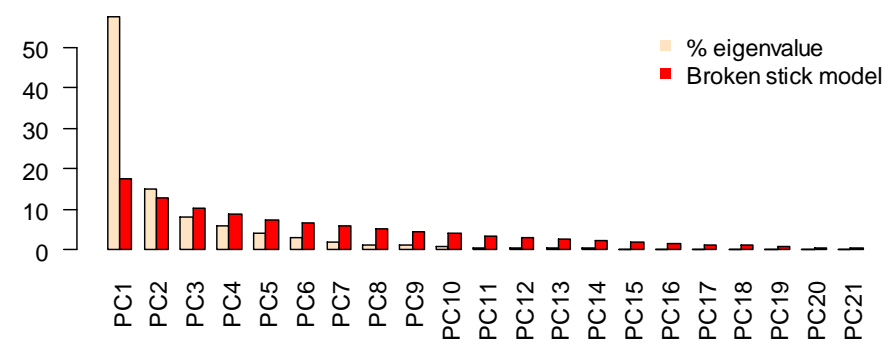

